\title{
Investigation on the anti-cancer activity of symmetric and unsymmetric cyclic sulfamides
}

\author{
Jaden Jungho Jun, ${ }^{1,2}$ Divya Duscharla, ${ }^{3}$ Ramesh Ummanni, ${ }^{3}$ \\ Paul R. Hanson, ${ }^{2, *}$ Sanjay V. Malhotra ${ }^{4,5,6^{*}}$
}

1) Department of Pharmaceutical Sciences and Computational Chemical Genomics Screening Center, NIH National Center of Excellence for Computational Drug Abuse Research, Drug Discovery Institute, School of Pharmacy, University of Pittsburgh, Pittsburgh, Pennsylvania 15261, United States.

2) Department of Chemistry, University of Kansas, 1567 Irving Hill Road, Lawrence, Kansas 66045-7582, United States.

3) Centre for Chemical Biology, Indian Institute of Chemical Technology, Hyderabad 500607, India

4) Department of Cell, Development and Cancer Biology, Oregon Health \& Science University, Portland, Oregon 97201

5) Center for Experimental Therapeutics, Knight Cancer Institute, Oregon Health \& Science University, Portland, Oregon 97201

6) Lead author

1. Chemistry

2. Biology

3. ${ }^{1} \mathrm{H}$ and ${ }^{13} \mathrm{C}$ NMR Spectrum

4. References 


\section{Chemistry}

\section{General methods}

All reactions were carried out in flame-dried glassware under argon. Toluene, $\mathrm{THF}_{\mathrm{F}} \mathrm{Et}_{2} \mathrm{O}$, and $\mathrm{CH}_{2} \mathrm{Cl}_{2}$ were purified by passage through a purification system (Solv-Tek) employing activated $\mathrm{Al}_{2} \mathrm{O}_{3}$. Flash column chromatography was performed with Sorbent Technologies, Inc. silica gel (10930-25, 230-450 mesh). Thin layer chromatography was performed on silica gel 60F 254 plates (EM-5715-7, Merck). All amino acid precursors were purchased from Advanced Chem Tech. ${ }^{1} \mathrm{H}$ and ${ }^{13} \mathrm{C}$ spectra were recorded in $\mathrm{CDCl}_{3}$ on either a Bruker DRX-400 or a Bruker AM-500 spectrometer operating at 400/100 MHz and 500/125 MHz, respectively. High-resolution mass spectrometry (HRMS) was obtained on a VG Instrument ZAB double-focusing mass spectrometer. Stretching frequencies were obtained on a Nicolet 320 Fourier Transform Infrared Spectrophotometers. Melting points were obtained on a Thomas Hoover capillary melting point apparatus. Optical rotations were determined on a Rudolph Automatic Polarimeter (AUTOPOL IV).

\section{$N, N$ '-Sulfonyl bis- $L$-phenylalanine dimethyl ester (3)}

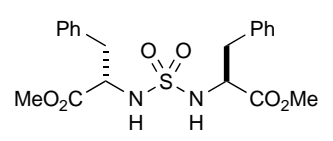

This compound was prepared according to literature procedure. ${ }^{1}$ To a solution of $L$ phenylalanine methyl ester hydrochloride $(4.01 \mathrm{~g}, 18.62 \mathrm{mmol})$ in $\mathrm{CH}_{2} \mathrm{Cl}_{2}(80 \mathrm{~mL})$ was added $\mathrm{Et}_{3} \mathrm{~N}$ $(5.7 \mathrm{~mL}, 40.90 \mathrm{mmol})$ for $10 \mathrm{~min}$ at $0{ }^{\circ} \mathrm{C}$. Then sulfuryl chloride $(0.68 \mathrm{~mL}, 8.46 \mathrm{mmol})$ was added over $30 \mathrm{~min}$. The resulting white solid was purified by flash chromatography (2:1 hexanes/EtOAc) to afford the desired diester compound $\mathbf{3}$ (3.05 g, 86\%).

\section{$N$, $N$ '-Bis-benzyl- $N$ - $N$ '-bis-[(1S)-1-(2-phenylethyl)-2-methoxycarbonyl]-sulfamide (5)

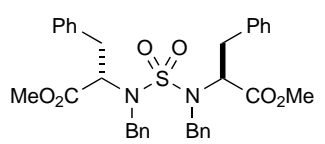

To a solution of $\mathbf{3}(1.05 \mathrm{~g}, 2.49 \mathrm{mmol})$ in $\mathrm{CH}_{3} \mathrm{CN}(20 \mathrm{~mL})$ was added benzyl bromide $(0.7 \mathrm{~mL}$, $6.08 \mathrm{mmol})$ and $\mathrm{K}_{2} \mathrm{CO}_{3}(1.06 \mathrm{~g}, 7.67 \mathrm{mmol})$ and then brought to reflux at $85^{\circ} \mathrm{C}$. The resulting oil was purified by flash chromatography (2:1 hexanes/EtOAc) to afford the desired diester compound $\mathbf{5}$ as clear oil $(1.55 \mathrm{~g}, 99 \%)$. TLC $\mathrm{R}_{\mathrm{f}}=0.63\left(2: 1\right.$ hexanes/EtOAc); $[\alpha]^{25} \mathrm{D}=-24.4\left(c=1.1, \mathrm{CHCl}_{3}\right) ;{ }^{1} \mathrm{H} \mathrm{NMR}$ 
$\left(\mathrm{CDCl}_{3}, 400 \mathrm{MHz}\right) \delta 7.31(\mathrm{~m}, 5 \mathrm{H}), 7.17(\mathrm{~m}, 5 \mathrm{H}), 4.48(\mathrm{~d}, J=15.4 \mathrm{~Hz}, 1 \mathrm{H}), 4.42(\mathrm{dd}, J=7.9,6.3 \mathrm{~Hz}$, 1H), 4.27 (d, $J=15.4 \mathrm{~Hz}, 1 \mathrm{H}), 3.53(\mathrm{~s}, 3 \mathrm{H}), 3.36$ (dd, $J=14.0,8.1 \mathrm{~Hz}, 1 \mathrm{H}), 3.11$ (dd, $J=14.0,6.1$ $\mathrm{Hz}, 1 \mathrm{H}) ;{ }^{13} \mathrm{C} \mathrm{NMR}\left(\mathrm{CDCl}_{3}, 100 \mathrm{MHz}\right) \delta 171.1,137.9,136.2,129.6,129.1,128.7,128.6,128.1,126.9$, 61.6, 52.3, 50.5, 36.3; FTIR (neat) 3062, 3030, 2951, 1741, 1454, 1437, 1337, 1220, 1147, 1027, 744, $698 \mathrm{~cm}^{-1}$; HRMS $(\mathrm{M}+\mathrm{H})^{+}$calcd for $\mathrm{C}_{34} \mathrm{H}_{37} \mathrm{~N}_{2} \mathrm{O}_{6} \mathrm{~S}(\mathrm{M}+\mathrm{H})^{+}$required 601.2372, found 601.2343.

\section{$N, N^{\prime}$-Bis-benzyl- $N$ - $N$ '-bis-[(1S)-2-hydroxy-1-(2-phenylethyl)ethyl]-sulfamide (9)}

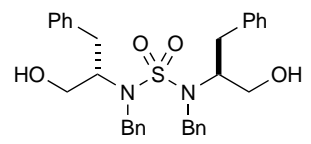

To a solution of 5 (1.52 g, $2.53 \mathrm{mmol})$ in THF (40 mL) was added LAH (526 mg, $13.87 \mathrm{mmol})$ at $0{ }^{\circ} \mathrm{C}$. The resulting oil was purified by flash chromatography $(2: 1$ hexanes/EtOAc) to afford the desired diester compound 9 as a white solid $(1.31 \mathrm{~g}, 95 \%)$. $\mathrm{Mp}=163{ }^{\circ} \mathrm{C}$; TLC $\mathrm{R}_{\mathrm{f}}=0.35(2: 1$ hexanes/EtOAc); $[\alpha]^{25} \mathrm{D}=-43.6\left(c=1.1, \mathrm{CHCl}_{3}\right) ;{ }^{1} \mathrm{H} \mathrm{NMR}\left(\mathrm{CDCl}_{3}, 400 \mathrm{MHz}\right) \delta 7.57(\mathrm{~d}, J=6.9 \mathrm{~Hz}$, 2H), 7.40-7.34 (m, 3H), 7.24-7.19 (m, 3H), $7.01(\mathrm{~d}, J=6.1 \mathrm{~Hz}, 2 \mathrm{H}), 4.60(\mathrm{~s}, 2 \mathrm{H}), 3.95-3.89(\mathrm{~m}, 1 \mathrm{H})$, $3.63(\mathrm{dd}, J=12.1,0 \mathrm{~Hz}, 1 \mathrm{H}), 3.56(\mathrm{dd}, J=12.1,4.6 \mathrm{~Hz}, 1 \mathrm{H}), 3.17(\mathrm{dd}, J=13.4,3.2 \mathrm{~Hz}, 1 \mathrm{H}), 2.45$ (s, 1H), $2.35(\mathrm{dd}, J=13.4,10.9 \mathrm{~Hz}, 1 \mathrm{H}) ;{ }^{13} \mathrm{C} \mathrm{NMR}\left(\mathrm{CDCl}_{3}, 100 \mathrm{MHz}\right) \delta 138.8,138.7,129.2,129.0,128.8$, 128.8, 128.0, 126.7, 61.9, .61.4, 49.1, 37.8; FTIR (neat) 3319, 3028, 2939, 2918, 1494, 1454, 1329, 1321, 1130, 1034, 972, 784, $730698 \mathrm{~cm}^{-1}$; HRMS $(\mathrm{M}+\mathrm{H})^{+}$calcd for $\mathrm{C}_{32} \mathrm{H}_{37} \mathrm{~N}_{2} \mathrm{O}_{4} \mathrm{~S}(\mathrm{M}+\mathrm{H})^{+}$required 545.2474, found 545.2484.

\section{L-Phenylalanine-derived C2-symmetric sulfamide aldehyde (12)}

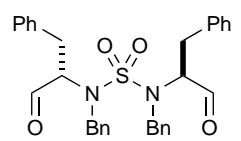

To a solution of oxalyl chloride $(0.48 \mathrm{~mL}, 5.50 \mathrm{mmol})$ in $\mathrm{CH}_{2} \mathrm{Cl}_{2}(1.5 \mathrm{~mL})$ at $-78{ }^{\circ} \mathrm{C}$ under an argon gas atmosphere was added dimethyl sulfoxide $(0.48 \mathrm{~mL}, 6.76 \mathrm{mmol})$ in $\mathrm{CH}_{2} \mathrm{Cl}_{2}(1.5 \mathrm{~mL})$ for 20 min. After $40 \mathrm{~min}$ a solution of $9(1.21 \mathrm{~g}, 2.22 \mathrm{mmol})$ in $\mathrm{CH}_{2} \mathrm{Cl}_{2}(15 \mathrm{~mL})$ was added for $20 \mathrm{~min}$. After $4 \mathrm{~h}, \mathrm{Et}_{3} \mathrm{~N}(2.3 \mathrm{~mL}, 16.50 \mathrm{mmol})$ was added and the reaction temperature maintained at $-78{ }^{\circ} \mathrm{C}$ for 30 min and at $0{ }^{\circ} \mathrm{C}$ for $2 \mathrm{~h}$. The reaction mixture was cooled to $-78^{\circ} \mathrm{C}$ and aqueous THF $\left(10 \mathrm{~mL}, \mathrm{THF}: \mathrm{H}_{2} \mathrm{O}\right.$ $=1: 1)$ was added. 10 min later, the reaction mixture was warmed up to $0{ }^{\circ} \mathrm{C}$. The reaction mixture was extracted with $\mathrm{CH}_{2} \mathrm{Cl}_{2}(50 \mathrm{~mL})$, washed with $2 \mathrm{M} \mathrm{HCl}$, dried $\left(\mathrm{MgSO}_{4}\right)$, filtered, and concentrated 
under reduced pressure. The resulting white solid was purified by flash chromatography (2:1 hexanes/EtOAc) to afford the desired dialdehyde sulfamide compound $\mathbf{1 2}$ as a white solid (1.19 g, 99\%). $\mathrm{Mp}=57^{\circ} \mathrm{C} ;$ TLC $\mathrm{R}_{\mathrm{f}}=0.58(1: 1$ hexanes/EtOAc $) ;[\alpha]^{25} \mathrm{D}=-65.7\left(c=0.95, \mathrm{CHCl}_{3}\right) ;{ }^{1} \mathrm{H} \mathrm{NMR}$ $\left(\mathrm{CDCl}_{3}, 400 \mathrm{MHz}\right) \delta 9.45(\mathrm{~s}, 1 \mathrm{H}), 7.32-7.17(\mathrm{~m}, 10 \mathrm{H}), 4.33(\mathrm{~d}, J=14.9 \mathrm{~Hz}, 1 \mathrm{H}), 4.08(\mathrm{~d}, J=15.2$ $\mathrm{Hz}, 1 \mathrm{H}), 4.04(\mathrm{dd}, J=7.9,6.2 \mathrm{~Hz}, 1 \mathrm{H}), 3.42(\mathrm{dd}, J=14.5,6.2 \mathrm{~Hz}, 1 \mathrm{H}), 3.08(\mathrm{dd}, J=14.5,8.0 \mathrm{~Hz}$, $1 \mathrm{H}) ;{ }^{13} \mathrm{C} \mathrm{NMR}\left(\mathrm{CDCl}_{3}, 100 \mathrm{MHz}\right) \delta 198.1,137.6,135.1,129.5,129.2,129.1,129.0,128.8,127.2$, 67.4, 51.0, 34.1; FTIR (neat) 3063, 3030, 2931, 2826, 2729, 1956, 1736, 1602, 1497, 1454, 1328, $1146,1083,1053,1030,883,848,746,700 \mathrm{~cm}^{-1}$; HRMS $(\mathrm{M}+\mathrm{H})^{+}$calcd for $\mathrm{C}_{32} \mathrm{H}_{33} \mathrm{~N}_{2} \mathrm{O}_{4} \mathrm{~S}(\mathrm{M}+\mathrm{H})^{+}$ required 541.2161, found 541.2166.

\section{$N$, $N$ '-Bis-benzyl- $N$ - $N$ '-bis-[(1S)-1-(2-phenylethyl)-2-propenyl]-sulfamide (15)}

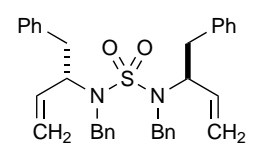

To a solution of methyl triphenyl phosphonium bromide in THF $(25 \mathrm{~mL})$ was added $n$ butyllithium (1.6 M in hexane) at $0{ }^{\circ} \mathrm{C}$ and the reaction was stirred for $3 \mathrm{~h}$. After cooling down the reaction mixture to $-78^{\circ} \mathrm{C}$, the solution of dialdehyde 12 in $\mathrm{THF}(25 \mathrm{~mL})$ was cooled to $-78^{\circ} \mathrm{C}$ and added to the Wittig solution and then stirred $16 \mathrm{~h}$. The reaction mixture was extracted with EtOAc (30 $\mathrm{mL} \times 3)$ and dried $\left(\mathrm{MgSO}_{4}\right)$. The reaction mixture was filtered and evaporated under reduced pressure to obtain a crude solid. Flash chromatography (10:1 Hexanes/EtOAc) gave $519 \mathrm{mg}(50 \%)$ of the 15 as a white solid. $\mathrm{Mp}=99{ }^{\circ} \mathrm{C}$; TLC $\mathrm{R}_{\mathrm{f}}=0.43\left(10: 1\right.$ hexanes/EtOAc); $[\alpha]^{25} \mathrm{D}=-54.6(c=$ $\left.0.60, \mathrm{CHCl}_{3}\right) ;{ }^{1} \mathrm{H} \mathrm{NMR}\left(\mathrm{CDCl}_{3}, 400 \mathrm{MHz}\right) \delta 7.37-7.30(\mathrm{~m}, 5 \mathrm{H}), 7.17-7.12(\mathrm{~m}, 3 \mathrm{H}), 6.94(\mathrm{~d}, J=6.2$ $\mathrm{Hz}, 2 \mathrm{H}), 5.90(\mathrm{ddd}, J=17.8,10.3,7.8 \mathrm{~Hz}, 1 \mathrm{H}), 5.13(\mathrm{~d}, J=10.4 \mathrm{~Hz}, 1 \mathrm{H}), 4.93(\mathrm{~d}, J=17.2 \mathrm{~Hz}, 1 \mathrm{H})$, $4.36(\mathrm{~d}, J=15.6,1 \mathrm{H}), 4.20(\mathrm{~d}, J=15.5 \mathrm{~Hz}, 1 \mathrm{H}), 4.21-4.17(\mathrm{~m}, 1 \mathrm{H}), 3.08(\mathrm{dd}, J=13.5,4.8 \mathrm{~Hz}, 1 \mathrm{H})$, $2.75(\mathrm{dd}, J=13.4,9.8 \mathrm{~Hz}, 1 \mathrm{H}) ;{ }^{13} \mathrm{C} \mathrm{NMR}\left(\mathrm{CDCl}_{3}, 100 \mathrm{MHz}\right) \delta 138.6,137.9,135.6,129.5,128.9$, 128.7, 128.4, 127.9, 126.4, 119.5, 63.4, 49.8, 40.1; FTIR (neat) 3063, 3028, 2930, 1497, 1454, 1331, 1147, 1045, 1027, 926, 737, $698 \mathrm{~cm}^{-1}$; HRMS calcd for $\mathrm{C}_{34} \mathrm{H}_{37} \mathrm{~N}_{2} \mathrm{O}_{2} \mathrm{~S}(\mathrm{M}+\mathrm{H})^{+}$required 537.2576, found 537.2563 .

(3S,6S)-2,3,6,7-Tetrabenzyl-2,3,6,7-tetrahydro-1,2,7-thiadiazepine-1,1-dioxide (18) 


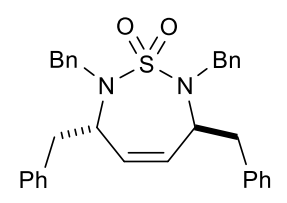

A stirring solution of the diene sulfamide $15(485 \mathrm{mg}, 0.904 \mathrm{mmol})$ in benzene $(30 \mathrm{~mL})$ was degassed with argon for $30 \mathrm{~min}$. The flask was quickly fitted with a condenser containing an argon balloon, and the solution was heated to reflux. The Grubbs' metathesis catalyst II (25 mg, 3 mol\%) was added to the refluxing solution and maintained at reflux for $18 \mathrm{~h}$. The solution was cooled to room temperature and silica gel was added with DMSO $(0.5 \mathrm{~mL})$ and the solution was stirred for 24 h. The solution was filtered, and the solvent was removed under reduced pressure to obtain a crude solid. Flash chromatography (5:1 Hexanes/EtOAc) gave $457 \mathrm{mg}(99 \%)$ of the $\mathbf{1 8}$ as a white solid. Mp $=148{ }^{\circ} \mathrm{C} ; \mathrm{TLC} \mathrm{R}_{\mathrm{f}}=0.43(5: 1$ hexanes/EtOAc $) ;[\alpha]^{25} \mathrm{D}=-47.8\left(c=0.95, \mathrm{CHCl}_{3}\right) ;{ }^{1} \mathrm{H} \mathrm{NMR}\left(\mathrm{CDCl}_{3}\right.$, $400 \mathrm{MHz}) \delta 7.41-7.06(\mathrm{~m}, 10 \mathrm{H}), 5.56(\mathrm{~s}, 1 \mathrm{H}), 4.83(\mathrm{~d}, J=16.2 \mathrm{~Hz}, 1 \mathrm{H}), 4.48(\mathrm{dd}, J=9.8,5.2 \mathrm{~Hz}$, $1 \mathrm{H}), 4.39(\mathrm{~d}, J=16.2 \mathrm{~Hz}, 1 \mathrm{H}), 3.01(\mathrm{dd}, J=13.7,5.3 \mathrm{~Hz}, 1 \mathrm{H}), 2.73(\mathrm{dd}, J=13.5,10.5 \mathrm{~Hz}, 1 \mathrm{H}) ;{ }^{13} \mathrm{C}$ NMR $\left(\mathrm{CDCl}_{3}, 100 \mathrm{MHz}\right) \delta 138.6,137.7,130.6,129.4,128.8,128.7,127.6,127.5,126.9,57.2,51.9$, 40.3; FTIR (neat) 3061, 3028, 2928, 1495, 1454, 1344, 1153, 929, 763, 725, $698 \mathrm{~cm}^{-1}$; HRMS calcd for $\mathrm{C}_{32} \mathrm{H}_{33} \mathrm{~N}_{2} \mathrm{O}_{2} \mathrm{~S}(\mathrm{M}+\mathrm{H})^{+}$required 509.2263, found 509.2279.

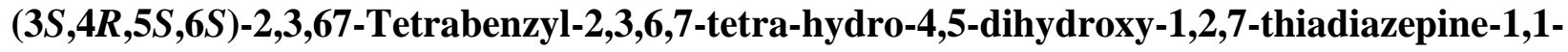

\section{dioxide (21)}

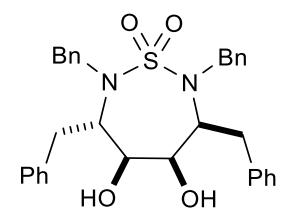

To a stirring solution of the sulfamide $18(72 \mathrm{mg}, 0.143 \mathrm{mmol})$ in distilled water $(0.28 \mathrm{~mL}$, $15.54 \mathrm{mmol})$ and acetone $(0.9 \mathrm{~mL}, 12.26 \mathrm{mmol})$ was added $\mathrm{NMO}(25 \mathrm{mg}, 0.185 \mathrm{mmol})$ and $\mathrm{OsO}_{4}(27$ $\mathrm{mg}, 0.143 \mathrm{mmol})$ in distilled water $(0.28 \mathrm{~mL}, 15.54 \mathrm{mmol})$ and acetone $(0.9 \mathrm{~mL}, 12.26 \mathrm{mmol})$ was added NMO (25 mg, 0.s washed with saturated $\mathrm{Na}_{2} \mathrm{~S}_{2} \mathrm{O}_{3}$ aqueous solution. The organic layer was washed with brine and dried over $\mathrm{MgSO}_{4}$, filtered, concentrated on a rotary evaporator. Flash chromatography $\left(2: 1\right.$ Hexanes/EtOAc) gave $67 \mathrm{mg}(87 \%)$ of the 21 as a white solid. $\mathrm{Mp}=102{ }^{\circ} \mathrm{C}$; TLC $\mathrm{R}_{\mathrm{f}}=0.29(2: 1$ hexanes/EtOAc $) ;[\alpha]^{25} \mathrm{D}=14.4\left(c=0.30, \mathrm{CHCl}_{3}\right) ;{ }^{1} \mathrm{H} \mathrm{NMR}\left(\mathrm{CDCl}_{3}, 400 \mathrm{MHz}\right) \delta$ 7.46-6.99 (m, 20H), $4.96(\mathrm{~d}, J=17.0 \mathrm{~Hz}, 1 \mathrm{H}), 4.73$ (d, J=15.8 Hz, 1H), 4.69 (d, J=14.4 Hz, 1H), $4.48(\mathrm{~d}, J=14.7 \mathrm{~Hz}, 1 \mathrm{H}), 4.00(\mathrm{dd}, J=8.4,6.0 \mathrm{~Hz}, 1 \mathrm{H}), 3.79(\mathrm{dd}, J=7.9,2.2 \mathrm{~Hz}, 1 \mathrm{H}), 3.76(\mathrm{~s}, 1 \mathrm{H})$, 
$3.72(\mathrm{dd}, J=14.5,7.8 \mathrm{~Hz}, 1 \mathrm{H}), 3.14(\mathrm{dd}, J=14.3,8.2 \mathrm{~Hz}, 1 \mathrm{H}), 3.02(\mathrm{dd}, J=18.4,13.4 \mathrm{~Hz}, 1 \mathrm{H}), 3.00$ (s, $1 \mathrm{H}), 2.86(\mathrm{dd}, J=14.3,6.3 \mathrm{~Hz}, 1 \mathrm{H}), 2.58(\mathrm{~s}, 1 \mathrm{H}), 1.59$ (s, $1 \mathrm{H}) ;{ }^{13} \mathrm{C} \mathrm{NMR}\left(\mathrm{CDCl}_{3}, 100 \mathrm{MHz}\right) \delta$ 139.5, 138.4, 138.2, 137.3, 129.5, 129.2, 1219.0, 129.0, 128.9, 128.9, 128.8, 128.2, 127.3, 127.3, 127.0, 74.6, 61.1, 60.3 53.6, 51.7, 39.5, 36.5; FTIR (neat) 3483, 3063, 3028, 2930, 1497, 1454, 1313 , $1145,1063,1022,870,781,735,698 \mathrm{~cm}^{-1}$; HRMS calcd for $\mathrm{C}_{32} \mathrm{H}_{34} \mathrm{~N}_{2} \mathrm{O}_{4} \mathrm{~S}(\mathrm{M}+\mathrm{H})^{+}$required 543.2318, found 543.2292 .

$(1 S, 2 R, 6 S, 7 S)$-2,3,5,6-Tetrabenzyl-8-oxa-4-thia-3,5-diaza-bicyclo[5.1.0]octane 4,4-dioxide (23)

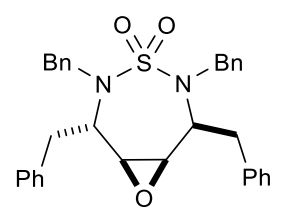

To a stirring solution of the sulfamide 18 (105 $\mathrm{mg}, 0.206 \mathrm{mmol})$ in $\mathrm{CH}_{2} \mathrm{Cl}_{2}(3 \mathrm{~mL})$ was added $m$-CPBA ( $81 \mathrm{mg}, 0.469 \mathrm{mmol})$ at room temperature and the solution was stirred for $24 \mathrm{~h}$. The organic layer was extracted with $\mathrm{CH}_{2} \mathrm{Cl}_{2}(20 \mathrm{~mL} \times 3)$ and ether $(30 \mathrm{~mL})$, and the organic layer was washed with saturated $\mathrm{NaHCO}_{3}$ aqueous solution and the organic layer was dried $\left(\mathrm{MgSO}_{4}\right)$, filtered, concentrated under reduced pressure. Flash chromatography (5:1 Hexanes/EtOAc) gave $57 \mathrm{mg}$ (53\%) of the 23 as clear oil. TLC $\mathrm{R}_{\mathrm{f}}=0.34\left(5: 1\right.$ hexanes/EtOAc); $[\alpha]^{25} \mathrm{D}=-18.8\left(c=0.30, \mathrm{CHCl}_{3}\right) ;{ }^{1} \mathrm{H} \mathrm{NMR}$ $\left(\mathrm{CDCl}_{3}, 400 \mathrm{MHz}\right) \delta 7.46(\mathrm{~d}, J=7.6 \mathrm{~Hz}, 2 \mathrm{H}), 7.35-7.02(\mathrm{~m}, 16 \mathrm{H}), 7.00(\mathrm{~d}, J=5.6 \mathrm{~Hz}, 2 \mathrm{H}), 4.93(\mathrm{~d}$, $J=17.3 \mathrm{~Hz}, 1 \mathrm{H}), 4.76(\mathrm{~d}, J=15.2 \mathrm{~Hz}, 1 \mathrm{H}), 4.60(\mathrm{dd}, J=11.1,4.5 \mathrm{~Hz}, 1 \mathrm{H}), 4.57(\mathrm{~d}, J=18.2 \mathrm{~Hz}, 1 \mathrm{H})$, $4.53(\mathrm{~d}, J=15.4 \mathrm{~Hz}, 1 \mathrm{H}), 4.00-3.95(\mathrm{~m}, 1 \mathrm{H}), 3.24(\mathrm{dd}, J=14.2,6.3 \mathrm{~Hz}, 1 \mathrm{H}), 3.1-2.89(\mathrm{~m}, 5 \mathrm{H}) ;{ }^{13} \mathrm{C}$ NMR $\left(\mathrm{CDCl}_{3}, 100 \mathrm{MHz}\right) \delta 129.6,129.2,129.0,128.8,128.4,128.0,127.3,127.1,126.9,59.6,55.7$, 53.6, 38.6; FTIR (neat) 3085, 3028, 2980, 1735, 1602, 1494, 1454, 1367, 1344, 1153, 1095, 1062, $1027,852,736,700 \mathrm{~cm}^{-1}$; HRMS calcd for $\mathrm{C}_{32} \mathrm{H}_{33} \mathrm{~N}_{2} \mathrm{O}_{3} \mathrm{~S}(\mathrm{M}+\mathrm{H})^{+}$required 525.2212, found 525.2187.

\section{$N, N$ 'Sulfonyl bis- $L$-leucine dimethyl ester (4)}

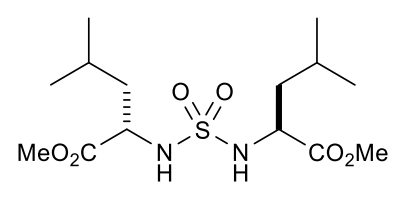

$N, N$ '-Sulfonyl bis- $L$-leucine dimethyl ester $\mathbf{4}$ were prepared according to literature procedure. ${ }^{1}$

\section{$N, N^{\prime}$-Bis-benzyl- $N$ - $N$ '-bis-[(1S)-1-(2-methylpropyl)-2-methoxycarbonyl]-sulfamide (6)}




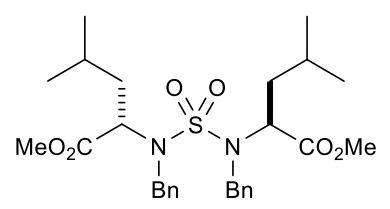

To a stirring solution of the leucine-derived sulfamide 4 (500 mg, $1.43 \mathrm{mmol})$ in $\mathrm{CH}_{3} \mathrm{CN}$ (20 $\mathrm{mL}$ ) at room temperature under an argon atmosphere was added $\mathrm{K}_{2} \mathrm{CO}_{3}(430 \mathrm{mg}, 3.13 \mathrm{mmol})$ and benzyl bromide $(0.37 \mathrm{~mL}, 3.11 \mathrm{mmol})$. The reaction mixture was heated to reflux for $24 \mathrm{~h}$, filtered, and concentrated under reduced pressure. The filtrate was extracted with EtOAc (50 mL x 2). The combined organic extracts were dried over $\mathrm{MgSO}_{4}$, filtered, and concentrated under reduced pressure. The resulting oil was purified by column chromatography (10:1 hexanes/EtOAc) to afford $750 \mathrm{mg}$ (99\%) of the desired dibenzyl sulfamide 6 as clear oil. TLC $R_{f}=0.28\left(10: 1\right.$ hexanes/EtOAc); $[\alpha]^{D_{25}}$ $=35.9\left(\mathrm{c}=1.00, \mathrm{CHCl}_{3}\right) ;{ }^{1} \mathrm{H} \mathrm{NMR}\left(\mathrm{CDCl}_{3}, 400 \mathrm{MHz}\right) \delta 7.41(\mathrm{~d}, J=7.4 \mathrm{~Hz}, 2 \mathrm{H}), 7.30-7.23(\mathrm{~m}, 3 \mathrm{H})$, $4.71(\mathrm{~d}, J=15.8 \mathrm{~Hz}, 1 \mathrm{H}), 4.44(\mathrm{~d}, J=15.8 \mathrm{~Hz}, 1 \mathrm{H}), 4.26(\mathrm{t}, J=6.5 \mathrm{~Hz}, 1 \mathrm{H}), 3.64(\mathrm{~s}, 3 \mathrm{H}), 1.82-1.77$ $(\mathrm{m}, 1 \mathrm{H}), 1.58-1.49(\mathrm{~m}, 2 \mathrm{H}), 0.85(\mathrm{~d}, J=6.2 \mathrm{~Hz}, 3 \mathrm{H}), 0.59(\mathrm{~d}, J=6.2 \mathrm{~Hz}, 3 \mathrm{H}) ;{ }^{13} \mathrm{C} \mathrm{NMR}\left(\mathrm{CDCl}_{3}, 100\right.$ MHz) $\delta 172.2,137.1,128.5,128.4,127.6,58.1,52.1,50.3,39.0$ 24.9, 22.2, 22.0; FTIR (neat) 3031, 2956, 1747, 1497, 1455, 1338, 1147, 755, $698 \mathrm{~cm}^{-1}$; HRMS calcd for $\mathrm{C}_{28} \mathrm{H}_{41} \mathrm{~N}_{2} \mathrm{O}_{6} \mathrm{~S}(\mathrm{M}+\mathrm{H})^{+}$required 533.2685, found 533.2672.

\section{$N, N^{\prime}$-Bis-benzyl- $N$ - $N$ '-bis-[(1S)-2-hydroxy-1-(2-methylpropyl)ethyl]-sulfamide (10)}

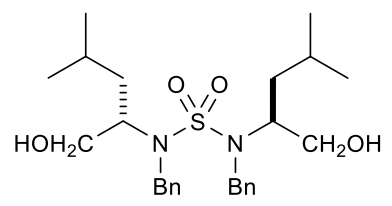

To a stirring solution of $6(110 \mathrm{mg}, 0.22 \mathrm{mmol})$ in THF $(30 \mathrm{~mL})$ at $0^{\circ}$ (under an argon atmosphere was added LAH (160 mg, $4.29 \mathrm{mmol})$. After $1 \mathrm{~h}$, a 15\% $\mathrm{NaOH}$ aqueous solution was added to quench the reaction, and the reaction mixture was filtered under reduced pressure. The filtrate was concentrated under reduced pressure and extracted with EtOAc (50 mL x 2). The combined organic extracts were dried $\left(\mathrm{MgSO}_{4}\right)$, filtered, concentrated under reduced pressure, and purified by column chromatography (1:1 hexanes/EtOAc) to afford $100 \mathrm{mg}(100 \%)$ of the desired sulfamide diol 10 as clear oil. TLC $\mathrm{R}_{\mathrm{f}}=0.51\left(1: 1\right.$ hexanes/EtOAc); $[\alpha]^{25} \mathrm{D}=+15.6^{\circ}\left(\mathrm{c}=1.00, \mathrm{CHCl}_{3}\right) ;{ }^{1} \mathrm{H} \mathrm{NMR} \delta$ $7.41(\mathrm{~d}, J=7.1 \mathrm{~Hz}, 4 \mathrm{H}), 7.26-7.16(\mathrm{~m}, 6 \mathrm{H}), 4.49(\mathrm{~d}, J=15.8 \mathrm{~Hz}, 2 \mathrm{H}), 4.45(\mathrm{~d}, J=15.8 \mathrm{~Hz}, 2 \mathrm{H})$, 3.83-3.75 (m, 2H), 3.63-3.56 (m, 4H), 2.60 (bs, 2H), 1.54-1.44 (m, 2H), 1.44-1.37 (m, 2H), 1.19$1.12(\mathrm{~m}, 2 \mathrm{H}), 0.79(\mathrm{~d}, J=6.5 \mathrm{~Hz}, 6 \mathrm{H}), 0.73(\mathrm{~d}, J=6.5 \mathrm{~Hz}, 6 \mathrm{H}) ;{ }^{13} \mathrm{C} \mathrm{NMR}\left(\mathrm{CDCl}_{3}, 100 \mathrm{MHz}\right) \delta 138.5$, 
128.5, 127.5, 62.5, 58.8, 49.2, 39.5, 25.1, 23.1, 21.7; FTIR (neat) 3386, 3029, 2956, 1604, 1496, 1455, 1323, 1143, 758, $698 \mathrm{~cm}^{-1}$; HRMS calcd for $\mathrm{C}_{26} \mathrm{H}_{41} \mathrm{~N}_{2} \mathrm{O}_{4} \mathrm{~S}(\mathrm{M}+\mathrm{H})^{+}$required 477.2787, found 477.2808.

\section{$N, N^{\prime}$-Bis-benzyl- $N$ - $N$ '-bis-[(1S)-1-(2-methylpropyl)-2-propenyl]-sulfamide (16)}

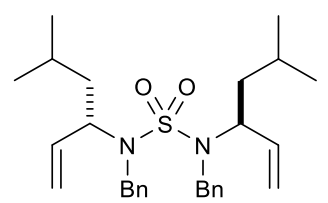

To a stirring solution of oxalyl chloride $(0.30 \mathrm{~mL}, 3.44 \mathrm{mmol})$ in $\mathrm{CH}_{2} \mathrm{Cl}_{2}(1 \mathrm{~mL})$ at $-78{ }^{\circ} \mathrm{C}$ under an argon atmosphere was added DMSO $(0.30 \mathrm{~mL}, 4.23 \mathrm{mmol})$ in $\mathrm{CH}_{2} \mathrm{Cl}_{2}(1 \mathrm{~mL})$ over $20 \mathrm{~min}$. After $40 \mathrm{~min}$, the sulfamide diol 10 (477 mg, $1.00 \mathrm{mmol})$ in $\mathrm{CH}_{2} \mathrm{Cl}_{2}(10 \mathrm{~mL})$ was added over $30 \mathrm{~min}$ with an addition funnel, and the funnel was rinsed with $\mathrm{CH}_{2} \mathrm{Cl}_{2}(10 \mathrm{~mL})$. The mixture was stirred at $-78^{\circ} \mathrm{C}$ for $5 \mathrm{~h}$ and monitored by TLC. $\mathrm{Et}_{3} \mathrm{~N}(1.5 \mathrm{~mL}, 10.76 \mathrm{mmol})$ was added over $15 \mathrm{~min}$ and stirred at $-78^{\circ} \mathrm{C}$ for $2 \mathrm{~h}$. THF ( $\left.4 \mathrm{~mL}, 1: 1 \mathrm{H}_{2} \mathrm{O} / \mathrm{THF}\right)$ was added at $-78^{\circ} \mathrm{C}$ for $5 \mathrm{~min}$, and the mixture stirred at $0{ }^{\circ} \mathrm{C}$ for $\mathrm{h}$. The reaction mixture was extracted with $\mathrm{CH}_{2} \mathrm{Cl}_{2}(50 \mathrm{~mL})$, washed with $2 \mathrm{M} \mathrm{HCl}$, dried over $\mathrm{MgSO}_{4}$, filtered, and concentrated under reduced pressure to afford $507 \mathrm{mg}(99 \%)$ of the desired dialdehyde sulfamide as a white solid 13 that was carried on immediately without further purification. TLC $R_{\mathrm{f}}=0.91(1: 1$ hexanes/EtOAc).

To a stirring solution of $\mathrm{CH}_{3} \mathrm{PPh}_{3} \mathrm{Br}(2.69 \mathrm{~g}, 7.53 \mathrm{mmol})$ in $\mathrm{THF}(25 \mathrm{~mL})$ at $0{ }^{\circ} \mathrm{C}$ under an argon atmosphere was slowly added a solution of BuLi $(3.75 \mathrm{~mL}, 6.0 \mathrm{mmol}, 1.6 \mathrm{M}$ in hexanes) over $3 \mathrm{~min}$. After $3 \mathrm{~h}$, the yellow ylide solution was cooled to $-78^{\circ} \mathrm{C}$ and a solution of dial sulfamide (474 $\mathrm{mg}, 1.00 \mathrm{mmol})$ in THF $(25 \mathrm{~mL})$ at $-78^{\circ} \mathrm{C}$ was added via cannula. After $24 \mathrm{~h}$, acetone $(30 \mathrm{~mL})$ was added to quench the reaction. The reaction mixture was concentrated under reduced pressure and extracted with EtOAc (50 mL x 2). The combined organic extracts were dried over $\mathrm{MgSO}_{4}$, filtered, and concentrated under reduced pressure. Flash chromatography (10:1 hexanes/EtOAc) gave $418 \mathrm{mg}$ $(89 \%)$ of the desired sulfamide diene 16 as white solid. $\mathrm{Mp}=86{ }^{\circ} \mathrm{C}$; TLC $\mathrm{R}_{\mathrm{f}}=0.66(10: 1$ hexanes/EtOAc); $[\alpha]^{25} \mathrm{D}=-18.5\left(\mathrm{c}=1.00, \mathrm{CHCl}_{3}\right) ;{ }^{1} \mathrm{H} \mathrm{NMR}\left(\mathrm{CDCl}_{3}, 400 \mathrm{MHz}\right) \delta 7.38(\mathrm{~d}, J=7.2 \mathrm{~Hz}$, 2H), 7.34-7.22 (m, 3H), $5.86(\mathrm{ddd}, J=17.5,10.3,7.8 \mathrm{~Hz}, 1 \mathrm{H}), 5.19(\mathrm{~d}, J=10.3 \mathrm{~Hz}, 1 \mathrm{H}), 5.11(\mathrm{~d}, J$ $=17.2 \mathrm{~Hz}, 1 \mathrm{H}), 4.34(\mathrm{~d}, J=15.6 \mathrm{~Hz}, 1 \mathrm{H}), 4.22(\mathrm{~d}, J=15.6 \mathrm{~Hz}, 1 \mathrm{H}), 4.02(\mathrm{dd}, J=13.6,7.8 \mathrm{~Hz}, 1 \mathrm{H})$, $1.52-1.34(\mathrm{~m}, 3 \mathrm{H}), 0.79(\mathrm{~d}, J=6.1 \mathrm{~Hz}, 3 \mathrm{H}), 0.64(\mathrm{~d}, J=6.2 \mathrm{~Hz}, 3 \mathrm{H}) ;{ }^{13} \mathrm{C} \mathrm{NMR}\left(\mathrm{CDCl}_{3}, 100 \mathrm{MHz}\right)$ 
$\delta 138.1,136.8,128.6,128.4,127.4,118.2,59.8,49.3,41.5,24.6,23.1,21.5$; FTIR (neat) 3033, 2956, 2930, 1496, 1455, 1332, 1147, 700, $744 \mathrm{~cm}^{-1}$; HRMS calcd for $\mathrm{C}_{28} \mathrm{H}_{41} \mathrm{~N}_{2} \mathrm{O}_{2} \mathrm{~S}(\mathrm{M}+\mathrm{H})^{+}$required 469.2889, found 469.2875 .

(3S,6S)-2,7-Dibenzyl-3,6-diisobutyl-2,3,6,7-tetrahydro-1,2,7-thiadiazepine-1,1-dioxide (19)

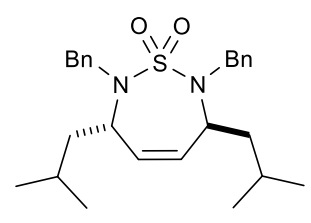

To a degassed solution of $\mathbf{1 6}(320 \mathrm{mg}, 0.68 \mathrm{mmol})$ in benzene $(25 \mathrm{~mL})$ was added $\left(\mathrm{ImesH}_{2}\right)(\mathrm{PCy})(\mathrm{Cl})_{2} \mathrm{Ru}=\mathrm{CHPh}(20 \mathrm{mg}, 0.030 \mathrm{mmol})$ at room temperature. After $24 \mathrm{~h}$, DMSO (1.0 $\mathrm{mL}$ ) and silica gel were added to remove the catalyst. After $24 \mathrm{~h}$, the reaction mixture was filtered, and concentrated under reduced pressure. Flash chromatography (5:1 hexanes/EtOAc) afforded 210 $\mathrm{mg}(69 \%)$ of the desired cyclic sulfamide 19 as white solid. $\mathrm{Mp}=108{ }^{\circ} \mathrm{C}$; TLC $\mathrm{R}_{\mathrm{f}}=0.79$ (5:1 hexanes/EtOAc); $[\alpha]^{25} \mathrm{D}=-55.1\left(\mathrm{c}=1.00, \mathrm{CHCl}_{3}\right) ;{ }^{1} \mathrm{H} \mathrm{NMR}\left(\mathrm{CDCl}_{3}, 400 \mathrm{MHz}\right) \delta 7.39(\mathrm{~d}, J=10.3$ $\mathrm{Hz}, 2 \mathrm{H}), 7.33-7.22(\mathrm{~m}, 3 \mathrm{H}), 5.52(\mathrm{~s}, 1 \mathrm{H}), 4.86(\mathrm{~d}, J=16.0 \mathrm{~Hz}, 1 \mathrm{H}), 4.23(\mathrm{dd}, J=9.1,5.2 \mathrm{~Hz}, 1 \mathrm{H})$, $4.20(\mathrm{~d}, J=16.0 \mathrm{~Hz}, 1 \mathrm{H}), 1.61-1.53(\mathrm{~m}, 1 \mathrm{H}), 1.39-1.33(\mathrm{~m}, 1 \mathrm{H}), 1.18-1.11(\mathrm{~m}, 1 \mathrm{H}), 0.80(\mathrm{~d}, J=6.5$ $\mathrm{Hz}, 3 \mathrm{H}), 0.48(\mathrm{~d}, J=6.7 \mathrm{~Hz}, 3 \mathrm{H}) ;{ }^{13} \mathrm{C} \mathrm{NMR}\left(\mathrm{CDCl}_{3}, 100 \mathrm{MHz}\right) \delta 139.0,132.1,128.3,127.7,127.2$, 53.4, 50.9, 42.6, 24.2, 22.3, 21.4; FTIR (neat) 3064, 3028, 2957, 1606, 1496, 1338, $1147 \mathrm{~cm}^{-1}$; HRMS calcd for $\mathrm{C}_{26} \mathrm{H}_{37} \mathrm{~N}_{2} \mathrm{O}_{2} \mathrm{~S}(\mathrm{M}+\mathrm{H})^{+}$required 441.2576, found 441.2584 .

\section{(3S,4R,5S,6S)-2,7-Dibenzyl-3,6-diisobutyl-2,3,6,7-tetra-hydro-4,5-dihydroxy-1,2,7-}

thiadiazepine-1,1-dioxide (22)

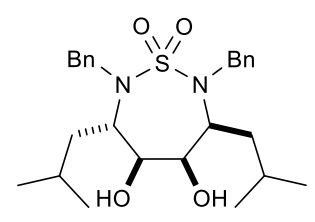

To a stirring solution of cyclic sulfamide $19(40 \mathrm{mg}, 0.10 \mathrm{mmol})$ in acetone $(630 \mathrm{~mL})$ and water $(200 \mathrm{~mL})$ was added NMO $(15 \mathrm{mg}, 0.12 \mathrm{mmol})$ and $\mathrm{OsO}_{4}(18 \mathrm{~mL}, 2.8 \mathrm{mmol}, 4 \mathrm{wt} \%$ solution in water). After 3 days, the reaction mixture was washed with saturated $\mathrm{Na}_{2} \mathrm{SO}_{3}$, dried $\left(\mathrm{MgSO}_{4}\right)$, filtered, and concentrated under reduced pressure. Flash chromatography (5:1 hexanes/EtOAc) afforded 50 mg (99\%) of the desired sulfamide diol 22 as a white solid. $\mathrm{Mp}=174{ }^{\circ} \mathrm{C}$; TLC $\mathrm{R}_{\mathrm{f}}=0.28(5: 1$ hexanes/EtOAc); $[\alpha]^{25} \mathrm{D}=-65.1\left(\mathrm{c}=1.00, \mathrm{CHCl}_{3}\right) ;{ }^{1} \mathrm{H} \mathrm{NMR}\left(\mathrm{CDCl}_{3}, 400 \mathrm{MHz}\right) \delta 7.49-7.45(\mathrm{~m}, 4 \mathrm{H})$, 
7.35-7.26 (m, 6H), $4.92(\mathrm{~d}, J=16.8 \mathrm{~Hz}, 1 \mathrm{H}), 4.62(\mathrm{~d}, J=16.8 \mathrm{~Hz}, 1 \mathrm{H}), 4.52(\mathrm{~d}, J=16.0 \mathrm{~Hz}, 1 \mathrm{H})$, $4.46(\mathrm{~d} J=16.0 \mathrm{~Hz}, 1 \mathrm{H}), 3.81(\mathrm{ddd}, J=9.6,9.6,4.4 \mathrm{~Hz}, 1 \mathrm{H}), 3.75(\mathrm{dd}, J=4.0,4.0 \mathrm{~Hz}, 1 \mathrm{H}), 3.67$ (dd, $J=6.9,6.9 \mathrm{~Hz}, 1 \mathrm{H}), 3.48(\mathrm{ddd}, J=10,5,5 \mathrm{~Hz}, 1 \mathrm{H}), 2.27(\mathrm{~d}, J=5.0 \mathrm{~Hz}, 1 \mathrm{H}), 2.12(\mathrm{~d}, J=7.2 \mathrm{~Hz}, 1 \mathrm{H})$, $1.79(\mathrm{ddd}, J=13.7,8.3,5.4 \mathrm{~Hz}, 1 \mathrm{H}), 1.67-1.47$ (m, 3H), 1.46-1.36 (m, 1H), 1.31-1.17 (m, 1H), 0.90 $(\mathrm{d}, J=6.0 \mathrm{~Hz}, 3 \mathrm{H}), 0.83(\mathrm{~d}, J=6.4 \mathrm{~Hz}, 3 \mathrm{H}), 0.69(\mathrm{~d}, J=6.6 \mathrm{~Hz}, 3 \mathrm{H}), 0.67(\mathrm{~d}, J=6.2 \mathrm{~Hz}, 3 \mathrm{H}) ;{ }^{13} \mathrm{C}$ $\mathrm{NMR}\left(\mathrm{CDCl}_{3}, 100 \mathrm{MHz}\right) \delta 139.3,138.3,128.6,128.5,128.4,127.6,127.5,127.2,73.9,71.3,55.4$, 54.4, 51.5, 49.0, 39.8, 36.9, 24.8, 24.1, 23.1, 22.3, 22.1, 21.3; FTIR (neat) 3483, 2956, 1454, 1309, $1144 \mathrm{~cm}^{-1}$; HRMS calcd for $\mathrm{C}_{26} \mathrm{H}_{39} \mathrm{~N}_{2} \mathrm{O}_{4} \mathrm{~S}(\mathrm{M}+\mathrm{H})^{+}$required 475.2631, found 475.2609.

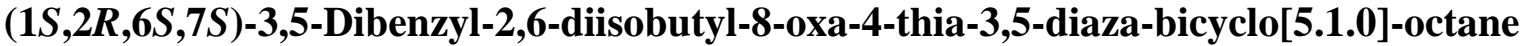

dioxide (24)

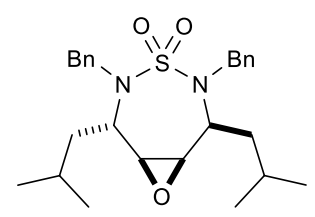

To a stirring solution of $19(250 \mathrm{mg}, 0.56 \mathrm{mmol})$ in $\mathrm{CH}_{2} \mathrm{Cl}_{2}(5.0 \mathrm{~mL})$ at $0{ }^{\circ} \mathrm{C}$ was added $\mathrm{m}$ CPBA (390 mg, $2.27 \mathrm{mmol}$ ). After $48 \mathrm{~h}$, the reaction mixture was filtered, and the filtrate was extracted with $\mathrm{CH}_{2} \mathrm{Cl}_{2}\left(50 \mathrm{~mL}\right.$ x 2), and washed with $\mathrm{NaHCO}_{3}$ (saturated aq). The combined organic extracts were dried over $\mathrm{MgSO}_{4}$, filtered, and concentrated under reduced pressure. Flash chromatography (5:1 hexanes/EtOAc) afforded $140 \mathrm{mg}(52 \%)$ of the desired epoxy sulfamide 24 as clear oil. $[\alpha]^{25}=-33.9\left(\mathrm{c}=1.00, \mathrm{CHCl}_{3}\right)$; TLC $\mathrm{R}_{\mathrm{f}}=0.41(5: 1$ hexanes/EtOAc $) ;{ }^{1} \mathrm{H} \mathrm{NMR}\left(\mathrm{CDCl}_{3}\right.$, $400 \mathrm{MHz}) \delta 7.27-7.05(\mathrm{~m}, 10 \mathrm{H}), 4.83(\mathrm{~d}, J=17.1 \mathrm{~Hz}, 1 \mathrm{H}), 4.63(\mathrm{~d}, J=15.5 \mathrm{~Hz}, 1 \mathrm{H}), 4.53(\mathrm{~d}, J=$ $15.5 \mathrm{~Hz}, 1 \mathrm{H}), 4.42(\mathrm{~d}, J=17.1 \mathrm{~Hz}, 1 \mathrm{H}), 4.05(\mathrm{dd}, J=9.0,4.8 \mathrm{~Hz}, 1 \mathrm{H}), 3.71(\mathrm{ddd}, J=10,4.5,4.5 \mathrm{~Hz}$, 1H), $2.92(\mathrm{dd}, J=4.2,4.2 \mathrm{~Hz}, 1 \mathrm{H}), 2.84(\mathrm{~d}, J=4.2 \mathrm{~Hz}, 1 \mathrm{H}), 1.85(\mathrm{ddd}, J=14.1,9.4,4.9 \mathrm{~Hz}, 1 \mathrm{H})$, 1.73-1.65 (m, 1H), 1.65-1.55 (m, 1H) 1.45 (ddd, $J=14.2,8.4,6.2 \mathrm{~Hz}, 1 \mathrm{H}), 1.34-1.25$ (m, 2H), 0.82 $(\mathrm{d}, J=5.8 \mathrm{~Hz}, 3 \mathrm{H}), 0.76(\mathrm{~d}, J=5.8 \mathrm{~Hz}, 3 \mathrm{H}), 0.75(\mathrm{~d}, J=6.0 \mathrm{~Hz}, 3 \mathrm{H}), 0.51(\mathrm{~d}, J=6.0 \mathrm{~Hz}, 3 \mathrm{H}) ;{ }^{13} \mathrm{C}$ NMR $\left(\mathrm{CDCl}_{3}, 100 \mathrm{MHz}\right) \delta 139.4,138.0,128.5,128.4,128.3,127.7,127.1,126.9,59.8,58.4,54.0$, 52.0, 51.8, 51.4, 41.3, 41.1, 24.7, 24.4, 22.5, 22.0, 21.8, 21.5; FTIR (neat) 3031, 2958, 1605, 1496, $1338,1150 \mathrm{~cm}^{-1}$; HRMS calcd for $\mathrm{C}_{26} \mathrm{H}_{37} \mathrm{~N}_{2} \mathrm{O}_{3} \mathrm{~S}(\mathrm{M}+\mathrm{H})^{+}$required 457.2525, found 457.2534.

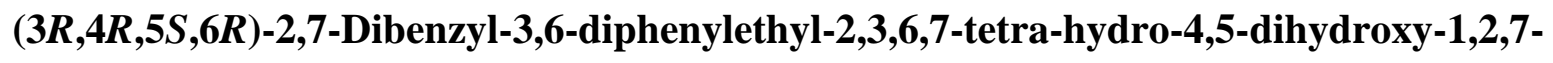
thiadiazepine-1,1-dioxide (25) 


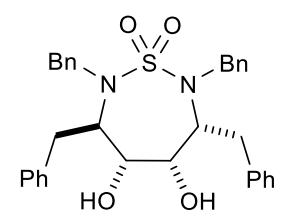

Under argon gas atmosphere, $\mathrm{Zn}$ powder $(35 \mathrm{mg}, 0.53 \mathrm{mmol})$, was added to a solution of $\mathrm{VCl}_{3}(\mathrm{THF})_{3}(348 \mathrm{mg}, 0.93 \mathrm{mmol})$ in $\mathrm{CH}_{2} \mathrm{Cl}_{2}(1 \mathrm{~mL})$ at room temperature, causing a color change from red to green (after stirring for $30 \mathrm{~min}$ ). A solution of dialdehyde 13 (212 mg, $0.393 \mathrm{mmol}$ ) in $\mathrm{CH}_{2} \mathrm{Cl}_{2}$ $(5 \mathrm{~mL})$ was added causing a color change from green to brown. After being stirred for $3 \mathrm{~h}$, the reaction solution was opened to air and poured into $1 \mathrm{M} \mathrm{HCl}(10 \mathrm{~mL})$. The two phases were stirred together for $12 \mathrm{~h}$ giving a colorless $\mathrm{CH}_{2} \mathrm{Cl}_{2}$ layer and a blue aqueous layer. The organic layer and aqueous layer were separated and the aqueous layer was extracted with $\mathrm{CH}_{2} \mathrm{Cl}_{2}(30 \mathrm{~mL} \times 2)$. The combined organic layer was washed with saturated $\mathrm{NaHCO}_{3}(5 \mathrm{~mL})$ and brine $(5 \mathrm{~mL})$ and then dried $\left(\mathrm{MgSO}_{4}\right)$. The reaction mixture was filtered and evaporated to give white solid. The resulting solid was purified by flash chromatography (3:1 hexanes/EtOAc) to afford the desired diol compound 25 (110 $\mathrm{mg}, 51 \%)$. $\mathrm{Mp}=66{ }^{\circ} \mathrm{C}$ TLC $\mathrm{R}_{\mathrm{f}}=0.29(2: 1$ hexanes/EtOAc $) ;[\alpha]^{25} \mathrm{D}=-26.3\left(c=0.01, \mathrm{CHCl}_{3}\right) ;{ }^{1} \mathrm{H} \mathrm{NMR}\left(\mathrm{CDCl}_{3}\right.$, $400 \mathrm{MHz}) \delta 7.43-6.97(\mathrm{~m}, 20 \mathrm{H}), 4.92(\mathrm{~d}, J=16.9 \mathrm{~Hz}, 1 \mathrm{H}), 4.68(\mathrm{~d}, J=17.1 \mathrm{~Hz}, 1 \mathrm{H}), 4.67(\mathrm{~d}, J=$ 14.6 Hz, 1H), 4.46 (d, $J=14.7 \mathrm{~Hz}, 1 \mathrm{H}), 3.97$ (dd, $J=9.0,5.8 \mathrm{~Hz}, 1 \mathrm{H}), 3.78$ (dd, $J=7.7,0 \mathrm{~Hz}, 1 \mathrm{H})$, $3.73(\mathrm{dd}, 5.0,0 \mathrm{~Hz}, 1 \mathrm{H}), 3.65(\mathrm{dd}, J=14.6,8.2 \mathrm{~Hz}, 1 \mathrm{H}), 3.10(\mathrm{dd}, J=14.2,8.6 \mathrm{~Hz}, 1 \mathrm{H}), 2.97$ (m, 2H), $2.82(\mathrm{dd}, J=14.1,6.1 \mathrm{~Hz}, 1 \mathrm{H}), 2.43(\mathrm{~s}, 1 \mathrm{H}), 1.55(\mathrm{~s}, 1 \mathrm{H}) ;{ }^{13} \mathrm{C} \mathrm{NMR}\left(\mathrm{CDCl}_{3}, 100 \mathrm{MHz}\right) \delta 139.5,138.4$, 138.2, 137.3, 129.5, 129.3, 129.1, 129.0, 128.9, 128.9, 128.8, 128.3, 127.4, 127.3, 127.0, 127.0, 77.4, 77.1, 61.4, 60.4, 53.8, 51.7, 39.7, 36.5; FTIR (neat) 3481, 3062, 2926, 1811, 1496, 1321, 1147, 1062, 736, $698 \mathrm{~cm}^{-1}$; HRMS $(\mathrm{M}+\mathrm{H})^{+}$calcd for $\mathrm{C}_{32} \mathrm{H}_{35} \mathrm{~N}_{2} \mathrm{O}_{4} \mathrm{~S}(\mathrm{M}+\mathrm{H})^{+}$required 543.2318, found 543.2328.

\section{(S)-Methyl-2-(N-(tert-butoxycarbonyl)sulfamoylamino)-4-methylpentanoate (26)}

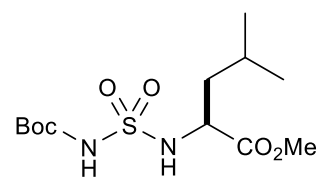

The solution of chlorosulfonyl isocynate $(1.23 \mathrm{~mL}, 14.13 \mathrm{mmol})$ in $\mathrm{CH}_{2} \mathrm{Cl}_{2}(40 \mathrm{~mL})$ was added at $0{ }^{\circ} \mathrm{C}$. The $1 \mathrm{M}$ solution of tert-butyl alcohol $(1.35 \mathrm{~mL}, 14.6 \mathrm{mmol})$ in $\mathrm{CH}_{2} \mathrm{Cl}_{2}(14 \mathrm{~mL})$ was added slowly. This solution was cannulated to a solution of $\mathrm{H}-\mathrm{Val}-\mathrm{OMe}$ hydrochloride $(2.38 \mathrm{~g}, 13.12 \mathrm{mmol})$ and $\mathrm{Et}_{3} \mathrm{~N}(4 \mathrm{~mL}, 28.7 \mathrm{mmol})$ in $\mathrm{CH}_{2} \mathrm{Cl}_{2}(40 \mathrm{~mL})$ at $0{ }^{\circ} \mathrm{C}$. The reaction mixture was extracted with 
$\mathrm{CH}_{2} \mathrm{Cl}_{2}(40 \mathrm{~mL} \times 3)$ and the organic layer dried $\left(\mathrm{MgSO}_{4}\right)$. The reaction mixture was filtered and evaporated under reduced pressure to obtain a crude solid. Flash chromatography (2:1 Hexanes/EtOAc) produced $26(3.34 \mathrm{~g}, 78 \%)$ as a white solid. $\mathrm{Mp}=101{ }^{\circ} \mathrm{C}$; $\mathrm{TLC} \mathrm{R}_{\mathrm{f}}=0.49(2: 1$ hexanes/EtOAc); $[\alpha]^{25} \mathrm{D}=67.3\left(c=1.01, \mathrm{CHCl}_{3}\right) ;{ }^{1} \mathrm{H} \mathrm{NMR}\left(\mathrm{CDCl}_{3}, 400 \mathrm{MHz}\right) \delta 7.60(\mathrm{~s}, 1 \mathrm{H}), 5.82$ (d, $J=9.2 \mathrm{~Hz}, 1 \mathrm{H}), 4.21(\mathrm{dd}, J=15.1,8.5 \mathrm{~Hz}, 1 \mathrm{H}), 3.75$ (s, 3H), 1.83 (qqt, $J=20.3,13.5,6.7 \mathrm{~Hz}$, $1 \mathrm{H}), 1.59(\mathrm{dd}, J=7.1,0 \mathrm{~Hz}, 1 \mathrm{H}), 1.57(\mathrm{dd}, J=6.4,1.6 \mathrm{~Hz}, 1 \mathrm{H}), 1.49$ (s, 9H), 0.96 (d, $J=6.6 \mathrm{~Hz}, 3 \mathrm{H})$, $0.93(\mathrm{~d}, J=6.7 \mathrm{~Hz}, 3 \mathrm{H}) ;{ }^{13} \mathrm{C} \mathrm{NMR}\left(\mathrm{CDCl}_{3}, 100 \mathrm{MHz}\right) \delta 173.0,150.2,83.9,55.5,52.7,42.2,28.1$, 24.5, 23.0, 21.7; FTIR (neat) 2959, 2937, 1736, 1437, 1369, ,1246, 1146, 972, 827, $731 \mathrm{~cm}^{-1}$; HRMS $(\mathrm{M}+\mathrm{H})^{+}$calcd for $\mathrm{C}_{12} \mathrm{H}_{24} \mathrm{~N}_{2} \mathrm{NaO}_{6} \mathrm{~S}(\mathrm{M}+\mathrm{H})^{+}$required 347.1253, found 347.1232.

\section{$N$-[(1,1-Dimethylethoxy)carbonyl]-[N-(1R)-1-(2-methylpropyl)-2-methoxycarbonyl- $N$ '-[(1S)-1-}

(2-methylpropyl)-2-methoxycarbonyl]-sulfamide (27)

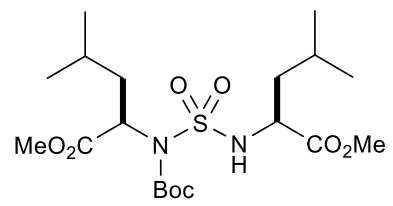

26 (1.75 g, $5.41 \mathrm{mmol})$ and DIAD (1.07 mL, $5.43 \mathrm{mmol})$ were dissolved in THF (10 $\mathrm{mL})$ at room temperature and then the mixed solution of methyl $(S)$-2-hydroxy-4-methylpentanoate $(0.79 \mathrm{~g}$, $5.40 \mathrm{mmol})$ and triphenylphosphine $(1.42 \mathrm{~g}, 5.41 \mathrm{mmol})$ in THF $(10 \mathrm{~mL})$ was added at room temperature. The reaction mixture was evaporated under reduced pressure to obtain a crude solid. Flash chromatography (5:1 Hexanes/EtOAc) gave $1.76 \mathrm{~g}(72 \%)$ of the 27 as a white solid. $\mathrm{Mp}=74$ ${ }^{\circ} \mathrm{C} ;$ TLC $\mathrm{R}_{\mathrm{f}}=0.47\left(5: 1\right.$ hexanes/EtOAc); $[\alpha]^{25} \mathrm{D}=-85.7\left(c=0.93, \mathrm{CHCl}_{3}\right) ;{ }^{1} \mathrm{H}_{\mathrm{NMR}}\left(\mathrm{CDCl}_{3}, 400\right.$ $\mathrm{MHz}) \delta 6.20(\mathrm{~d}, J=7.1 \mathrm{~Hz}, 1 \mathrm{H}), 4.88(\mathrm{ddd}, J=8.2,6.5,0 \mathrm{~Hz}, 1 \mathrm{H}), 4.30(\mathrm{ddd}, J=13.3,7.6,0 \mathrm{~Hz}$, $1 \mathrm{H}), 3.81(\mathrm{~s}, 3 \mathrm{H}), 3.73(\mathrm{~s}, 3 \mathrm{H}), 1.93(\mathrm{dd}, J=5.6,1.9 \mathrm{~Hz}, 1 \mathrm{H}), 1.91(\mathrm{dd}, J=6.1,1.4 \mathrm{~Hz}, 1 \mathrm{H}), 1.90$ (qqt, $J=20.4,13.0,6.4 \mathrm{~Hz}, 1 \mathrm{H}), 1.74$ (qqt, $J=19.8,13.0,6.5 \mathrm{~Hz}, 1 \mathrm{H}), 1.64-1.58$ (m, 2H), 1.49 (s, 9H), $0.97(\mathrm{~d}, J=1.7 \mathrm{~Hz}, 3 \mathrm{H}), 0.96(\mathrm{~d}, J=1.5 \mathrm{~Hz}, 3 \mathrm{H}), 0.95$ (d, $J=6.7 \mathrm{~Hz}, 3 \mathrm{H}), 0.92$ (d, $J=6.7 \mathrm{~Hz}, 3 \mathrm{H})$; ${ }^{13} \mathrm{C} \mathrm{NMR}\left(\mathrm{CDCl}_{3}, 100 \mathrm{MHz}\right) \delta 172.6,171.2,150.7,85.0,59.2,55.4,52.7,52.6,43.5,39.6,28.1,24.9$, 24.4, 23.6, 22.9, 22.1, 21.8; FTIR (neat) 2957, 2872, 1747, 1731, 1433, 1369, 1299, 1284, 1272, 1236, 1151, 1030, 987, 843, 773, $721 \mathrm{~cm}^{-1}$; HRMS $(\mathrm{M}+\mathrm{H})^{+}$calcd for $\mathrm{C}_{19} \mathrm{H}_{36} \mathrm{~N}_{2} \mathrm{NaO}_{8} \mathrm{~S}(\mathrm{M}+\mathrm{H})^{+}$required 475.2090, found 475.2080. 
$N$-[(1,1-Dimethylethoxy)carbonyl]- $N$-[(1R)-1-(2-methylpropyl)-2-methoxycarbonyl]- $N$ '-benzyl$N$ '-[(1S)-1-(2-methylpropyl)-2-ethoxycarbonyl]-sulfamide (28)

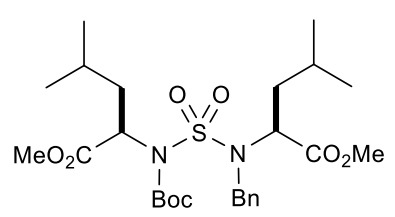

To a solution of $27(1.62,3.59 \mathrm{mmol})$ in $\mathrm{CH}_{3} \mathrm{CN}(50 \mathrm{~mL})$ with $\mathrm{K}_{2} \mathrm{CO}_{3}(0.70 \mathrm{~g}, 5.06 \mathrm{mmol})$ was added benzyl bromide $(0.58 \mathrm{~mL}, 5.04 \mathrm{mmol})$ and heated to $75^{\circ} \mathrm{C}$. After $2 \mathrm{~h}$, the reaction mixture was extracted with EtOAc $(50 \mathrm{~mL}$ x 2$)$, dried $\left(\mathrm{MgSO}_{4}\right)$, filtered, and concentrated under reduced pressure. Flash chromatography (2:1 hexanes/EtOAc) gave $1.37 \mathrm{~g}$ (77\%) of the desired sulfamide $\mathbf{2 8}$ as a white solid. $\mathrm{Mp}=98^{\circ} \mathrm{C}$; $\mathrm{TLC} \mathrm{R}_{\mathrm{f}}=0.24(10: 1$ hexanes/EtOAc $) ;[\alpha]^{25} \mathrm{D}=49.3\left(c=1.00, \mathrm{CHCl}_{3}\right)$; ${ }^{1} \mathrm{H} \mathrm{NMR}\left(\mathrm{CDCl}_{3}, 400 \mathrm{MHz}\right) \delta 7.46(\mathrm{~d}, J=7.2 \mathrm{~Hz}, 2 \mathrm{H}), 7.34-7.24(\mathrm{~m}, 3 \mathrm{H}), 5.05(\mathrm{~d}, J=16.8 \mathrm{~Hz}, 1 \mathrm{H})$, $4.96(\mathrm{dd}, J=8.1,5.5 \mathrm{~Hz}, 1 \mathrm{H}), 4.76(\mathrm{dd}, J=8.3,5.8 \mathrm{~Hz}, 1 \mathrm{H}), 4.68(\mathrm{~d}, J=16.8 \mathrm{~Hz}, 1 \mathrm{H}), 3.73(\mathrm{~s}, 3 \mathrm{H})$, 3.67 (s, 3H), 2.07-1.97 (m, 1H), 1.85 (dd, $J=9.6,4.8 \mathrm{~Hz}, 1 \mathrm{H}), 1.87-1.77(\mathrm{~m}, 1 \mathrm{H}), 1.52(\mathrm{~s}, 9 \mathrm{H}), 1.52-$ $1.46(\mathrm{~m}, 3 \mathrm{H}), 1.01(\mathrm{~d}, J=6.3 \mathrm{~Hz}, 3 \mathrm{H}), 0.98(\mathrm{~d}, J=6.4 \mathrm{~Hz}, 3 \mathrm{H}), 0.88(\mathrm{~d}, J=5.8 \mathrm{~Hz}, 3 \mathrm{H}), 0.52(\mathrm{~d}, J=$ $5.8 \mathrm{~Hz}, 3 \mathrm{H}) ;{ }^{13} \mathrm{C} \mathrm{NMR}\left(\mathrm{CDCl}_{3}, 100 \mathrm{MHz}\right) \delta 171.6,171.2,150.7,138.3,128.5,128.5,127.6,84.5$, 59.8, 59.1, 52.5, 52.1 , 51.2, 40.1, 39.6, 28.3, 25.1, 24.7, 23.4, 22.2, 22.2, 22.0; FTIR (neat) 3030, 2957, 1743, 1454, 1436, 1369, 1280, 1267, 1251, 1150, 1047, 1029, 731, $700 \mathrm{~cm}^{-1}$; HRMS $(\mathrm{M}+\mathrm{H})^{+}$calcd for $\mathrm{C}_{26} \mathrm{H}_{43} \mathrm{~N}_{2} \mathrm{O}_{8} \mathrm{~S}(\mathrm{M}+\mathrm{H})^{+}$required 543.2740, found 543.2750.

\section{$N$-[(1R)-1-(2-Methylpropyl)-2-methoxycarbonyl]- $N$ '-benzyl- $N$ '-[(1S)-1-(2-methylpropyl)-2-} methoxycarbonyl]-sulfamide (29)

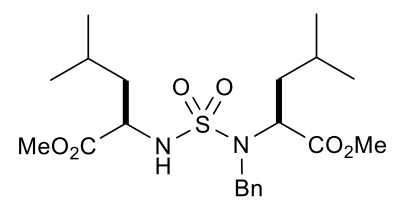

To a solution of $28(1.28 \mathrm{~g}, 2.58 \mathrm{mmol})$ in $\mathrm{CH}_{2} \mathrm{Cl}_{2}(5 \mathrm{~mL})$ was added TFA ( $5 \mathrm{~mL}, 64.90$ $\mathrm{mmol}$ ) at room temperature, and then the reaction solution was stirred for $48 \mathrm{~h}$. The reaction mixture was extracted with EtOAc $(50 \mathrm{~mL} \times 2)$, washed with saturated aqueous $\mathrm{NaHCO}_{3}$ solution. The organic layer was dried $\left(\mathrm{MgSO}_{4}\right)$, filtered, and concentrated under reduced pressure. Flash chromatography (3:1 hexanes/EtOAc) gave $1.00 \mathrm{~g}$ (97\%) of the desired sulfamide 29 as clear oil. TLC $\mathrm{R}_{\mathrm{f}}=0.68$ (3:1 hexanes/EtOAc); $[\alpha]^{25} \mathrm{D}=28.9\left(c=0.95, \mathrm{CHCl}_{3}\right) ;{ }^{1} \mathrm{H} \mathrm{NMR}\left(\mathrm{CDCl}_{3}, 400 \mathrm{MHz}\right) \delta 7.20(\mathrm{~d}, J=7.1 \mathrm{~Hz}$, 2H), 7.11-7.03 (m, 3H), $5.15(\mathrm{~d}, J=9.4 \mathrm{~Hz}, 1 \mathrm{H}), 4.40(\mathrm{~d}, J=16.0 \mathrm{~Hz}, 1 \mathrm{H}), 4.24(\mathrm{dd}, J=7.4,0 \mathrm{~Hz}$, 
1H), $4.05(\mathrm{~d}, J=16.0 \mathrm{~Hz}, 1 \mathrm{H}), 3.89(\mathrm{ddd}, J=12.7,8.4,6.4 \mathrm{~Hz}, 1 \mathrm{H}), 3.58(\mathrm{~s}, 3 \mathrm{H}), 3.52$ (s, 3H), 1.59$1.52(\mathrm{~m}, 1 \mathrm{H}), 1.41-1.32(\mathrm{~m}, 4 \mathrm{H}), 1.32-1.21(\mathrm{~m}, 1 \mathrm{H}), 0.73(\mathrm{~d}, J=6.6 \mathrm{~Hz}, 3 \mathrm{H}), 0.73(\mathrm{~d}, J=6.6 \mathrm{~Hz}$, $3 \mathrm{H}), 0.55(\mathrm{~d}, J=6.4 \mathrm{~Hz}, 3 \mathrm{H}), 0.33(\mathrm{~d}, J=6.6 \mathrm{~Hz}, 3 \mathrm{H}) ;{ }^{13} \mathrm{C} \mathrm{NMR}\left(\mathrm{CDCl}_{3}, 100 \mathrm{MHz}\right) \delta 173.9,173.2$, 137.3, 128.8, 128.6, 128.0, 60.0, 54.5, 52.7, 52.6, 50.9, 42.8, 39.0, 24.8, 24.6, 22.7, 22.6, 22.3, 21.5; FTIR (neat) 3030, 2957, 2870, 1744, 1454, 1437, 1340, 1271, 1201, 1145, 1027, 929, 899, 729, 700 $\mathrm{cm}^{-1}$; HRMS $(\mathrm{M}+\mathrm{H})^{+}$calcd for $\mathrm{C}_{21} \mathrm{H}_{35} \mathrm{~N}_{2} \mathrm{O}_{6} \mathrm{~S}(\mathrm{M}+\mathrm{H})^{+}$required 443.2216, found 443.2202.

$N, N^{\prime}$-Bis-benzyl- $N$ - $N$ '- (1S),(1R)- bis- [1-(2-methylpropyl)-2-methoxycarbonyl]-sulfamide (30)

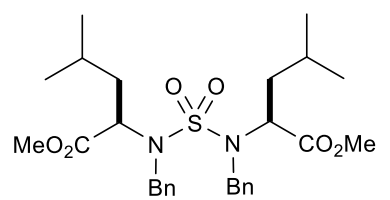

To a solution of $29(758 \mathrm{mg}, 1.90 \mathrm{mmol})$ in $\mathrm{CH}_{3} \mathrm{CN}(20 \mathrm{~mL})$ was added $\mathrm{K}_{2} \mathrm{CO}_{3}(602 \mathrm{mg}, 4.36$ $\mathrm{mmol})$ and benzyl bromide $(0.33 \mathrm{~mL}, 2.87 \mathrm{mmol})$ at room temperature and then the reaction mixture was refluxed for 16h. The reaction mixture was extracted with EtOAc (30 mL x 2), washed with brine, dried $\left(\mathrm{MgSO}_{4}\right)$, filtered, and concentrated under reduced pressure. Flash chromatography (10:1 hexanes/EtOAc) gave $923 \mathrm{mg}(91 \%)$ of the desired sulfamide 30 as clear oil. TLC $\mathrm{R}_{\mathrm{f}}=0.36(10: 1$ hexanes/EtOAc); ${ }^{1} \mathrm{H} \mathrm{NMR}\left(\mathrm{CDCl}_{3}, 400 \mathrm{MHz}\right) \delta 7.45-7.26(\mathrm{~m}, 5 \mathrm{H}), 4.75(\mathrm{~d}, J=15.9 \mathrm{~Hz}, 1 \mathrm{H}), 4.46$ $(\mathrm{d}, J=15.9 \mathrm{~Hz}, 1 \mathrm{H}), 4.30(\mathrm{dd}, J=7.2,0 \mathrm{~Hz}, 1 \mathrm{H}), 3.67(\mathrm{~s}, 3 \mathrm{H}), 1.75(\mathrm{ddd}, J=13.4,6.7,6.7 \mathrm{~Hz}, 1 \mathrm{H})$, $1.59-1.53(\mathrm{~m}, 1 \mathrm{H}), 1.49(\mathrm{ddd}, J=13.4,6.7,6.7 \mathrm{~Hz}, 1 \mathrm{H}), 0.86(\mathrm{~d}, J=6.3 \mathrm{~Hz}, 3 \mathrm{H}), 0.67(\mathrm{~d}, J=6.4$ $\mathrm{Hz}, 3 \mathrm{H}) ;{ }^{13} \mathrm{C} \mathrm{NMR}\left(\mathrm{CDCl}_{3}, 100 \mathrm{MHz}\right) \delta 172.3,137.7,128.8,128.6,127.8,58.5,52.2,50.3,39.5,25.0$, 22.6, 22.1; FTIR (neat) 3030, 2957, 1743, 1454, 1437, 1344, 1201, 1146, 1027, 865, $698 \mathrm{~cm}^{-1}$; HRMS $(\mathrm{M}+\mathrm{H})^{+}$calcd for $\mathrm{C}_{28} \mathrm{H}_{41} \mathrm{~N}_{2} \mathrm{O}_{6} \mathrm{~S}(\mathrm{M}+\mathrm{H})^{+}$required 533.2685, found 533.2672.

\section{$N, N^{\prime}-B i s-b e n z y l-N$-[(1S)-2-hydroxy-1-(2-methylpropyl)ethyl]- $N^{\prime}-[(1 R)-2-h y d r o x y-1-(2-$} methylpropyl)ethyl]-sulfamide (31)

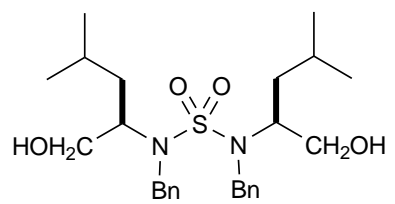

To a solution of $\mathbf{3 0}(829 \mathrm{mg}, 1.56 \mathrm{mmol})$ in THF $100 \mathrm{~mL}$ was added LAH (739 mg, 19.46 mmol) at $0{ }^{\circ} \mathrm{C}$. After $1 \mathrm{~h}, 15 \%$ of $\mathrm{NaOH}$ aqueous solution was added to the reaction solution until the color of solution was changed from colorless to white. The reaction mixture was filtered to remove 
white solid and concentrated under reduced pressure. Flash chromatography (1:1 hexanes/EtOAc) gave $750 \mathrm{mg}(99 \%)$ of the desired sulfamide 31 as white solid. $\mathrm{Mp}=104{ }^{\circ} \mathrm{C}$; $\mathrm{TLC} \mathrm{R}_{\mathrm{f}}=0.55(1: 1$ hexanes/EtOAc); ${ }^{1} \mathrm{H} \mathrm{NMR}\left(\mathrm{CDCl}_{3}, 400 \mathrm{MHz}\right) \delta 7.49(\mathrm{~d}, J=7.1 \mathrm{~Hz}, 2 \mathrm{H}), 7.35-7.27(\mathrm{~m}, 3 \mathrm{H}), 4.51(\mathrm{~d}$, $J=15.8 \mathrm{~Hz}, 1 \mathrm{H}), 4.33(\mathrm{~d}, J=15.8 \mathrm{~Hz}, 1 \mathrm{H}), 4.00-3.93(\mathrm{~m}, 1 \mathrm{H}), 3.69-3.59$ (m, 2H), $2.83(\mathrm{~s}, 1 \mathrm{H}), 1.63-$ $1.53(\mathrm{~m}, 1 \mathrm{H}), 1.27$ (ddd, $J=13.6,6.9,6.9 \mathrm{~Hz}, 1 \mathrm{H}), 1.09(\mathrm{ddd}, J=14.2,7.3,7.3 \mathrm{~Hz}, 1 \mathrm{H}), 0.85(\mathrm{~d}, J=$ $6.5 \mathrm{~Hz}, 3 \mathrm{H}), 0.74(\mathrm{~d}, J=6.6 \mathrm{~Hz}, 3 \mathrm{H}) ;{ }^{13} \mathrm{C} \mathrm{NMR}\left(\mathrm{CDCl}_{3}, 100 \mathrm{MHz}\right) \delta 138.4,128.8,128.8,127.9,63.0$, 59.7, 49.0, 39.9, 25.1, 23.2, 22.2; FTIR (neat) 3421, 2957, 2870, 1456, 1325, 1136, 1091, 1053, 871 $\mathrm{cm}^{-1}$; HRMS $(\mathrm{M}+\mathrm{H})^{+}$calcd for $\mathrm{C}_{26} \mathrm{H}_{41} \mathrm{~N}_{2} \mathrm{O}_{4} \mathrm{~S}(\mathrm{M}+\mathrm{H})^{+}$required 477.2787, found 477.2791.

\section{$N, N^{\prime}$-Bis-benzyl- $N$-[(1S)-1-(2-methylpropyl)-2-propenyl]- $N$ '-[(1R)-1-(2-methylpropyl)-2-} propenyl]-sulfamide (33)

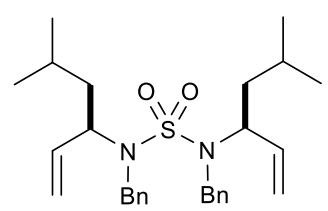

To a stirring solution of oxalyl chloride $(0.30 \mathrm{~mL}, 3.44 \mathrm{mmol})$ in $\mathrm{CH}_{2} \mathrm{Cl}_{2}(1 \mathrm{~mL})$ at $-78{ }^{\circ} \mathrm{C}$ under an argon atmosphere was added DMSO (0.30 mL, $4.23 \mathrm{mmol})$ in $\mathrm{CH}_{2} \mathrm{Cl}_{2}(1 \mathrm{~mL})$ over $20 \mathrm{~min}$. After $30 \mathrm{~min}$, the sulfamide diol $31(681 \mathrm{mg}, 1.43 \mathrm{mmol})$ in $\mathrm{CH}_{2} \mathrm{Cl}_{2}(10 \mathrm{~mL})$ was added over $30 \mathrm{~min}$ with an addition funnel, and the funnel was rinsed with $\mathrm{CH}_{2} \mathrm{Cl}_{2}(10 \mathrm{~mL})$. The mixture was stirred at $78^{\circ} \mathrm{C}$ for $5 \mathrm{~h}$ and monitored by TLC. $\mathrm{Et}_{3} \mathrm{~N}(1.5 \mathrm{~mL}, 10.76 \mathrm{mmol})$ was added over $15 \mathrm{~min}$ and stirred at $-78{ }^{\circ} \mathrm{C}$ for $2 \mathrm{~h}$. THF ( $4 \mathrm{~mL}, 1: 1 \mathrm{H}_{2} \mathrm{O} / \mathrm{THF}$ ) was added at $-78{ }^{\circ} \mathrm{C}$ for $5 \mathrm{~min}$, and the mixture stirred at $0{ }^{\circ} \mathrm{C}$ for $6 \mathrm{~h}$. The reaction mixture was extracted with $\mathrm{CH}_{2} \mathrm{Cl}_{2}(50 \mathrm{~mL})$, washed with $2 \mathrm{M} \mathrm{HCl}$, dried $\left(\mathrm{MgSO}_{4}\right)$, filtered, and concentrated under reduced pressure to afford $671 \mathrm{mg}(99 \%)$ of the desired dialdehyde sulfamide $\mathbf{3 2}$ as a white solid that was carried on immediately without further purification. TLC $R_{\mathrm{f}}=0.87(1: 1$ hexanes/EtOAc).

To a stirring solution of $\mathrm{CH}_{3} \mathrm{PPh}_{3} \mathrm{Br}(3.11 \mathrm{~g}, 8.72 \mathrm{mmol})$ in $\mathrm{THF}(25 \mathrm{~mL})$ at $0{ }^{\circ} \mathrm{C}$ under an argon atmosphere was slowly added a solution of BuLi (3.20 mL, 7.04 mmol, 1.6 M in hexanes) over $3 \mathrm{~min}$. After $3 \mathrm{~h}$, the yellow ylide solution was cooled to $-78^{\circ} \mathrm{C}$ and a solution of dial sulfamide (647 $\mathrm{mg}, 1.37 \mathrm{mmol})$ in THF (25 mL) at $-78^{\circ} \mathrm{C}$ was added via cannulation. After $24 \mathrm{~h}, 30 \mathrm{~mL}$ acetone was added to quench the reaction. The reaction mixture was concentrated under reduced pressure and extracted with EtOAc (50 mL x 2). The combined organic extracts were dried $\left(\mathrm{MgSO}_{4}\right)$, filtered, and 
concentrated under reduced pressure. Flash chromatography (10:1 hexanes/EtOAc) gave $555 \mathrm{mg}$ $(87 \%)$ of the desired sulfamide diene 33 as clear oil. TLC $\mathrm{R}_{\mathrm{f}}=0.72$ (5:1 hexanes/EtOAc); ${ }^{1} \mathrm{H}$ NMR $\left(\mathrm{CDCl}_{3}, 400 \mathrm{MHz}\right) \delta 7.40(\mathrm{~d}, J=6.9 \mathrm{~Hz}, 2 \mathrm{H}), 7.35-7.26(\mathrm{~m}, 3 \mathrm{H}), 5.88(\mathrm{ddd}, J=17.5,10.4,7.8 \mathrm{~Hz}$, $1 \mathrm{H}), 5.21(\mathrm{~d}, J=10.3 \mathrm{~Hz}, 1 \mathrm{H}), 5.12(\mathrm{~d}, J=17.2 \mathrm{~Hz}, 1 \mathrm{H}), 4.37(\mathrm{~d}, J=15.6 \mathrm{~Hz}, 1 \mathrm{H}), 4.24(\mathrm{~d}, J=15.7$ $\mathrm{Hz}, 1 \mathrm{H}), 4.07$ (ddd, $J=13.8,8.2,0 \mathrm{~Hz}, 1 \mathrm{H}), 1.54-1.37(\mathrm{~m}, 3 \mathrm{H}), 0.83$ (d, $J=6.2 \mathrm{~Hz}, 3 \mathrm{H}), 0.69$ (d, $J=$ $6.2 \mathrm{~Hz}, 3 \mathrm{H}) ;{ }^{13} \mathrm{C} \mathrm{NMR}\left(\mathrm{CDCl}_{3}, 100 \mathrm{MHz}\right) \delta 138.3,137.1,128.8,128.6,127.7,118.4,60.1,49.6,41.8$, 24.8, 23.3, 21.8; FTIR (neat) 3064, 3029, 2957, 1456, 1332, 1145, 1026, 921, 860, $700 \mathrm{~cm}^{-1}$; HRMS $(\mathrm{M}+\mathrm{H})^{+}$calcd for $\mathrm{C}_{28} \mathrm{H}_{41} \mathrm{~N}_{2} \mathrm{O}_{2} \mathrm{~S}(\mathrm{M}+\mathrm{H})^{+}$required 469.2889, found 469.2885.

(3R,6S)-2,7-Dibenzyl-3,6-diisobutyl-2,3,6,7-tetrahydro-1,2,7-thiadiazepine-1,1-dioxide (34)

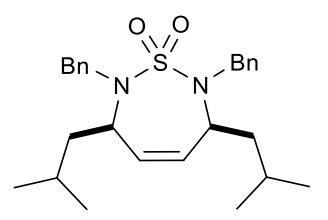

To a degassed solution of 33 (495 $\mathrm{mg}, 1.06 \mathrm{mmol})$ in benzene $(10 \mathrm{~mL})$ was added $\left(\mathrm{ImesH}_{2}\right)(\mathrm{PCy})(\mathrm{Cl})_{2} \mathrm{Ru}=\mathrm{CHPh}(63 \mathrm{mg}, 0.14 \mathrm{mmol})$ at room temperature. After $24 \mathrm{~h}$, DMSO (1.0 $\mathrm{mL}$ ) and silica gel were added to remove the catalyst. After $24 \mathrm{~h}$, the reaction mixture was filtered, and concentrated under reduced pressure. Flash chromatography (5:1 hexanes/EtOAc) afforded 407 mg $(85 \%)$ of the desired cyclic sulfamide 34 as white solid. $\mathrm{Mp}=142{ }^{\circ} \mathrm{C}$; TLC $\mathrm{R}_{\mathrm{f}}=0.55(5: 1) ;{ }^{1} \mathrm{H}$ NMR $\left(\mathrm{CDCl}_{3}, 400 \mathrm{MHz}\right) \delta 7.41(\mathrm{~d}, J=7.4 \mathrm{~Hz}, 2 \mathrm{H}), 7.33-7.23(\mathrm{~m}, 3 \mathrm{H}), 5.90(\mathrm{~d}, J=3.3 \mathrm{~Hz}, 1 \mathrm{H}), 4.75$ $(\mathrm{d}, J=15.7 \mathrm{~Hz}, 1 \mathrm{H}), 4.50(\mathrm{ddd}, J=9.3,6.1,3.3 \mathrm{~Hz}, 1 \mathrm{H}), 4.02(\mathrm{~d}, J=15.7 \mathrm{~Hz}, 1 \mathrm{H}), 1.54(\mathrm{ddd}, J=$ 14.0, 9.4, 5.1 Hz, 1H), 1.46-1.36 (m, 1H), $1.19(\mathrm{ddd}, J=14.2,8.4,6.3 \mathrm{~Hz}, 1 \mathrm{H}), 0.82(\mathrm{~d}, J=6.6 \mathrm{~Hz}$, $3 \mathrm{H}), 0.50(\mathrm{~d}, J=6.7 \mathrm{~Hz}, 3 \mathrm{H}) ;{ }^{13} \mathrm{C} \mathrm{NMR}\left(\mathrm{CDCl}_{3}, 100 \mathrm{MHz}\right) \delta 139.2,136.4,128.5,128.0,127.4,54.9$, 50.2, 42.6, 24.4, 22.4, 22.1; FTIR (neat) 3028, 2955, 2866, 1495, 1456, 1360, 1346, 1161, 1148, 1089 , 916, 841, 766, $706 \mathrm{~cm}^{-1}$; HRMS $(\mathrm{M}+\mathrm{H})^{+}$calcd for $\mathrm{C}_{26} \mathrm{H}_{37} \mathrm{~N}_{2} \mathrm{O}_{2} \mathrm{~S}(\mathrm{M}+\mathrm{H})^{+}$required 440.2497, found 441.2581 .

\section{$N$-Benzyl- $N$ - $N$ '-bis-[(1S)-1-(2-methylpropyl)-2-methoxycarbonyl]-sulfamide (7)}

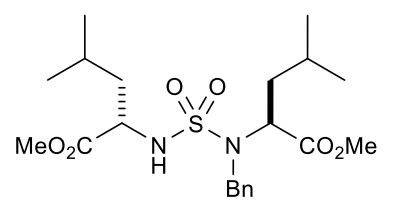


To a stirred solution of $4(3.82 \mathrm{~g}, 10.83 \mathrm{mmol})$ in $\mathrm{CH}_{3} \mathrm{CN}(20 \mathrm{~mL})$ at room temperature under an argon atmosphere was added $\mathrm{K}_{2} \mathrm{CO}_{3}(1.50 \mathrm{~g}, 10.83 \mathrm{mmol})$ and benzyl bromide $(1.25 \mathrm{~mL}, 10.86$ mmol). After the addition, the reaction mixture was refluxed at $80{ }^{\circ} \mathrm{C}$ for 24 hours. The reaction mixture was filtered under reduced aspirator vacuum and extracted with EtOAc $(50 \mathrm{~mL} \times 2)$. The combined organic extracts were dried $\left(\mathrm{MgSO}_{4}\right)$, filtered, concentrated on a rotary evaporator. The resulting white solid was purified by flash chromatography (silica gel, 6:1 hexanes/EtOAc) to afford the desired monobenzyl sulfamide $7(2.87 \mathrm{~g}, 67 \%) . \quad \mathrm{Mp}=64{ }^{\circ} \mathrm{C}$; TLC TLC $\mathrm{R}_{\mathrm{f}}=0.35$ (6:1 hexanes/EtOAc); $[\alpha]^{25} \mathrm{D}=-65.7\left(c=0.80, \mathrm{CHCl}_{3}\right) ;{ }^{1} \mathrm{H} \mathrm{NMR}\left(\mathrm{CDCl}_{3}, 400 \mathrm{MHz}\right) \delta 7.32(\mathrm{~m}, 5 \mathrm{H}) 5.26$ (d, $J=9.1 \mathrm{~Hz}, 1 \mathrm{H}), 4.55(\mathrm{~d}, J=15.9,1 \mathrm{H}) 4.34(\mathrm{t}, J=7.3 \mathrm{~Hz}, 1 \mathrm{H}), 4.28(\mathrm{~d}, J=15.9 \mathrm{~Hz}, 1 \mathrm{H}) 4.15$ (ddd, $J=8.4,8.9,6.19 \mathrm{~Hz}, 1 \mathrm{H}) 3.79(\mathrm{~s}, 3 \mathrm{H}), 3.72(\mathrm{~s}, 3 \mathrm{H}), 1.76(\mathrm{~m}, 1 \mathrm{H}), 1.60(\mathrm{dd}, J=7.4,7.3 \mathrm{~Hz}, 2 \mathrm{H}), 1.56$ (dd, $J=6.6,8.3 \mathrm{~Hz}, 2 \mathrm{H}) 1.48(\mathrm{~m}, 1 \mathrm{H}), 0.93(\mathrm{dd}, J=7.1,6.9 \mathrm{~Hz}, 6 \mathrm{H}), 0.76(\mathrm{~d}, J=6.5 \mathrm{~Hz}, 3 \mathrm{H}), 0.55$ $(\mathrm{d}, J=6.6 \mathrm{~Hz}, 3 \mathrm{H}) ;{ }^{13} \mathrm{C} \mathrm{NMR}\left(\mathrm{CDCl}_{3}, 100 \mathrm{MHz}\right) \delta 173.8,173.1,137.2,128.7,128.6,127.9,59.9$, 54.6, 52.7, 51.0, 42.9, 39.2, 24.7, 24.6, 22.8, 22.5, 22.2, 21.7; FTIR (neat) 3030, 2957, 1744, 1456, 1437, 1340, 1272, 1203, 1145, 1028, 901, 729, $700 \mathrm{~cm}^{-1}$; HRMS calcd for $\mathrm{C}_{21} \mathrm{H}_{34} \mathrm{~N}_{2} \mathrm{O}_{6} \mathrm{~S}(\mathrm{M}+\mathrm{H})^{+}$ required 443.2216, found 443.2194.

\section{$N$-Benzyl- $N$ '-(4-methoxy)-benzyl- $N, N$ '-bis-[(1S)-1-(2-methylpropyl)-2-methoxycarbonyl]- sulfamide (8)}

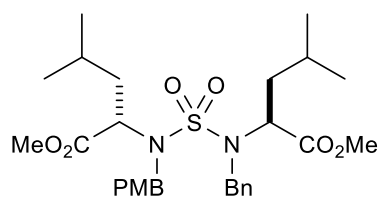

To a stirred solution of $7(0.30 \mathrm{~g}, 0.75 \mathrm{mmol})$ in $\mathrm{CH}_{3} \mathrm{CN}(20 \mathrm{~mL})$ at room temperature under an argon atmosphere was added $\mathrm{K}_{2} \mathrm{CO}_{3}(0.16 \mathrm{~g}, 1.18 \mathrm{mmol})$ and $p$-methoxybenzyl chloride $(0.13 \mathrm{~mL}$, $0.96 \mathrm{mmol}$ ). After the addition, the reaction mixture was refluxed at $80{ }^{\circ} \mathrm{C}$ for $48 \mathrm{~h}$. The reaction mixture was extracted with EtOAc $(50 \mathrm{~mL} \times 2)$. The combined organic extracts were dried $\left(\mathrm{MgSO}_{4}\right)$, filtered, concentrated on a rotary evaporator. The resulting oil was purified by flash chromatography (silica gel, 6:1 hexanes/EtOAc) to afford the desired compound $\mathbf{8}(0.26 \mathrm{~g}, 67 \%)$. TLC $\mathrm{R}_{\mathrm{f}}=0.32(6: 1$ hexanes/EtOAc); $[\alpha]^{25} \mathrm{D}=16.9\left(c=1.10, \mathrm{CHCl}_{3}\right) ;{ }^{1} \mathrm{H} \mathrm{NMR}\left(\mathrm{CDCl}_{3}, 400 \mathrm{MHz}\right) \delta 7.45(\mathrm{~d}, J=7.1 \mathrm{~Hz}$, 2H), $7.32(\mathrm{~m}, 5 \mathrm{H}), 6.86(\mathrm{~d}, J=8.7 \mathrm{~Hz}, 2 \mathrm{H}), 4.75(\mathrm{~d}, J=15.8 \mathrm{~Hz}, 1 \mathrm{H}), 4.65(\mathrm{~d}, J=15.5 \mathrm{~Hz}, 1 \mathrm{H}), 4.48$ $(\mathrm{d}, J=15.9 \mathrm{~Hz}, 1 \mathrm{H}), 4.41(\mathrm{~d}, J=15.5 \mathrm{~Hz}, 1 \mathrm{H}) 4.30(\mathrm{t}, J=7.0,6.5 \mathrm{~Hz}, 1 \mathrm{H}), 4.28(\mathrm{t}, J=6.9,6.6 \mathrm{~Hz}$, $1 \mathrm{H}), 3.79$ (s, 3H), 3.67 (s, 3H), 3.65 (s, 3H), $1.82(\mathrm{~m}, 2 \mathrm{H}), 1.78$ (m, 4H), 0.87 (dd, J = 6.2, $1.4 \mathrm{~Hz}$, 
$6 \mathrm{H}), 0.63(\mathrm{dd}, J=6.2,20.3 \mathrm{~Hz}, 6 \mathrm{H}) ;{ }^{13} \mathrm{C} \mathrm{NMR}\left(\mathrm{CDCl}_{3}, 100 \mathrm{MHz}\right) \delta 172.3,172.3,159.2,137.3,130.1$, 128.9, 128.6, 128.5, 127.7, 113.8, 58.2, 58.0, 55.3, 52.2, 50.4, 49.8, 49.7, 39.0, 38.9, 24.9, 24.8, 22.4, 22.3, 22.2, 22.1; FTIR (neat) 3081, 2957, 2870, 1744, 1612, 1514, 1456, 1438, 1340, 1247, 1203, $1148,1036,869,833,750,700 \mathrm{~cm}^{-1}$; HRMS calcd for $\mathrm{C}_{29} \mathrm{H}_{43} \mathrm{~N}_{2} \mathrm{O}_{7} \mathrm{~S}(\mathrm{M}+\mathrm{H})^{+}$required 563.2791, found 563.2794 .

\section{$N$-Benzyl- $N$ '-(4-methoxy)-benzyl- $N$ - $N$ '-bis-[(1S)-2-hydroxy-1-(2-methylpropyl)-ethyl]- sulfamide (11)}

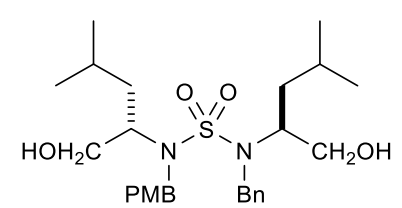

Following the same procedure as for 9; Ester $8(0.48 \mathrm{~g}, 0.92 \mathrm{mmol})$ was reduced with LAH $(0.71 \mathrm{~g}, 18.61 \mathrm{mmol})$ in THF $(100 \mathrm{~mL})$. The resulting oil was purified by flash chromatography $(1: 1$ hexanes/EtOAc) to afford the desired diol compound $11(0.35 \mathrm{~g}, 77 \%) . \mathrm{Mp}=54{ }^{\circ} \mathrm{C} ; \mathrm{TLC} \mathrm{R}_{\mathrm{f}}=0.5$ $\left(1: 1\right.$ hexanes/EtOAc); $[\alpha]^{25} \mathrm{D}=-73.8\left(c=0.82, \mathrm{CHCl}_{3}\right) ;{ }^{1} \mathrm{H} \mathrm{NMR}\left(\mathrm{CDCl}_{3}, 400 \mathrm{MHz}\right) \delta 7.37(\mathrm{~m}, 7 \mathrm{H})$ $6.86(\mathrm{~d}, J=8.5 \mathrm{~Hz}, 2 \mathrm{H}), 4.47$ (d, $J=10.8 \mathrm{~Hz}, 2 \mathrm{H}), 4.41(\mathrm{~s}, 2 \mathrm{H}), 3.79$ (s, 3H), 3.77 (m, 2H), 3.61 (d, $J=7.4 \mathrm{~Hz}, 4 \mathrm{H}), 3.18(\mathrm{~s}, 2 \mathrm{H}), 1.42(\mathrm{~m}, 4 \mathrm{H}), 1.1(\mathrm{~m}, 2 \mathrm{H}), 0.79(\mathrm{t}, J=5.2,5.2 \mathrm{~Hz}, 6 \mathrm{H}), 0.71(\mathrm{t}, J=5.9$, $6.1 \mathrm{~Hz}, 6 \mathrm{H}) ;{ }^{13} \mathrm{C} \mathrm{NMR}\left(\mathrm{CDCl}_{3}, 100 \mathrm{MHz}\right) \delta 159.3,138.8,130.6,130.1,128.8,128.7,127.8,114.1$, 62.9, 62.8, 58.9, 58.9, 55.5, 49.4, 48.8, 39.7, 39.7, 25.4, 25.4, 23.4, 23.4, 22.0, 22.0; FTIR (neat) 3384, 2957, 2341, 1612, 1514, 1465, 1323, 1247, 1141, 1035, 887, $736 \mathrm{~cm}^{-1}$; HRMS calcd for $\mathrm{C}_{27} \mathrm{H}_{43} \mathrm{~N}_{2} \mathrm{O}_{5} \mathrm{~S}$ $(\mathrm{M}+\mathrm{H})^{+}$required 507.2893, found 507.2884.

\section{$N$-Benzyl- $N$ '-(4-methoxy)-benzyl- $N$, $N$ '-bis-[(1S)-1-(2-methylpropyl)-2-propenyl]-sulfamide (17)}

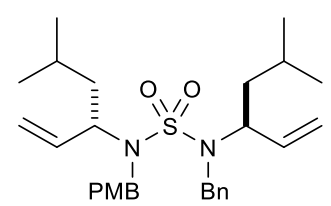

Following the same procedure as for 14; Diol $11(0.81 \mathrm{~g}, 1.65 \mathrm{mmol})$ was oxidized with DessMartin periodinane $(1.4 \mathrm{~g}, 3.30 \mathrm{mmol})$ in $\mathrm{CH}_{2} \mathrm{Cl}_{2}(10 \mathrm{~mL})$. The resulting oil was purified by flash chromatography (1:1 hexanes/EtOAc) to afford the desired aldehyde 14. $(0.73 \mathrm{~g}, 91 \%)$. TLC $\mathrm{R}_{\mathrm{f}}=0.8$ $(1: 1$ hexanes/EtOAc); 
Following the same procedure as for 15; aldehyde $14(0.73 \mathrm{~g}, 1.50 \mathrm{mmol})$ was transferred to terminal olefin sulfamide with using methyltriphenylphosphonium bromide (3.96 g, $11.07 \mathrm{mmol})$ in THF (10 mL), potassium bis (trimethylsilyl) amide $(20 \mathrm{~mL}, 10.0 \mathrm{mmol})$. The resulting solid was purified by flash chromatography (3:1 hexanes/EtOAc) to afford the desired terminal olefin sulfamide 17 as a white solid $(0.33 \mathrm{~g}, 46 \%) . \mathrm{Mp}=95{ }^{\circ} \mathrm{C}$; $\mathrm{TLC} \mathrm{R}_{\mathrm{f}}=0.85(3: 1$ hexanes/EtOAc $) ;[\alpha]^{25}{ }_{\mathrm{D}}=-51.1(c$ $\left.=1.0, \mathrm{CHCl}_{3}\right) ;{ }^{1} \mathrm{H} \mathrm{NMR}\left(\mathrm{CDCl}_{3}, 400 \mathrm{MHz}\right) \delta 7.30(\mathrm{~m}, 7 \mathrm{H}), 6.81(\mathrm{~d}, J=8.7 \mathrm{~Hz}, 2 \mathrm{H}), 5.82(\mathrm{ddd}, J=$ 19.7, 12.0, 7.8 Hz, 1H), 5.81 (ddd, $J=19.7,12.0,7.8 \mathrm{~Hz}, 1 \mathrm{H}), 5.16$ (dd, $J=10.3,6.8 \mathrm{~Hz}, 2 \mathrm{H}$ ), 5.08 $(\mathrm{dd}, J=17.2,3.0 \mathrm{~Hz}, 2 \mathrm{H}), 4.33-4.17(\mathrm{~m}, 4 \mathrm{H}), 4.00(\mathrm{~m}, 2 \mathrm{H}), 3.77(\mathrm{~s}, 3 \mathrm{H}), 1.40(\mathrm{~m}, 6 \mathrm{H}), 0.77(\mathrm{~d}, J=$ $5.7 \mathrm{~Hz}, 6 \mathrm{H}), 0.63(\mathrm{dd}, J=8.4,6.2 \mathrm{~Hz}, 6 \mathrm{H}) ;{ }^{13} \mathrm{C} \mathrm{NMR}\left(\mathrm{CDCl}_{3}, 100 \mathrm{MHz}\right) \delta 159.2,138.4,137.4,134.0$, $133.8,130.3,130.2,128.9,127.6,118.4,118.3,113.9,60.0,55.5,49.5,49.0,41.8,24.8,23.3,21.8$; FTIR (neat) 3069, 2955, 2931, 1514, 1466, 1456, 1437, 1330, 1248, 1145, 1038, 924, 862, 744, 698 $\mathrm{cm}^{-1}$; HRMS calcd for $\mathrm{C}_{29} \mathrm{H}_{43} \mathrm{~N}_{2} \mathrm{O}_{3} \mathrm{~S}(\mathrm{M}+\mathrm{H})^{+}$required 499.2994, found 499.2985.

\section{(3S,6S)-2-Benzyl-7-(4-methoxy)-benzyl-3,6-diisobutyl-2,3,6,7-tetrahydro-1,2,7-thiadiazepine-}

\section{1,1-dioxide (20)}

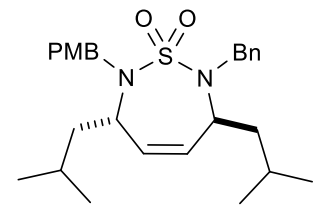

Following the same procedure as for 18; terminal olefin sulfamide 17 (0.28 g, $0.57 \mathrm{mmol})$ in benzene $(20 \mathrm{~mL})$ was metathesized with using $2 \mathrm{nd} \mathrm{Grubb's} \mathrm{catalyst}(0.05 \mathrm{~g}, 0.06 \mathrm{mmol})$. The resulting oil was purified by flash chromatography (5:1 hexanes/EtOAc) to afford the desired seven membered sulfamide ring $20(0.04 \mathrm{~g}, 16 \%)$. TLC $\mathrm{R}_{\mathrm{f}}=0.51\left(5: 1\right.$ hexanes/EtOAc); $[\alpha]^{25}{ }_{\mathrm{D}}=44.8\left(c=1.10, \mathrm{CHCl}_{3}\right)$; ${ }^{1} \mathrm{H} \mathrm{NMR}\left(\mathrm{CDCl}_{3}, 400 \mathrm{MHz}\right) \delta 7.34(\mathrm{~d}, J=7.4 \mathrm{~Hz}, 2 \mathrm{H}), 7.34-7.23(\mathrm{~m}, 5 \mathrm{H}), 6.86(\mathrm{~d}, J=8.6 \mathrm{~Hz}, 2 \mathrm{H})$, $55.3(\mathrm{~s}, 2 \mathrm{H}), 4.86(\mathrm{~d}, J=16.0 \mathrm{~Hz}, 1 \mathrm{H}), 4.79$ (d, $J=15.8 \mathrm{~Hz}, 1 \mathrm{H}), 4.24(\mathrm{ddd}, J=0,5.3,10.6 \mathrm{~Hz}, 2 \mathrm{H})$, $4.21(\mathrm{~d}, J=9.3 \mathrm{~Hz}, 1 \mathrm{H}), 4.18(\mathrm{~d}, J=9.1 \mathrm{~Hz}, 1 \mathrm{H}), 3.81$ (s, 3H), $1.62(\mathrm{ddd}, J=14.3,10.3,4.4 \mathrm{~Hz}, 1 \mathrm{H})$, 1.57(ddd, $J=14.3,10.3,4.4 \mathrm{~Hz}, 1 \mathrm{H}), 1.44-1.33(\mathrm{~m}, 2 \mathrm{H}), 1.17$ (m, 2H), 0.83 (d, J = 1.6 Hz, 3H), 0.82 $(\mathrm{d}, J=1.5 \mathrm{~Hz}, 3 \mathrm{H}), 0.56(\mathrm{~d}, J=6.7 \mathrm{~Hz}, 3 \mathrm{H}), 0.47(\mathrm{~d}, J=6.7 \mathrm{~Hz}, 3 \mathrm{H}) ;{ }^{13} \mathrm{C} \mathrm{NMR}\left(\mathrm{CDCl}_{3}, 100 \mathrm{MHz}\right) \delta$ 159.0, 139.2, 132.4, 131.3, 129.3, 128.5, 127.9, 127.3, 113.9, 55.5, 53.7, 53.6, 51.1, 50.5, 42.8, 24.4, 22.6, 21.7; FTIR (neat) 3028, 2957, 1612, 1514, 1467, 1340, 1245, 1170, 1149, 1111, 1035, 860, 829, 766, 745, 725, $698 \mathrm{~cm}^{-1}$; HRMS calcd for $\mathrm{C}_{27} \mathrm{H}_{39} \mathrm{~N}_{2} \mathrm{O}_{3} \mathrm{~S}(\mathrm{M}+\mathrm{H})^{+}$required 471.2681, found 471.2671. 
2-(3S,6R)-Benzyl-3-isopropyl-7-(4-methoxybenzyl)-6-methyl-2,3,6,7-tetrahydro-1,2,7thiadiazepine 1,1-dioxide (35)

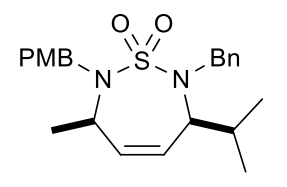

The product was obtained according to the literature procedure. ${ }^{1}$

2-(3S,4S,5R,6R)-Benzyl-4,5-dihydroxy-3-isopropyl-7-(4-methoxybenzyl)-6-methyl-1,2,7-

thiadiazepane 1,1-dioxide (36)

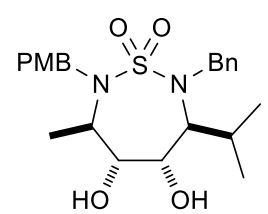

The product was obtained according to the literature procedure. ${ }^{1}$

(3S,4R,5S,6R)-2-Benzyl-4,5-dihydroxy-3-isopropyl-7-(4-methoxybenzyl)-6-methyl-1,2,7thiadiazepane 1,1-dioxide (37)

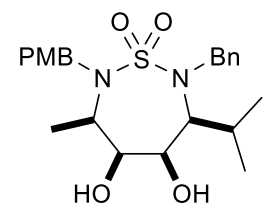

The product was obtained according to the literature procedure. ${ }^{1}$

Methyl (S)-2-((S)-6-isopropyl-1,1-dioxido-6,7-dihydro-1,2,7-thiadiazepin-2(3H)-yl)-4Methylpentanoate (38)

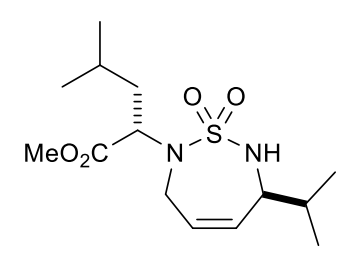

The product was obtained according to the literature procedure. ${ }^{2}$

Methyl (S)-2-((S)-7-benzyl-6-isopropyl-1,1-dioxido-6,7-dihydro-1,2,7-thiadiazepin-2(3H)-yl)-4methylpentanoate (39) 


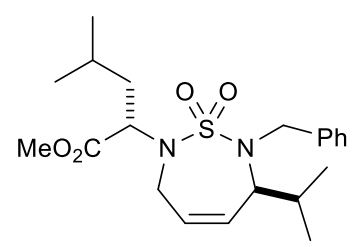

The product was obtained according to the literature procedure. ${ }^{2}$

Methyl (2S)-2-((4S,5R)-7-benzyl-6-((benzyloxy)methyl)-4,5-dihydroxy-1,1-dioxido-1,2,7thiadiazepan-2-yl)-3-methylbutanoate (40)

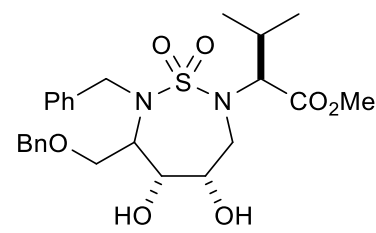

The product was obtained according to the literature procedure. ${ }^{1}$

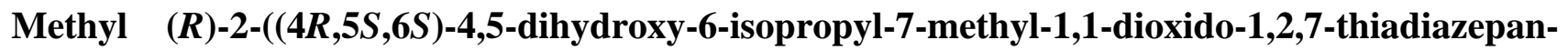
2-yl)-4-methylpentanoate (41)

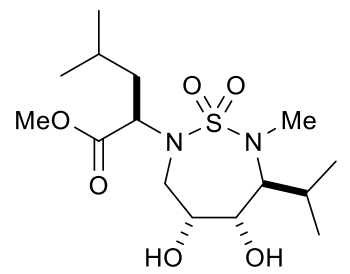

The product was obtained according to the literature procedure. ${ }^{1}$

Methyl (S)-2-((4R,5S,6S)-4,5-dihydroxy-6-isopropyl-1,1-dioxido-1,2,7-thiadiazepan-2-yl)-4methylpentanoate (42)

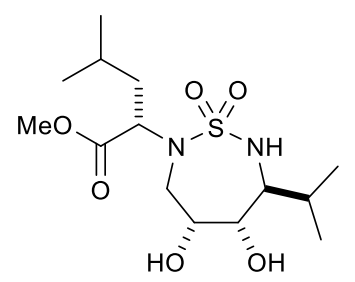

The product was obtained according to the literature procedure. ${ }^{2}$

Methyl (S)-2-(1,1-dioxido-6,7-dihydro-1,2,7-thiadiazepin-2(3H)-yl)-3-methylbutanoate (43) 


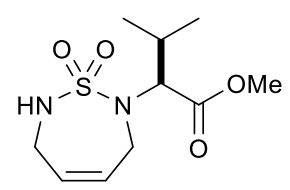

The product was obtained according to the literature procedure. ${ }^{3}$

Ethyl $(R)-2-((4 R, 5 S, 6 S)-4,5-d i h y d r o x y-6-i s o p r o p y l-7-m e t h y l-1,1-d i o x i d o-1,2,7-t h i a d i a z e p a n-2-$ yl)propanoate (44)

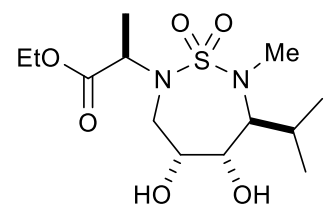

The product was obtained according to the literature procedure. ${ }^{1}$

Methyl (2S)-2-(6-((benzyloxy)methyl)-1,1-dioxido-6,7-dihydro-1,2,7-thiadiazepin-2(3H)-yl)-3methylbutanoate (45)

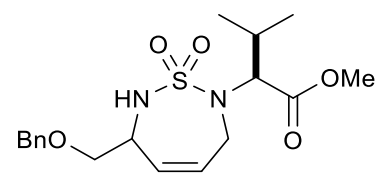

The product was obtained according to the literature procedure. ${ }^{1}$

\section{Dimethyl 3,3'-(1,1-dioxido-3,6-dihydro-1,2,7-thiadiazepine-2,7-diyl)(3S,3'S)-bis(5-methyl-2-} oxohexanoate) (46)

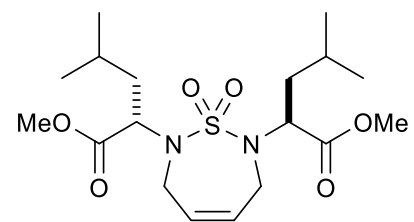

The product was obtained according to the literature procedure. ${ }^{4}$ 


\section{Biology}

Table s1. Antiproliferative $\left(\mathrm{GI}_{50} / \mu \mathrm{M}\right)^{\mathrm{a}}$ and cytoxicity $\left(\mathrm{LC}_{50} / \mu \mathrm{M}\right)^{\mathrm{b}}$ values for the selected data of compounds against NCI60-cell panel.

\begin{tabular}{|c|c|c|c|c|c|c|c|c|}
\hline \multirow{2}{*}{$\begin{array}{l}\text { Panel/cell } \\
\text { line }\end{array}$} & \multicolumn{2}{|c|}{18 (NSC 764190) } & \multicolumn{2}{|c|}{21 (NSC 751486) } & \multicolumn{2}{|c|}{23 (NSC 751478) } & \multicolumn{2}{|c|}{25 (NSC 764189) } \\
\hline & $\mathrm{GI}_{50}$ & $\mathrm{LC}_{50}$ & $\mathrm{GI}_{50}$ & $\mathrm{LC}_{50}$ & $\mathrm{GI}_{50}$ & $\mathrm{LC}_{50}$ & $\mathrm{GI}_{50}$ & $\mathrm{LC}_{50}$ \\
\hline \multicolumn{9}{|c|}{ Leukemia } \\
\hline CCRF-CEM & 3.85 & $>100$ & 5.96 & $>20$ & $>7.5$ & $>7.5$ & $>5.0$ & $>5.0$ \\
\hline HL-60(TB) & 3.43 & $>100$ & 2.97 & $>20$ & 4.75 & $>7.5$ & $>5.0$ & $>5.0$ \\
\hline K-562 & 2.00 & $>100$ & 3.05 & $>20$ & 3.34 & $>7.5$ & $>5.0$ & $>5.0$ \\
\hline MOLT-4 & 2.15 & $>100$ & 2.86 & $>20$ & 4.12 & $>7.5$ & $>5.0$ & $>5.0$ \\
\hline RPMI-8226 & 0.859 & $>100$ & 4.49 & $>20$ & 4.92 & $>7.5$ & $>5.0$ & $>5.0$ \\
\hline SR & 1.66 & $>100$ & nd & nd & nd & nd & nd & nd \\
\hline \multicolumn{9}{|c|}{ Non-small cell lung cancer } \\
\hline A549/ATCC & 7.67 & $>100$ & 2.99 & 19.4 & 3.78 & $>7.5$ & $>5.0$ & $>5.0$ \\
\hline EKVX & nd & $>100$ & 3.43 & $>20$ & 6.55 & $>7.5$ & $>5.0$ & $>5.0$ \\
\hline HOP-62 & $>100$ & $>100$ & 3.71 & 14.5 & $>7.5$ & $>7.5$ & $>5.0$ & $>5.0$ \\
\hline HOP-92 & 4.40 & $>100$ & 3.15 & 14.1 & $>7.5$ & $>7.5$ & $>5.0$ & $>5.0$ \\
\hline NCI-H226 & 4.35 & $>100$ & 3.04 & 12.5 & $>7.5$ & $>7.5$ & $>5.0$ & $>5.0$ \\
\hline NCI-H23 & 1.66 & $>100$ & 3.11 & 14.5 & 3.47 & $>7.5$ & $>5.0$ & $>5.0$ \\
\hline NCI-H322M & $>100$ & $>100$ & 4.48 & $>20$ & $>7.5$ & $>7.5$ & $>5.0$ & $>5.0$ \\
\hline NCI-H460 & 2.75 & $>100$ & 3.41 & 18.3 & 2.53 & $>7.5$ & $>5.0$ & $>5.0$ \\
\hline NCI-H522 & 5.46 & $>100$ & 0.847 & 14.5 & 1.83 & $>7.5$ & $>5.0$ & $>5.0$ \\
\hline \multicolumn{9}{|c|}{ Colon cancer } \\
\hline COLO 205 & $>100$ & $>100$ & 4.26 & $>20$ & $>7.5$ & $>7.5$ & $>5.0$ & $>5.0$ \\
\hline HCC-2998 & $>100$ & $>100$ & 3.41 & 11.3 & $>7.5$ & $>7.5$ & $>5.0$ & $>5.0$ \\
\hline НCT-116 & 0.535 & $>100$ & 2.43 & 10.5 & 0.844 & $>7.5$ & $>5.0$ & $>5.0$ \\
\hline НCТ-15 & 3.51 & $>100$ & 4.37 & $>20$ & 3.92 & $>7.5$ & $>5.0$ & $>5.0$ \\
\hline HT29 & 42.6 & $>100$ & 2.63 & 12.1 & $>7.5$ & $>7.5$ & $>5.0$ & $>5.0$ \\
\hline KM12 & 9.92 & $>100$ & 2.94 & 11.6 & 7.19 & $>7.5$ & $>5.0$ & $>5.0$ \\
\hline SW-620 & nd & $>100$ & 3.18 & 15.9 & $>7.5$ & $>7.5$ & $>5.0$ & $>5.0$ \\
\hline \multicolumn{9}{|c|}{ CNS cancer } \\
\hline SF-268 & 7.85 & $>100$ & 3.44 & 18.8 & 6.08 & $>7.5$ & $>5.0$ & $>5.0$ \\
\hline SF-295 & 0.667 & $>100$ & 2.62 & 12.3 & 1.80 & $>7.5$ & $>5.0$ & $>5.0$ \\
\hline SF-539 & $>100$ & $>100$ & 3.37 & 13.6 & $>7.5$ & $>7.5$ & $>5.0$ & $>5.0$ \\
\hline SNB-19 & $>100$ & $>100$ & 4.69 & $>20$ & $>7.5$ & $>7.5$ & $>5.0$ & $>5.0$ \\
\hline SNB-75 & $>100$ & $>100$ & 2.31 & $>20$ & $>7.5$ & $>7.5$ & $>5.0$ & $>5.0$ \\
\hline $\mathrm{U} 251$ & 1.11 & $>100$ & 3.07 & 13.6 & 1.84 & $>7.5$ & $>5.0$ & $>5.0$ \\
\hline \multicolumn{9}{|c|}{ Melanoma } \\
\hline LOX IMVI & 1.40 & $>100$ & 3.28 & 15.3 & 5.38 & $>7.5$ & $>5.0$ & $>5.0$ \\
\hline MALME-3M & $>100$ & $>100$ & 2.75 & 14.7 & $>7.5$ & $>7.5$ & $>5.0$ & $>5.0$ \\
\hline M14 & nd & $>100$ & 3.04 & 12.1 & $>7.5$ & $>7.5$ & $>5.0$ & $>5.0$ \\
\hline
\end{tabular}




\begin{tabular}{|c|c|c|c|c|c|c|c|c|}
\hline $\begin{array}{c}\text { MDA-MB- } \\
435\end{array}$ & $>100$ & $>100$ & 3.33 & 15.1 & $>7.5$ & $>7.5$ & $>5.0$ & $>5.0$ \\
\hline SK-MEL-2 & $>100$ & $>100$ & 2.80 & 11.8 & $>7.5$ & $>7.5$ & $>5.0$ & $>5.0$ \\
\hline SK-MEL-28 & $>100$ & $>100$ & 3.35 & 14.2 & 1.79 & $>7.5$ & $>5.0$ & $>5.0$ \\
\hline SK-MEL-5 & 1.14 & $>100$ & 3.05 & 11.1 & 2.89 & $>7.5$ & $>5.0$ & $>5.0$ \\
\hline UACC-257 & 2.23 & $>100$ & 2.89 & 12.2 & 6.75 & $>7.5$ & $>5.0$ & $>5.0$ \\
\hline UACC-62 & 2.66 & $>100$ & 2.86 & 14.3 & nd & nd & $>5.0$ & $>5.0$ \\
\hline \multicolumn{9}{|c|}{ Ovarian cancer } \\
\hline IGROV1 & $>100$ & $>100$ & 3.57 & 14.7 & 5.06 & $>7.5$ & $>5.0$ & $>5.0$ \\
\hline OVCAR-3 & 2.34 & $>100$ & 2.90 & 12.7 & 4.03 & $>7.5$ & $>5.0$ & $>5.0$ \\
\hline OVCAR-4 & 0.483 & $>100$ & 2.72 & 19.4 & $>7.5$ & $>7.5$ & $>5.0$ & $>5.0$ \\
\hline OVCAR-5 & $>100$ & $>100$ & 3.57 & $>20$ & $>7.5$ & $>7.5$ & $>5.0$ & $>5.0$ \\
\hline OVCAR-8 & $>100$ & $>100$ & 4.20 & $>20$ & $>7.5$ & $>7.5$ & $>5.0$ & $>5.0$ \\
\hline $\begin{array}{l}\text { NCI/ADR- } \\
\text { RES }\end{array}$ & 7.03 & $>100$ & 3.40 & $>20$ & 5.23 & $>7.5$ & $>5.0$ & $>5.0$ \\
\hline SK-OV-3 & $>100$ & $>100$ & 4.15 & $>20$ & $>7.5$ & $>7.5$ & $>5.0$ & $>5.0$ \\
\hline \multicolumn{9}{|c|}{ Renal cancer } \\
\hline $786-0$ & $>100$ & $>100$ & 3.24 & 14.5 & 5.12 & $>7.5$ & $>5.0$ & $>5.0$ \\
\hline A498 & 1.77 & $>100$ & 2.45 & 10.9 & $>7.5$ & $>7.5$ & $>5.0$ & $>5.0$ \\
\hline $\mathrm{ACHN}$ & 2.10 & $>100$ & 6.01 & $>20$ & 5.88 & $>7.5$ & $>5.0$ & $>5.0$ \\
\hline CAKI-1 & 2.83 & $>100$ & 3.65 & 14.7 & 0.949 & $>7.5$ & $>5.0$ & $>5.0$ \\
\hline RXF 393 & 28.0 & $>100$ & 2.60 & 10.5 & $>7.5$ & $>7.5$ & $>5.0$ & $>5.0$ \\
\hline SN12C & 9.42 & $>100$ & 3.26 & 18.1 & $>7.5$ & $>7.5$ & $>5.0$ & $>5.0$ \\
\hline TK-10 & 8.26 & $>100$ & 3.77 & 18.6 & 3.90 & $>7.5$ & $>5.0$ & $>5.0$ \\
\hline UO-31 & $>100$ & $>100$ & 2.73 & 13.1 & $>7.5$ & $>7.5$ & $>5.0$ & $>5.0$ \\
\hline \multicolumn{9}{|c|}{ Prostate cancer } \\
\hline PC-3 & 0.580 & $>100$ & 3.48 & $>20$ & 3.06 & $>7.5$ & $>5.0$ & $>5.0$ \\
\hline DU-145 & $>100$ & $>100$ & 3.21 & 17.8 & $>7.5$ & $>7.5$ & $>5.0$ & $>5.0$ \\
\hline \multicolumn{9}{|c|}{ Breast cancer } \\
\hline MCF7 & $>100$ & $>100$ & 4.77 & $>20$ & 4.27 & $>7.5$ & $>5.0$ & $>5.0$ \\
\hline $\begin{array}{l}\text { MDA-MB- } \\
\text { 231/ATCC }\end{array}$ & $>100$ & $>100$ & 2.82 & 14.5 & $>7.5$ & $>7.5$ & $>5.0$ & $>5.0$ \\
\hline HS 578T & $>100$ & $>100$ & 3.27 & $>20$ & $>7.5$ & $>7.5$ & $>5.0$ & $>5.0$ \\
\hline BT-549 & $>100$ & $>100$ & 2.65 & 11.6 & 4.09 & $>7.5$ & $>5.0$ & $>5.0$ \\
\hline $\mathrm{T}-47 \mathrm{D}$ & $>100$ & $>100$ & 3.95 & $>20$ & 6.81 & $>7.5$ & $>5.0$ & $>5.0$ \\
\hline $\begin{array}{c}\text { MDA-MB- } \\
468\end{array}$ & 0.267 & $>100$ & 2.98 & 17.3 & 0.74 & $>7.5$ & $>5.0$ & $>5.0$ \\
\hline
\end{tabular}

nd: not determined.

${ }^{\mathrm{a}} \mathrm{GI}_{50}: 50 \%$ growth inhibition, the concentration of drug resulting in a 50\% reduction in net protein increase compared with control cells.

${ }^{\mathrm{b}} \mathrm{LC}_{50}$ : lethal concentration, the concentration of drug lethal to $50 \%$ of cells. 
Figure s1. Dose-response curves of $\mathbf{1 8}$ for individual sub-panel for all 60 cell lines

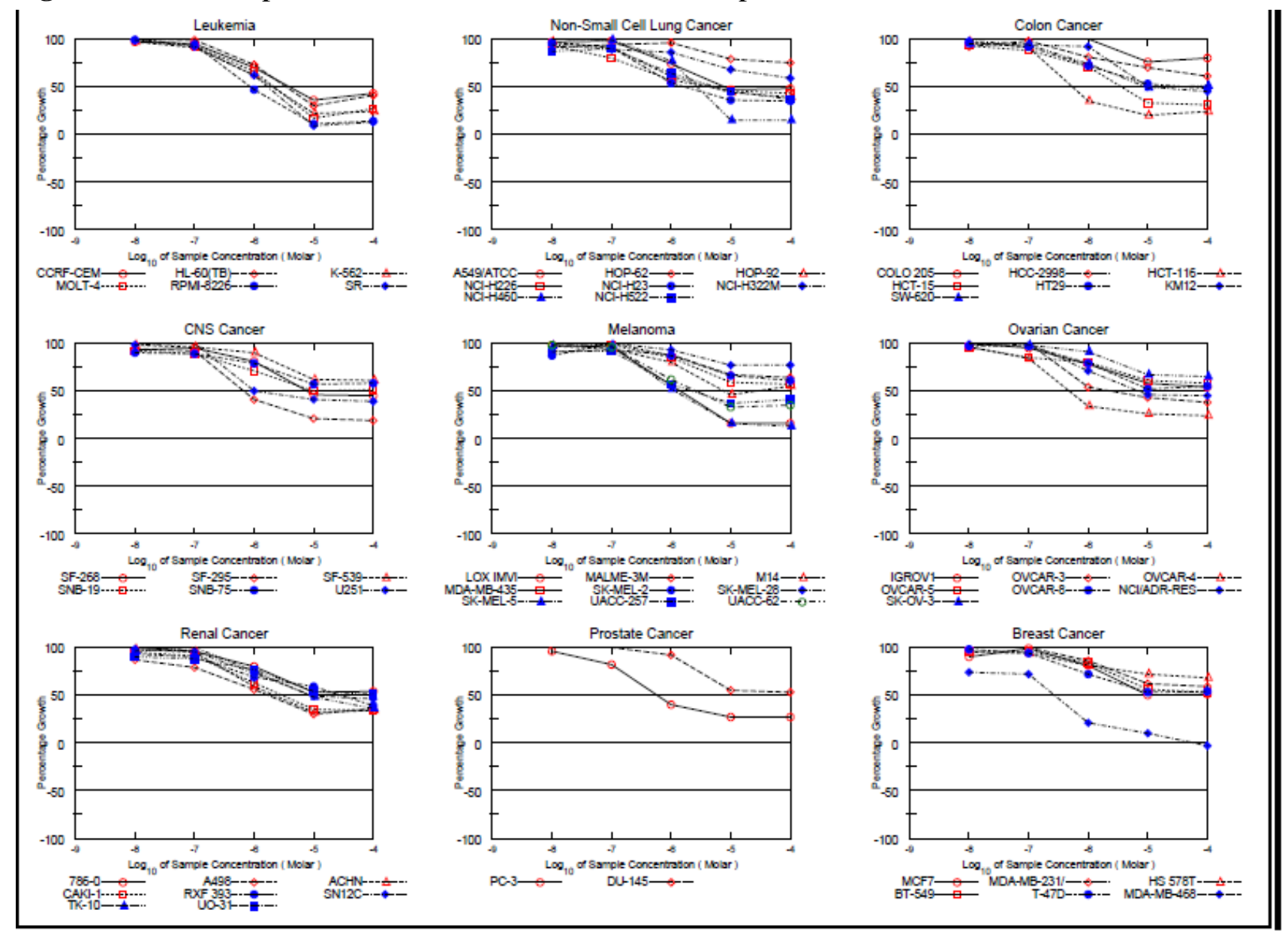

\section{Cell culture}

The A549 cell lines used in present study were obtained from ATCC (Manassas, USA) and cultivated in DMEM (Sigma) supplemented with 10\% fetal bovine serum, 100 units/mL penicillin and streptomycin. To avoid contamination of cells with mycoplasma, cells were regularly tested with the MycoAlert Kit (Cambrex Bio Science, Rockland, ME, USA).

\section{Cytotoxicity evaluation against A549 cells}

Cell viability was determined by MTT-micro cultured tetrazolium assay using the reported protocol with minor modifications (ref). Briefly, A549 cells were seeded to flat bottom 96 well plate $(5,000$ cells $/ 100 \mu \mathrm{L})$ and cultured for $18-24 \mathrm{~h}$ in the culture medium containing with constant supply of $5 \% \mathrm{CO}_{2}$ in humid incubator. Different concentration of test compound and doxorubicin (as standard control anticancer drug) prepared in DMSO was added to achieve final concentration of 0 to $100 \mu \mathrm{M}$ 
of compound to cells and cells were further continued to grow for $48 \mathrm{~h}$ with constant supply of $5 \%$ $\mathrm{CO}_{2}$ in humid incubator. The time course (0 to $72 \mathrm{~h}$ ) experiment was carried out simultaneously. Filter sterilized MTT dissolved in PBS at $5 \mathrm{mg} / \mathrm{mL}$ was added for assay at indicated time intervals. Cells were further incubated in the $\mathrm{CO}_{2}$ chamber for $2 \mathrm{~h}$. On termination of assay, the medium was removed and $100 \mu \mathrm{L}$ of DMSO was added to cells. The purple color obtained was measured at $562 \mathrm{~nm}$ in a multimode microplate reader (Tecan GENios), its absorbance is directly proportional to cell growth. From the observed percentage age of growth with and without test compound, IC $_{50}$ values were calculated. The results presented are from three independent experiments each in triplicates.

\section{Colony formation assay}

For observing long term effects of compound $\mathbf{1 8}$ on anchorage-independent growth of A549 cells soft agar assays were performed as reported previously ${ }^{7}$. To perform soft agar assay, bottom agar was prepared by mixing $1 \%$ of agarose (Bacto Agar: Becton, Dickinson, Sparks, MD) with $2 \times$ culture medium poured in 6-well plates at $37{ }^{\circ} \mathrm{C}$ to achieve final concentration of $0.5 \%$ of agar in $1 \times$ growth medium. Once bottom agar was solidified, $2.5 \times 10^{4}$ cells were mixed with cultivation medium containing different concentrations of compound and equal volume of agar solution achieving final concentration of $0.35 \%$ agar. The mixture was spread on the surface of base agar plates immediately and incubated under cultivation conditions. To avoid depletion of nutrients, culture medium was replenished every 3 days with fresh medium along with compound. After 14 days of incubation, the colonies observed in plates were stained with $0.005 \%$ crystal violet solution. After removing excess staining solution, colonies were observed and counted under a light microscope. Each experiment was performed in triplicates and repeated 3 times. The results analyzed are from three independent experiments each in triplicates.

\section{Wound healing/cell migration assay}

Cell migration assays were performed, as reported previously, with minor modifications. Briefly, after harvesting sub confluent A549 cells by trypsinization pellet was resuspended in culture medium by gentle pipetting to obtain single cells. For assays, $5 \times 10^{4}$ cells/well seeded into 24 well plates and allowed to grow for 18-24 h under standard culture conditions to create a confluent monolayer of cells. To determine the effect of compound on migration of cells, scraping the cells monolayer with p200 pipette tip creates "scratches". After smoothening the edge of the scratch by 
removing debris by washing with $0.5 \mathrm{ml}$ of growth medium and then the medium was replaced with $250 \mu \mathrm{L}$ of medium containing defined concentration of compound or DMSO as vehicle control. Further cells were incubated to grow for $24 \mathrm{~h}$ allowing migration of cells closing the scratches created in the dishes. The images acquired for each sample under a phase-contrast microscope were analyzed to observe influence of compound on migration of cells compared to DMSO treated control.

\section{Senescence associated $\beta$-gal staining:}

Detection for SA-ß3-galactosidase was performed as described previously [ref]. Briefly, A549 cells treated with different concentration of compound or DMSO were harvested at sub confluent density and fixed in phosphate buffered saline containing $2 \%$ PFA, $0.25 \%$ glutaraldehyde along with $1 \mathrm{mM} \mathrm{MgCl} 2$ (pH 6.0). Then the fixed cells were incubated in a staining solution containing potassium cyanide/X-gal in $\mathrm{PBS} / \mathrm{MgCl}_{2}\left(\mathrm{pH}\right.$ 6.0) at $37{ }^{\circ} \mathrm{C}$ overnight. Slides were analyzed using a Xi72 microscope (10 Å magnifications) (Olympus, Japan). The positive cells for $\beta$-gal staining upon exposure to compound are marked on images.

\section{PI uptake for cell death}

Cell death was analyzed with PI uptake as reported previously with minor modification. ${ }^{6}$ Cells were harvested, washed with PBS and fixed in $70 \%$ ethanol at $-20{ }^{\circ} \mathrm{C}$ for overnight. After centrifugation, cells were resuspended in PI solution containing RNase $(0.1 \mathrm{mg} / \mathrm{mL})$, Triton X-100 $(0.05 \%)$, PI $(50 \mu \mathrm{g} / \mathrm{mL})$ and incubated for $1 \mathrm{~h}$ in dark at room temperature. After washing with PBS buffer, PI uptake in cells was analyzed by fluorescence activated cell sorting (FACS Calibur System; BD Bio- science, Erembodegem, Belgium) on an FL-2 fluorescence detector (10000 events were recorded for each condition). Flow cytometry data were analyzed using FCS express 4 software (De Novo Software, Los Angeles, CA). 
$N$, $N$ '-Bis-benzyl- $N$ - $N$ '-bis-[(1S)-1-(2-phenylethyl)-2-methoxycarbonyl]-sulfamide (5)
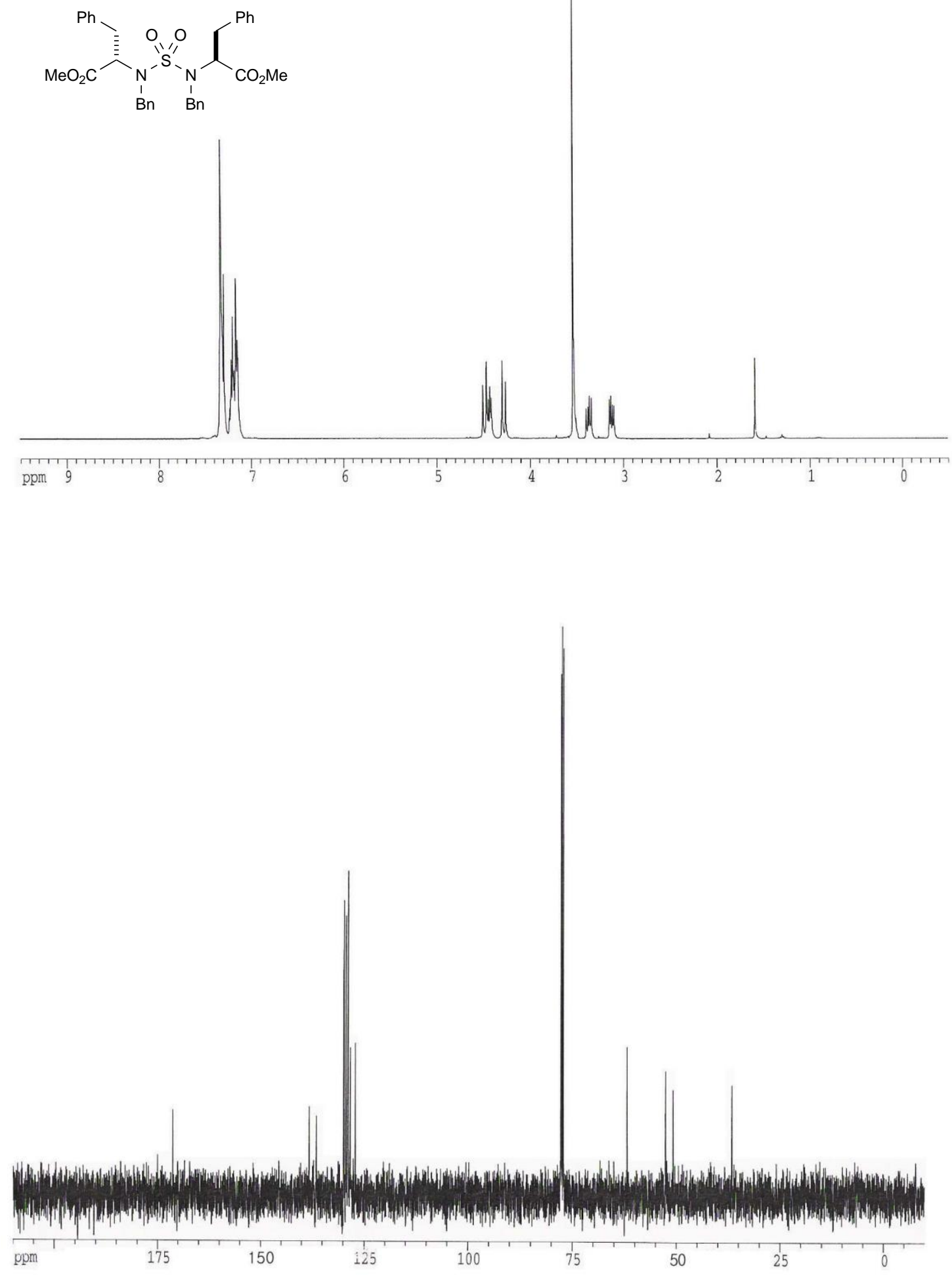
$N$, $N$ '-Bis-benzyl- $N$ - $N$ '-bis-[(1S)-2-hydroxy-1-(2-phenylethyl)ethyl]-sulfamide (9)
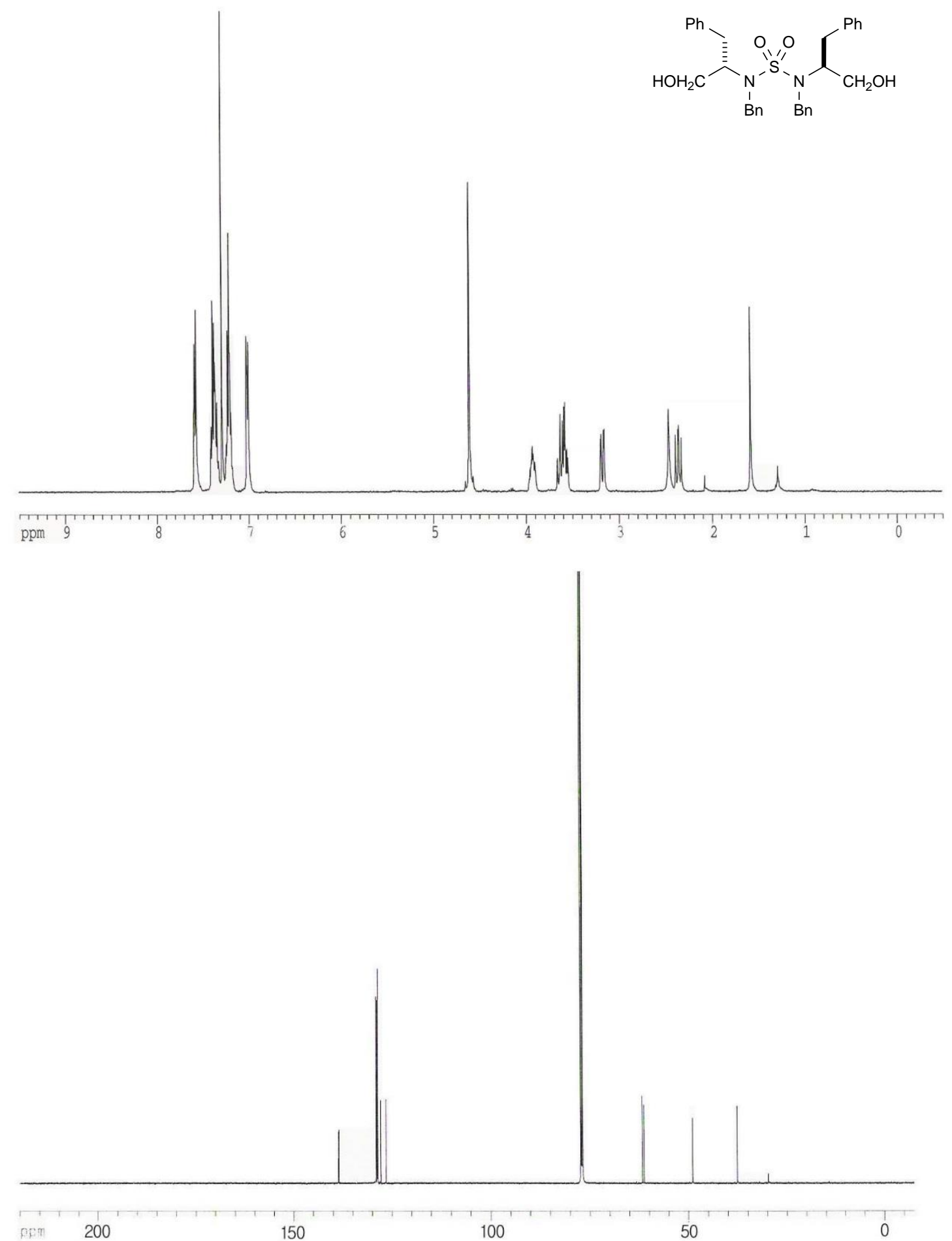
L-Phenylalanine-derived $\mathrm{C}_{2}$-symmetric sulfamide aldehyde (12)
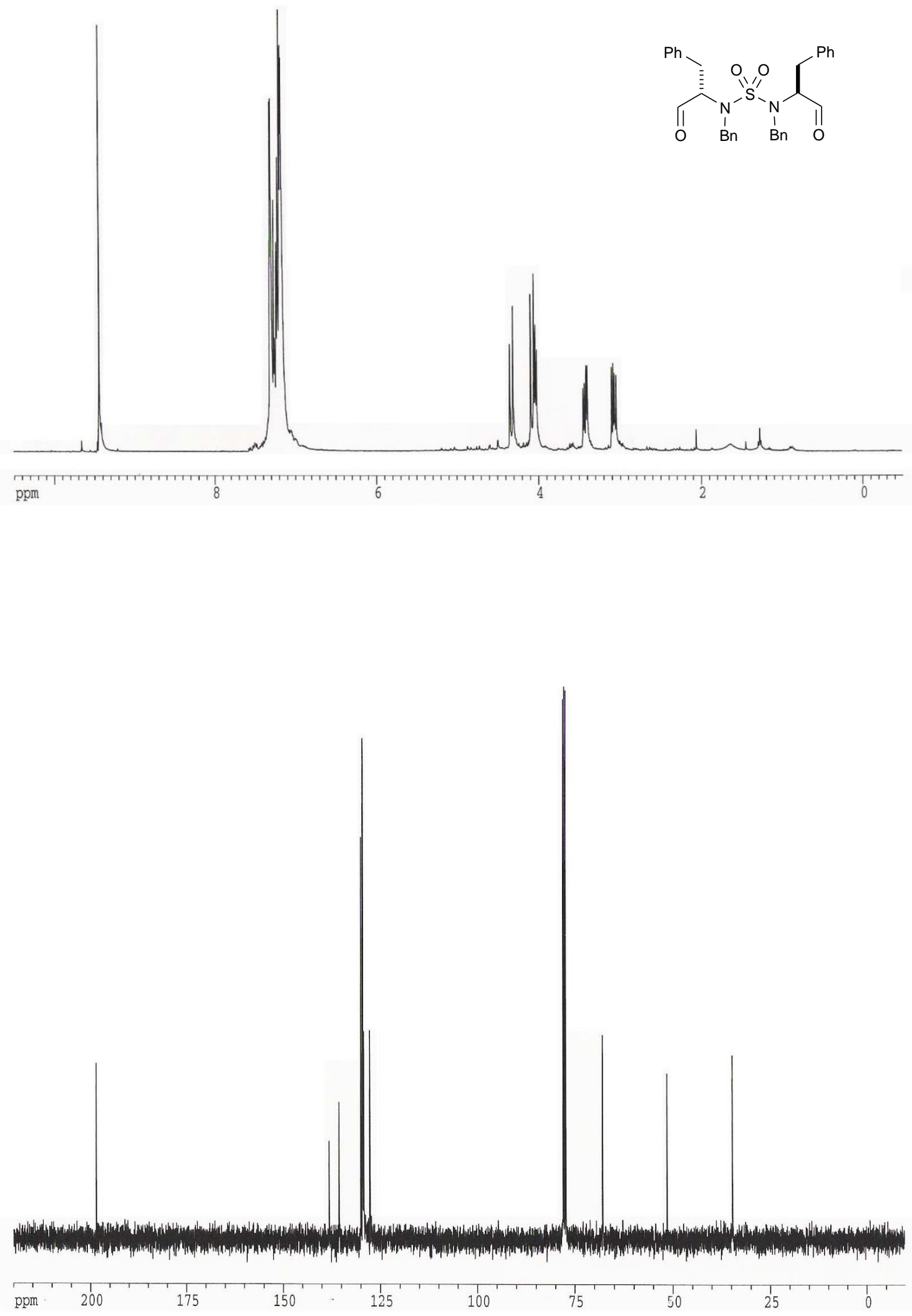
$N$, $N$ '-Bis-benzyl- $N$ - $N$ '-bis-[(1S)-1-(2-phenylethyl)-2-propenyl]-sulfamide (15)
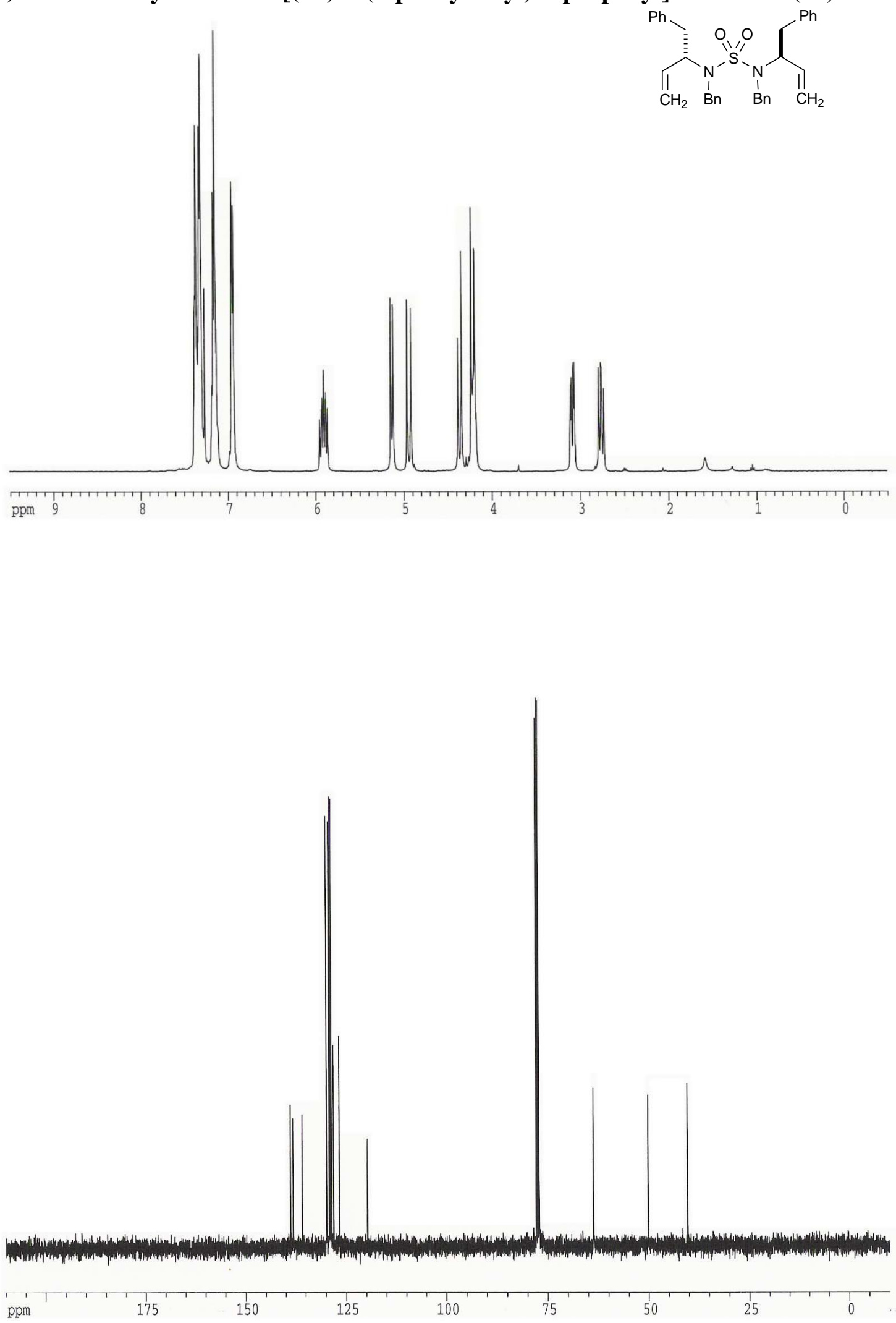

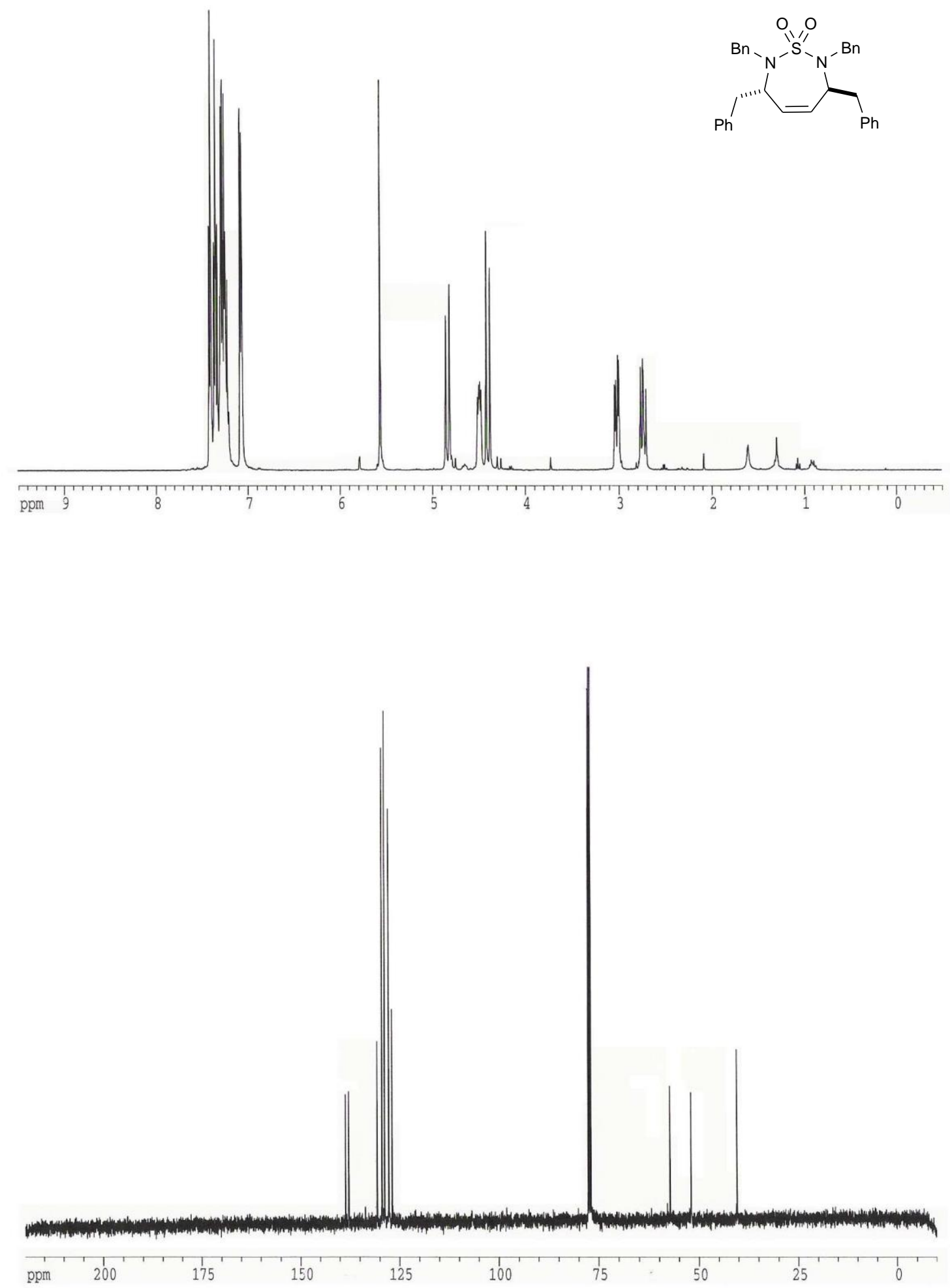
$(3 S, 4 R, 5 S, 6 S)$-2,3,67-Tetrabenzyl-2,3,6,7-tetra-hydro-4,5-dihydroxy-1,2,7-thiadiazepine-1,1dioxide (21)
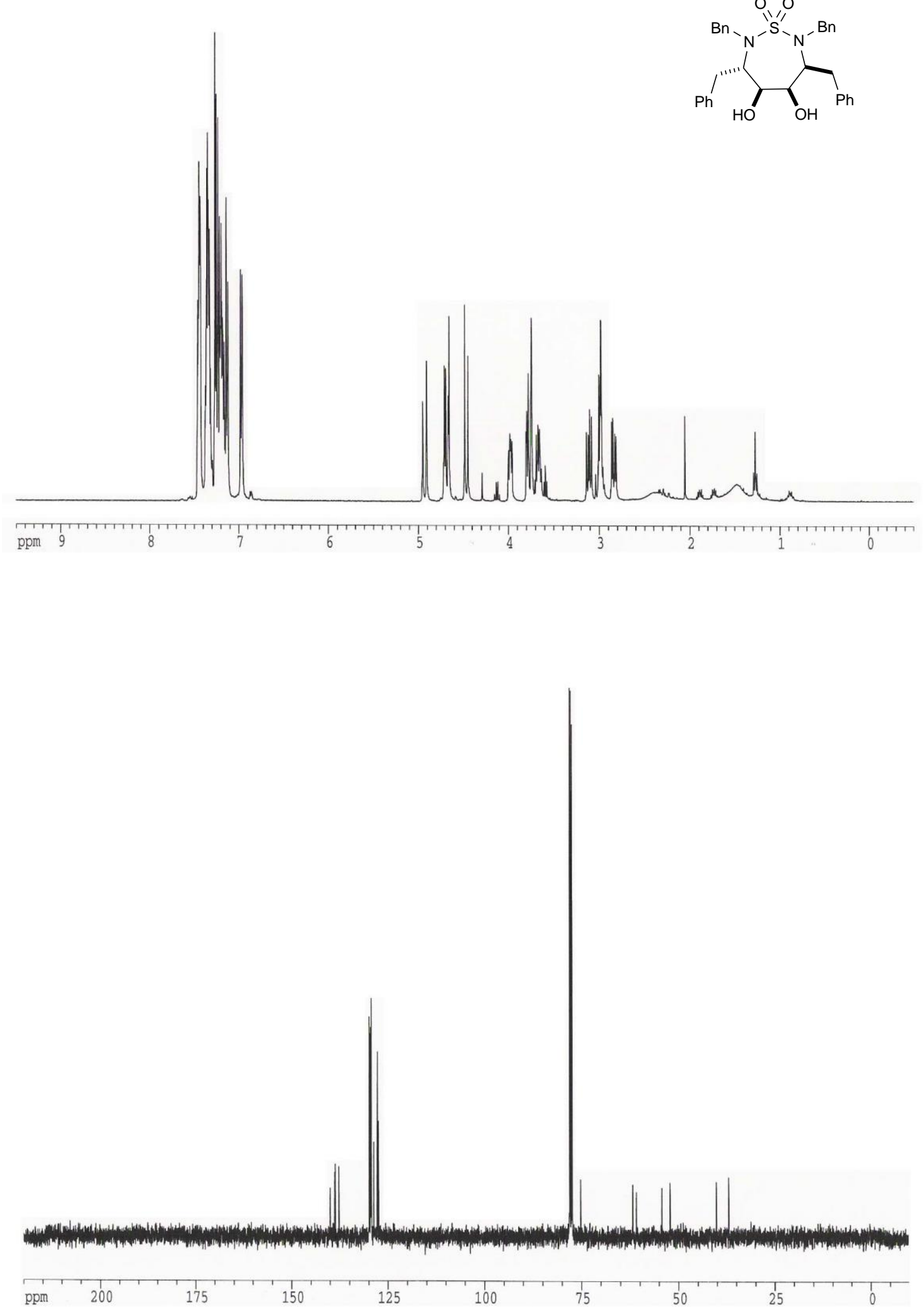

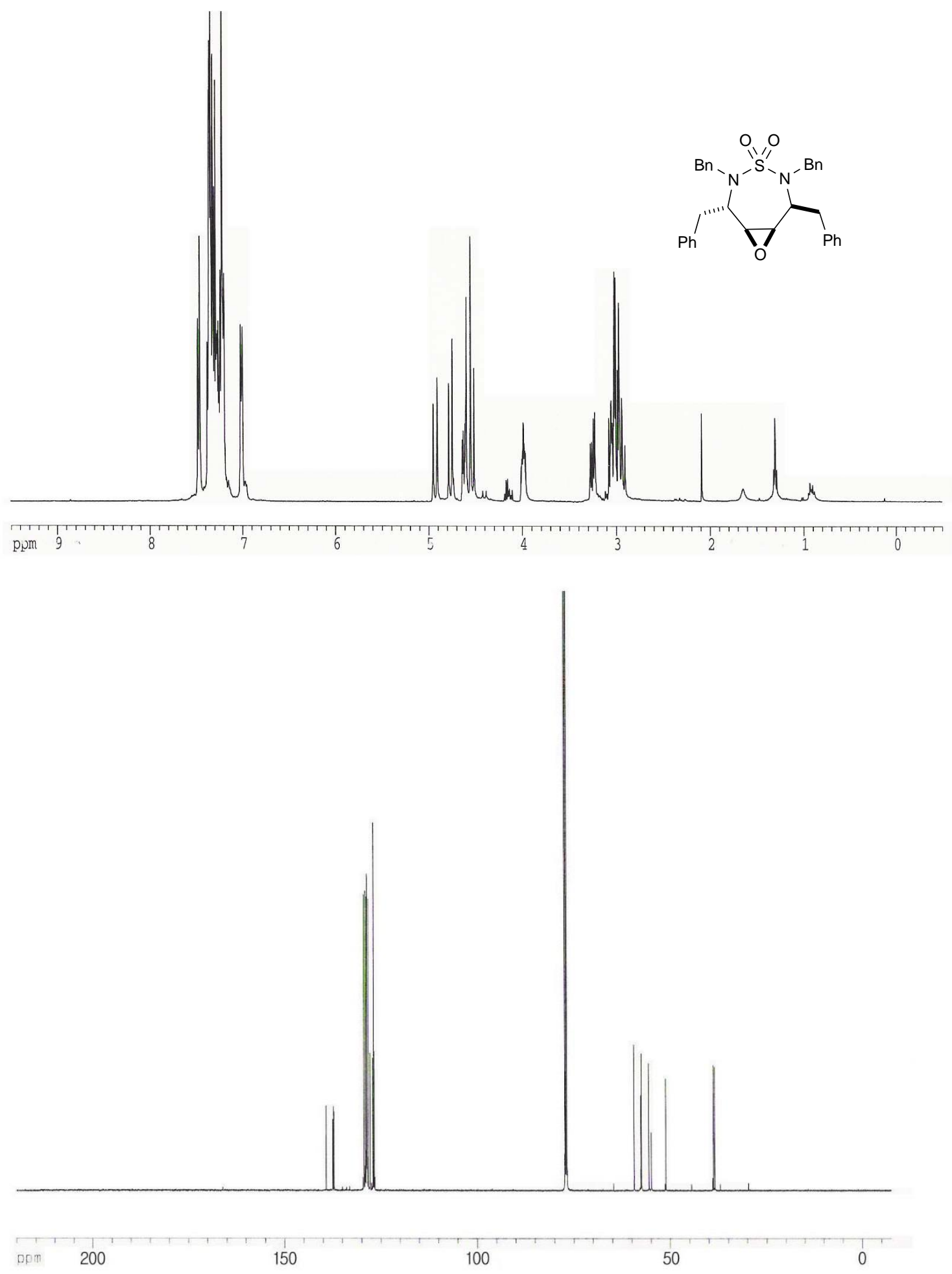
$N, N^{\prime}$-Bis-benzyl- $N$ - $N$ '-bis-[(1S)-1-(2-methylpropyl)-2-methoxycarbonyl]-sulfamide (6)
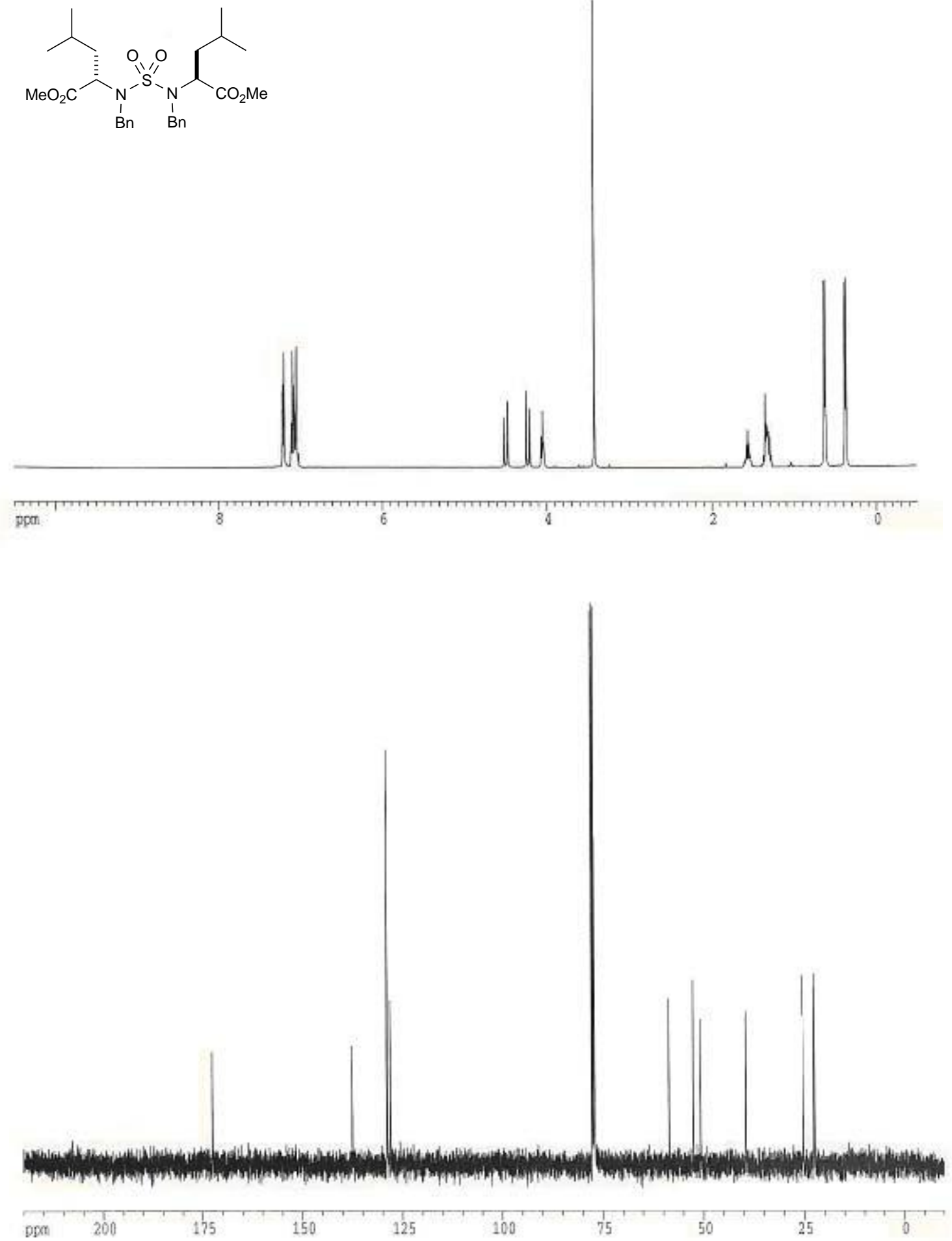
$N$, $N$ '-Bis-benzyl- $N$ - $N$ '-bis-[(1S)-2-hydroxy-1-(2-methylpropyl)ethyl]-sulfamide (10)
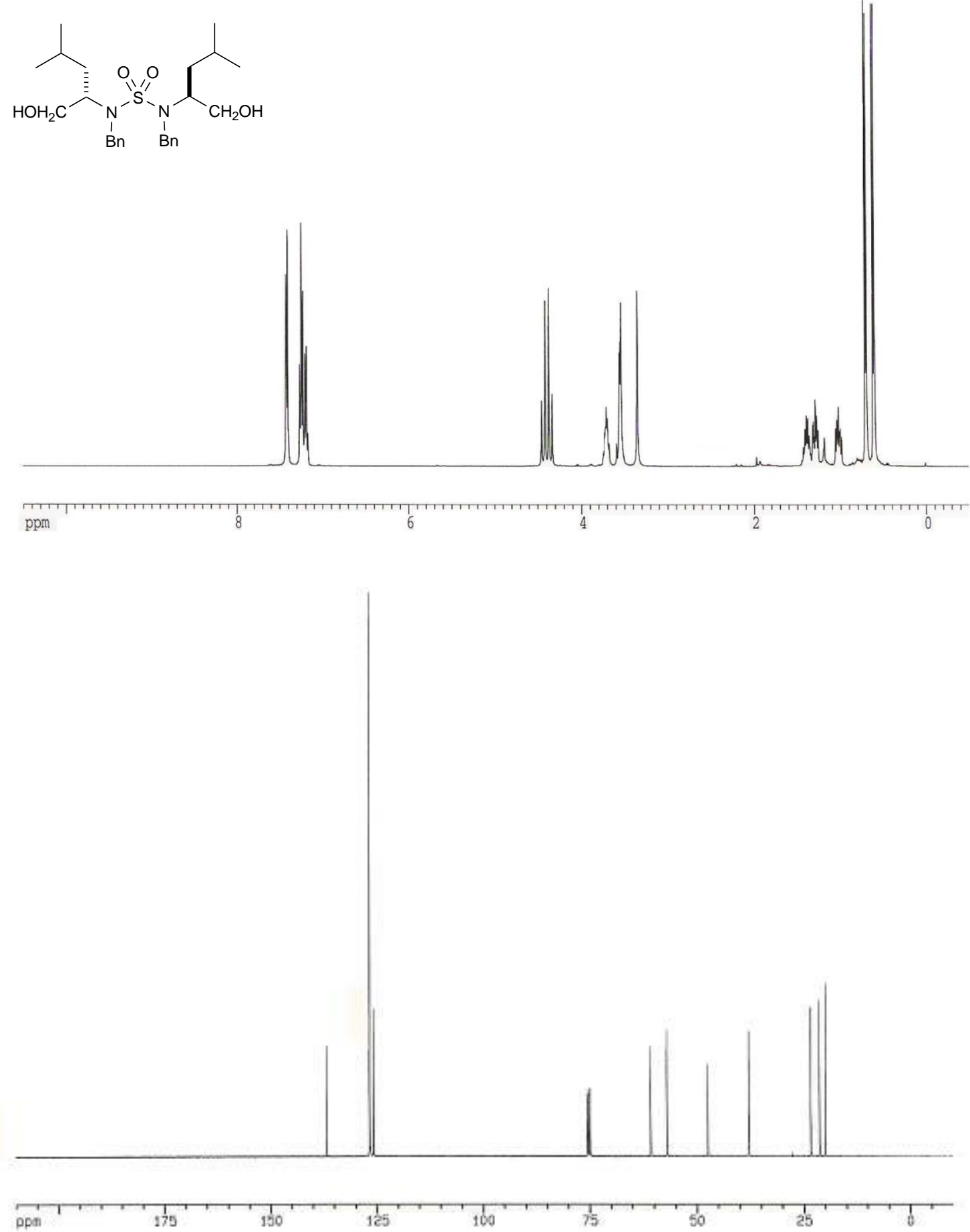
$N$, $N$ '-Bis-benzyl- $N$ - $N$ '-bis-[(1S)-1-(2-methylpropyl)-2-propenyl]-sulfamide (16)<smiles>C=CC(CC(C)C)N(Br)S(=O)(=O)N(CC(C)C)C(C=C)CC(C)C</smiles>
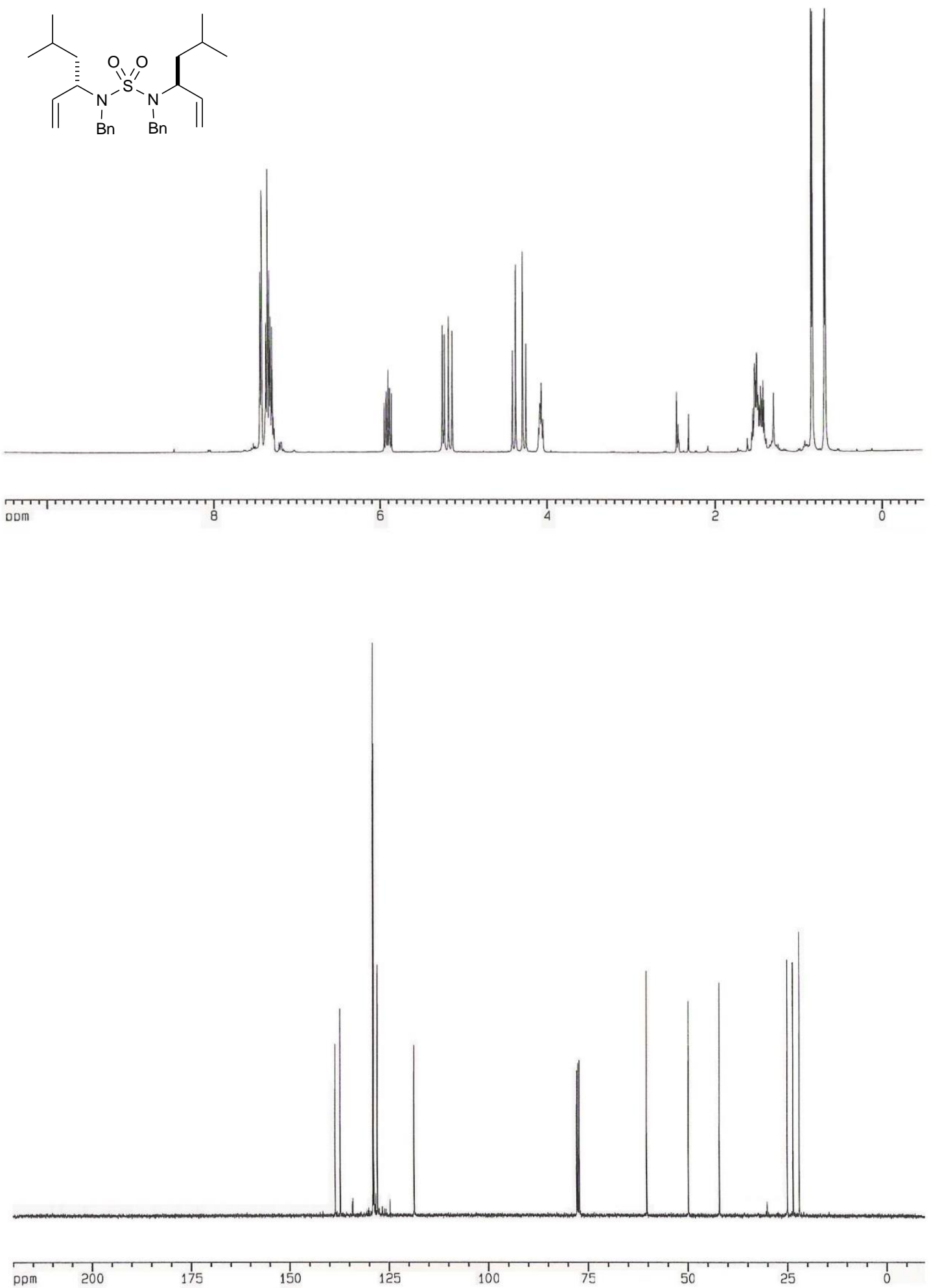

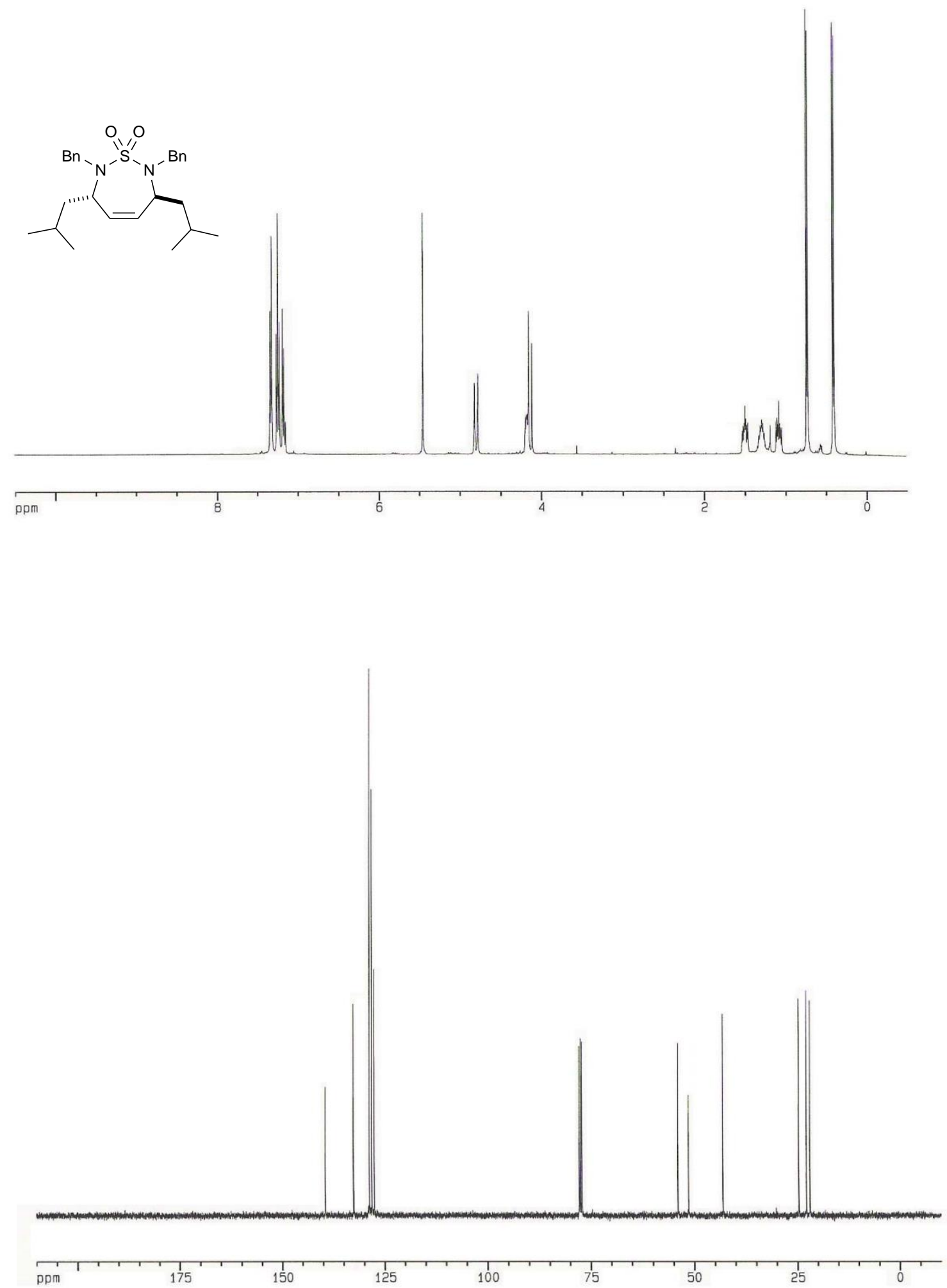
(3S,4R,5S,6S)-2,7-Dibenzyl-3,6-diisobutyl-2,3,6,7-tetra-hydro-4,5-dihydroxy-1,2,7thiadiazepine-1,1-dioxide (22)
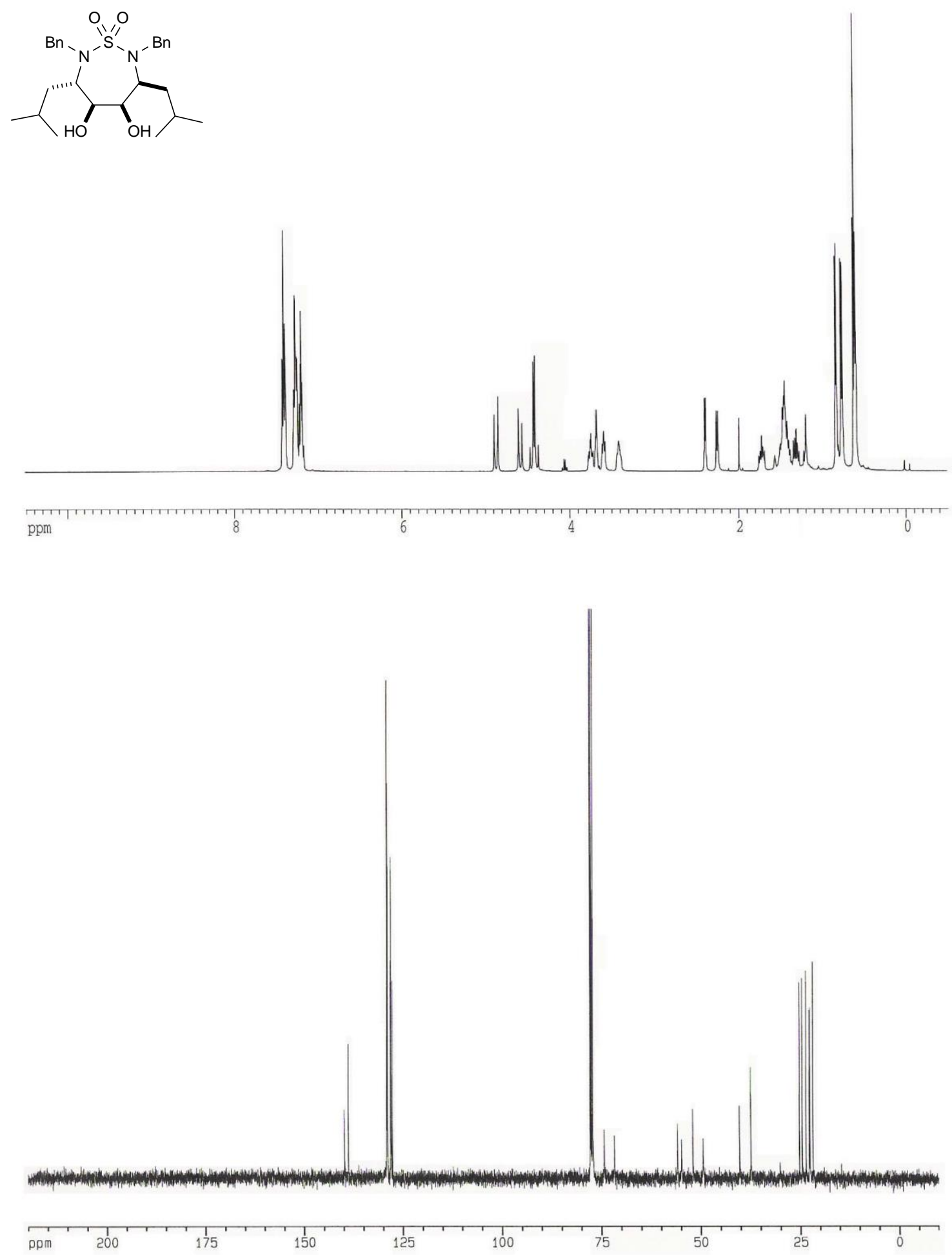

dioxide (24)
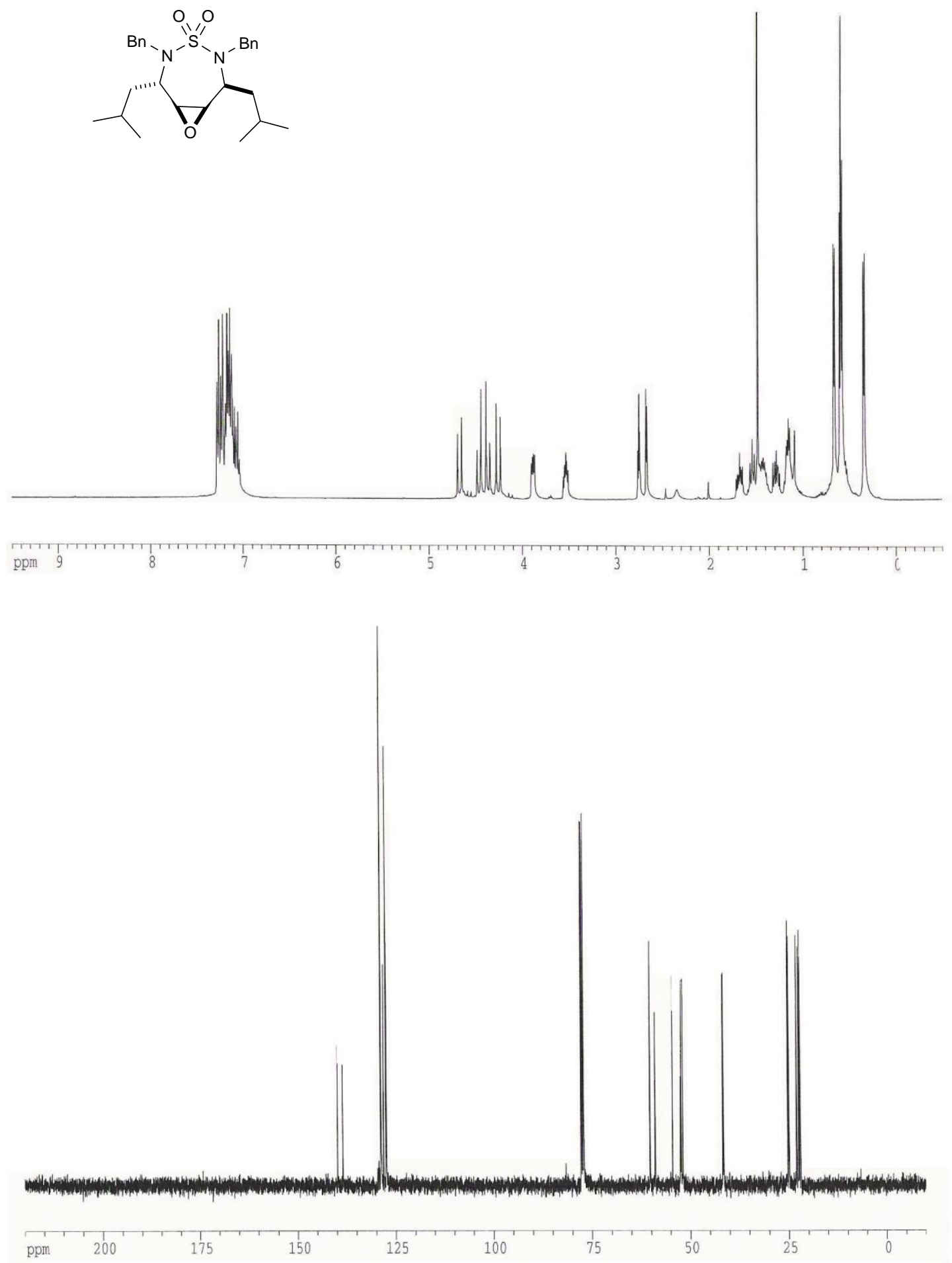
(3R,4R,5S,6R)-2,7-Dibenzyl-3,6-diphenylethyl-2,3,6,7-tetra-hydro-4,5-dihydroxy-1,2,7thiadiazepine-1,1-dioxide (25)
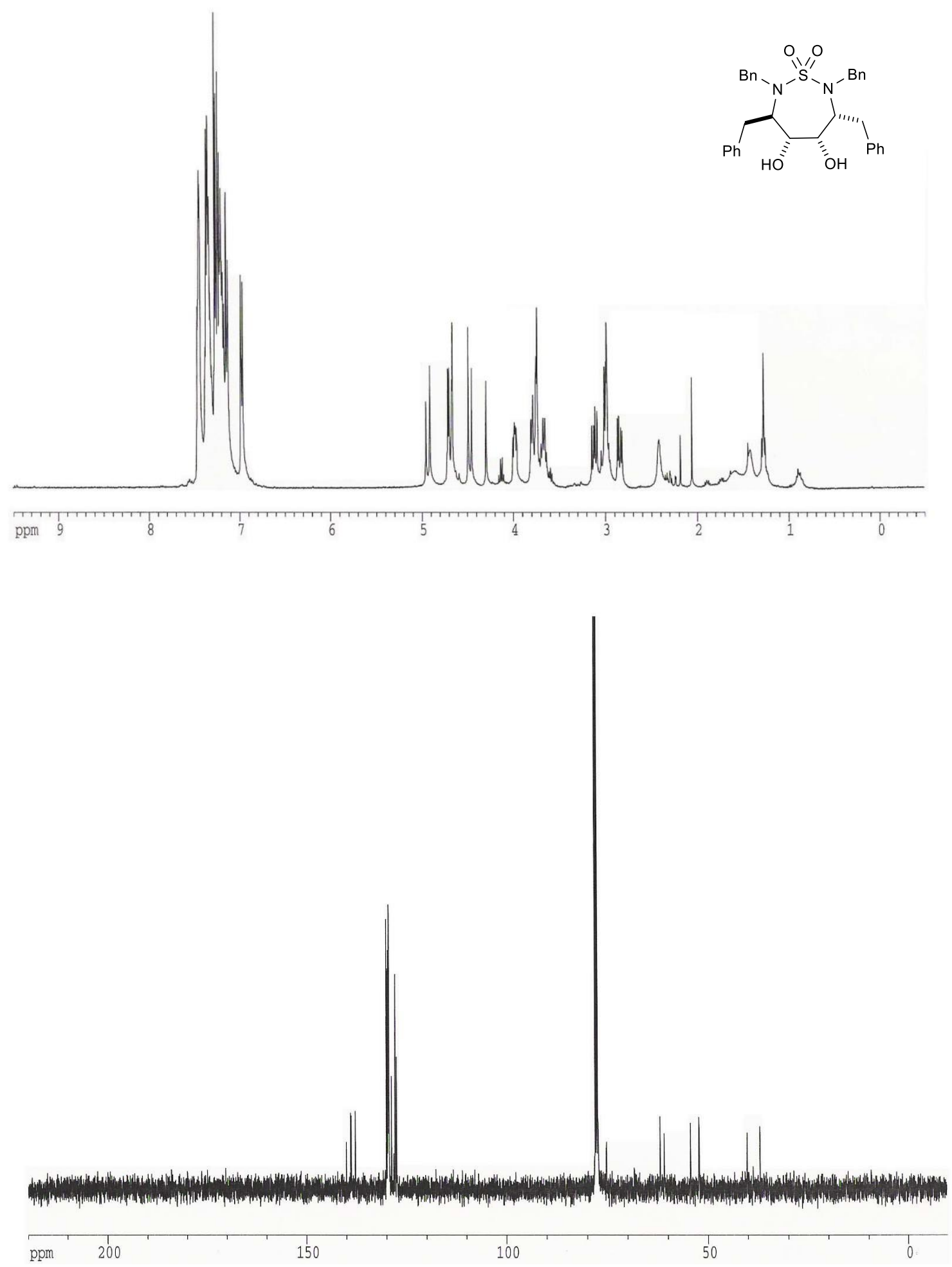
(S)-Methyl-2-( $N$-(tert-butoxycarbonyl)sulfamoylamino)-4-methylpentanoate (26)
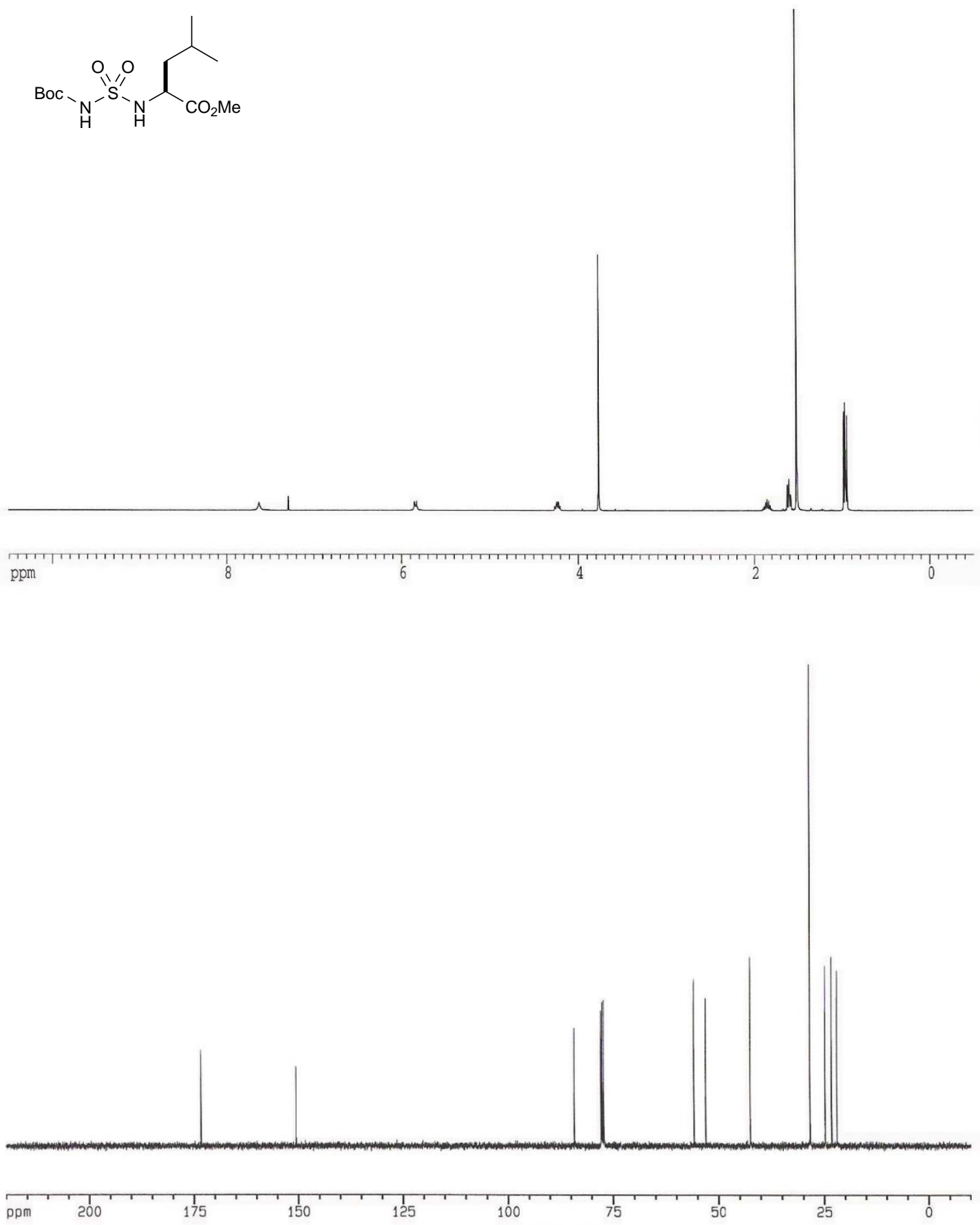
$N$-[(1,1-Dimethylethoxy)carbonyl]-[N-(1R)-1-(2-methylpropyl)-2-methoxycarbonyl- $N$ '-[(1S)-1(2-methylpropyl)-2-methoxycarbonyl]-sulfamide (27)
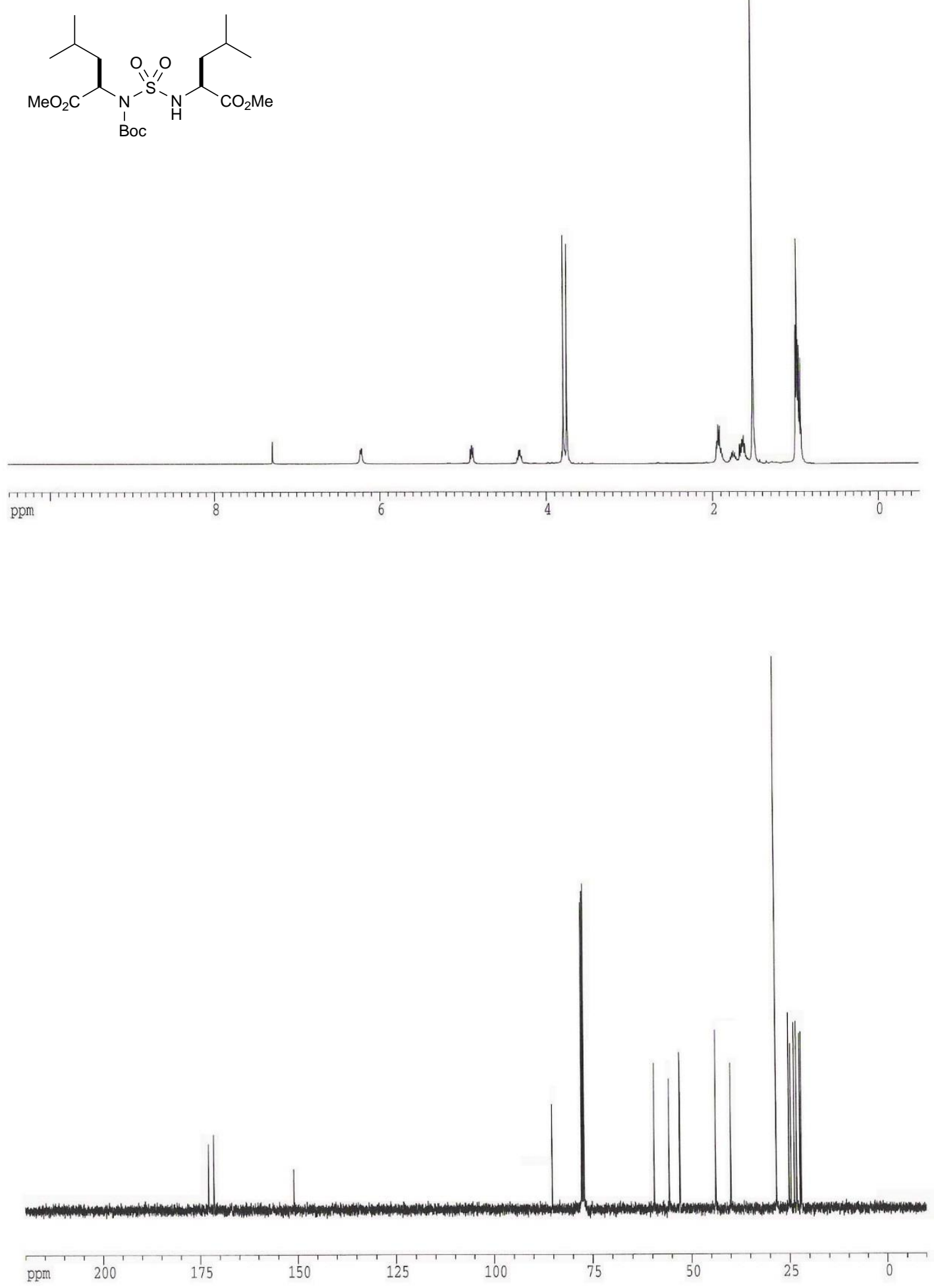
$N$-[(1,1-Dimethylethoxy)carbonyl]- $N$-[(1R)-1-(2-methylpropyl)-2-methoxycarbonyl]- $N$ '-benzyl$N^{\prime}$-[(1S)-1-(2-methylpropyl)-2-ethoxycarbonyl]-sulfamide (28)
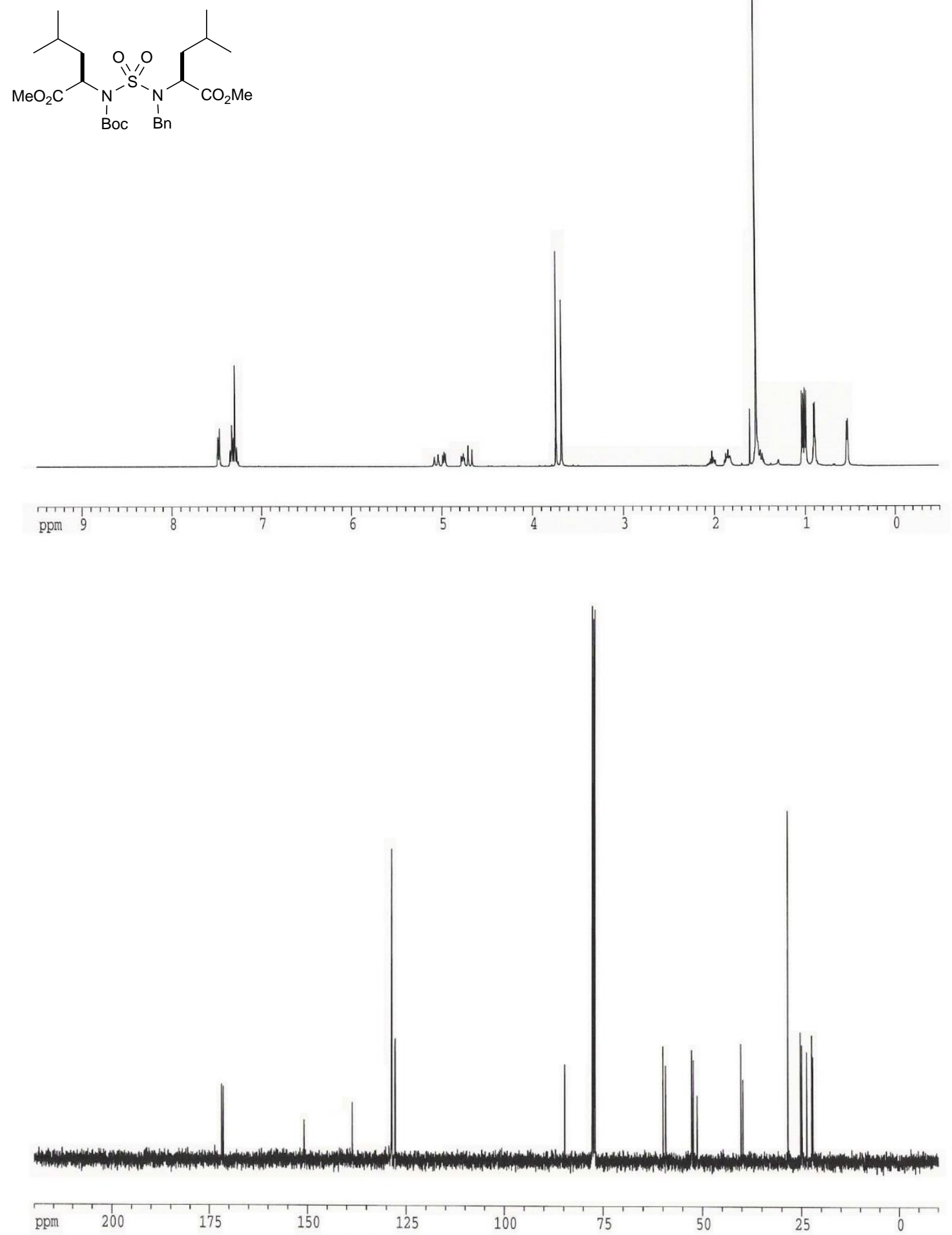
$N$-[(1R)-1-(2-Methylpropyl)-2-methoxycarbonyl]- $N$ '-benzyl- $N$ '-[(1S)-1-(2-methylpropyl)-2methoxycarbonyl]-sulfamide (29)<smiles>CC(=O)C(CC(C)C)NS(=O)(=O)N(Cc1ccccc1)C(C)CC(C)C</smiles>
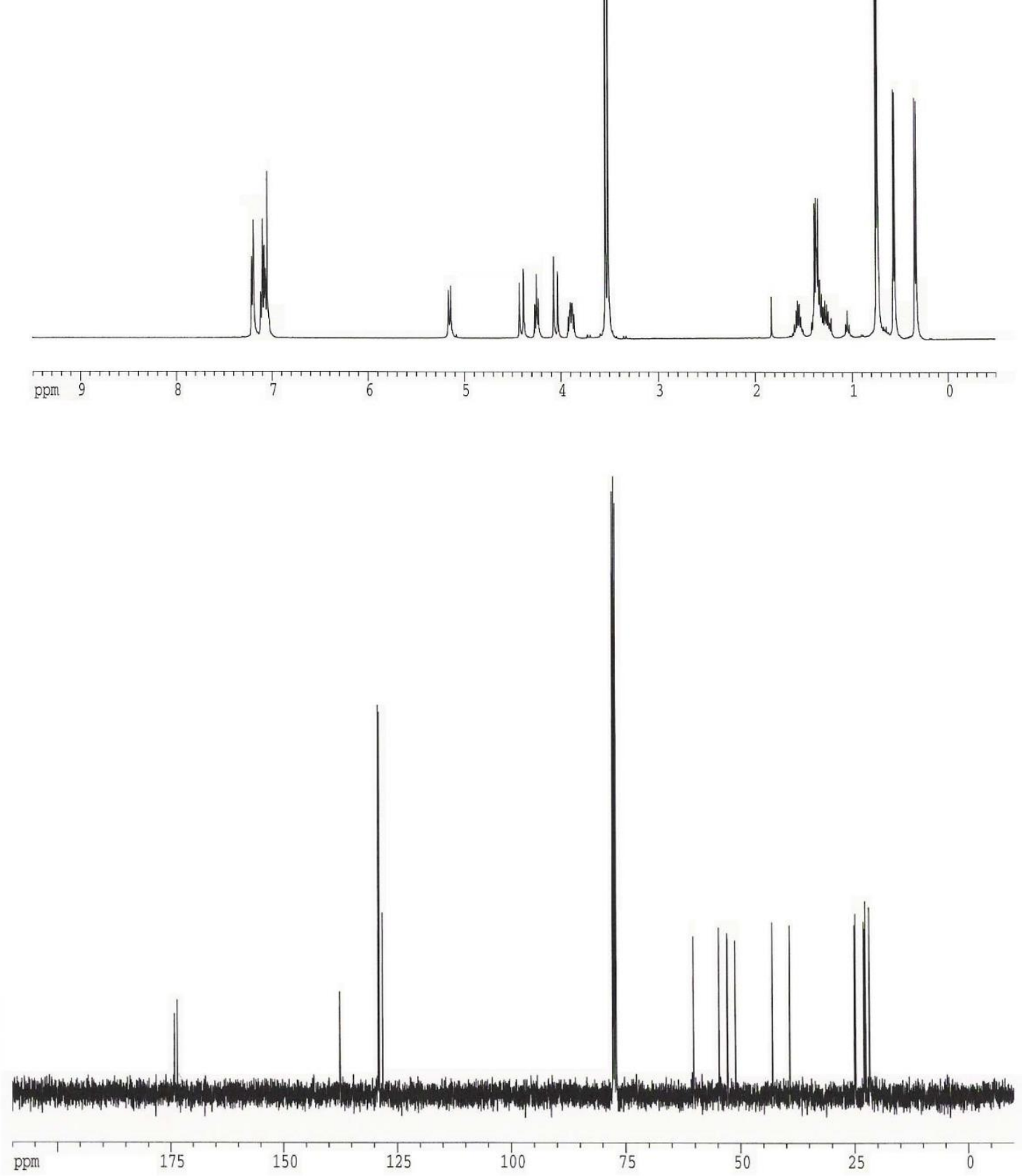
$N$, $N$ '-Bis-benzyl- $N$ - $N$ '- (1S),(1R)- bis- [1-(2-methylpropyl)-2-methoxycarbonyl]-sulfamide (30)<smiles>CC(=O)C(CC(C)C)N(Cc1ccccc1)S(=O)(=O)N(Cc1ccccc1)C(C)=O</smiles>
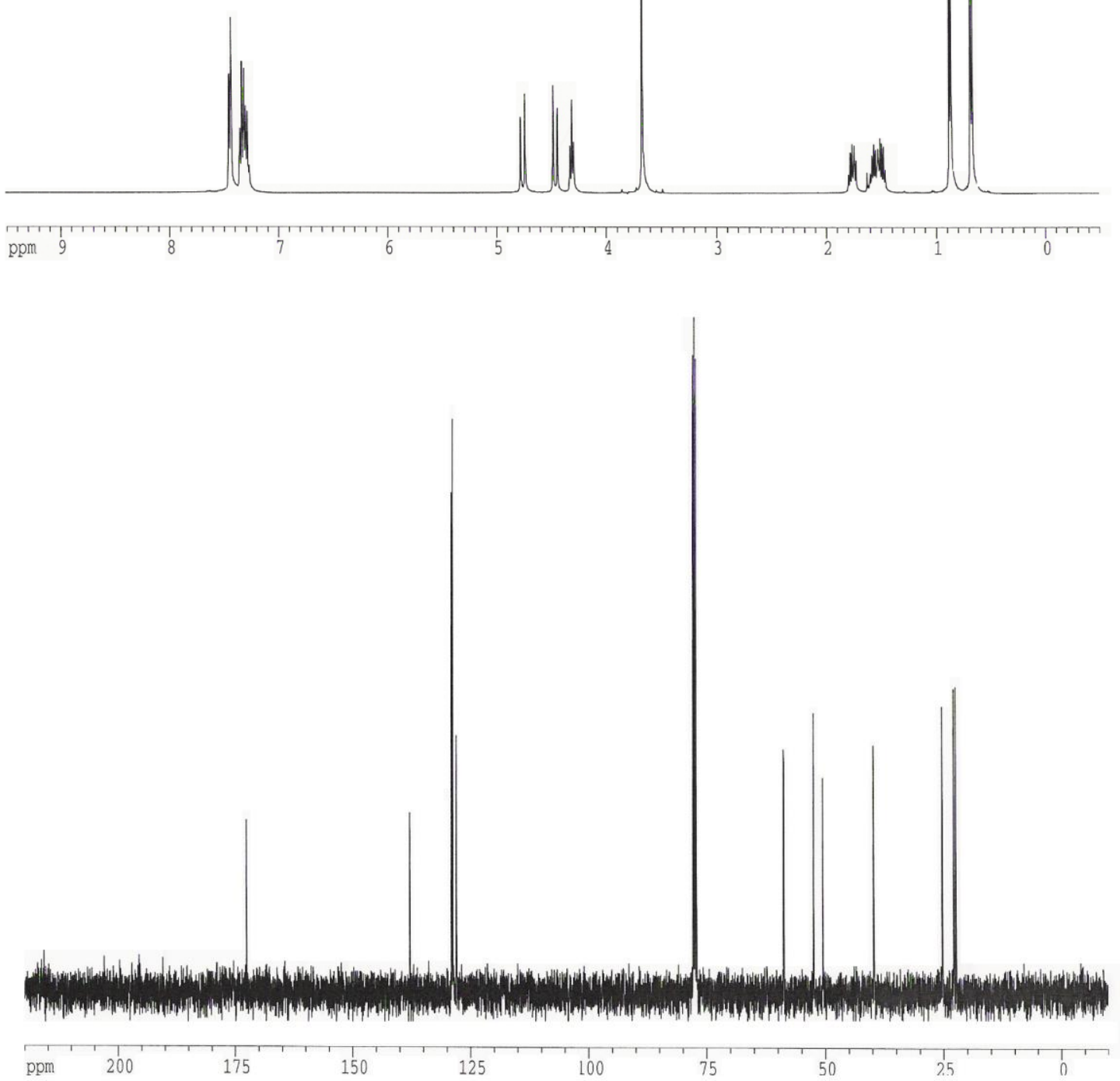
$N, N$ '-Bis-benzyl- $N$-[(1S)-2-hydroxy-1-(2-methylpropyl)ethyl]- $N$ '-[(1R)-2-hydroxy-1-(2methylpropyl)ethyl]-sulfamide (31)
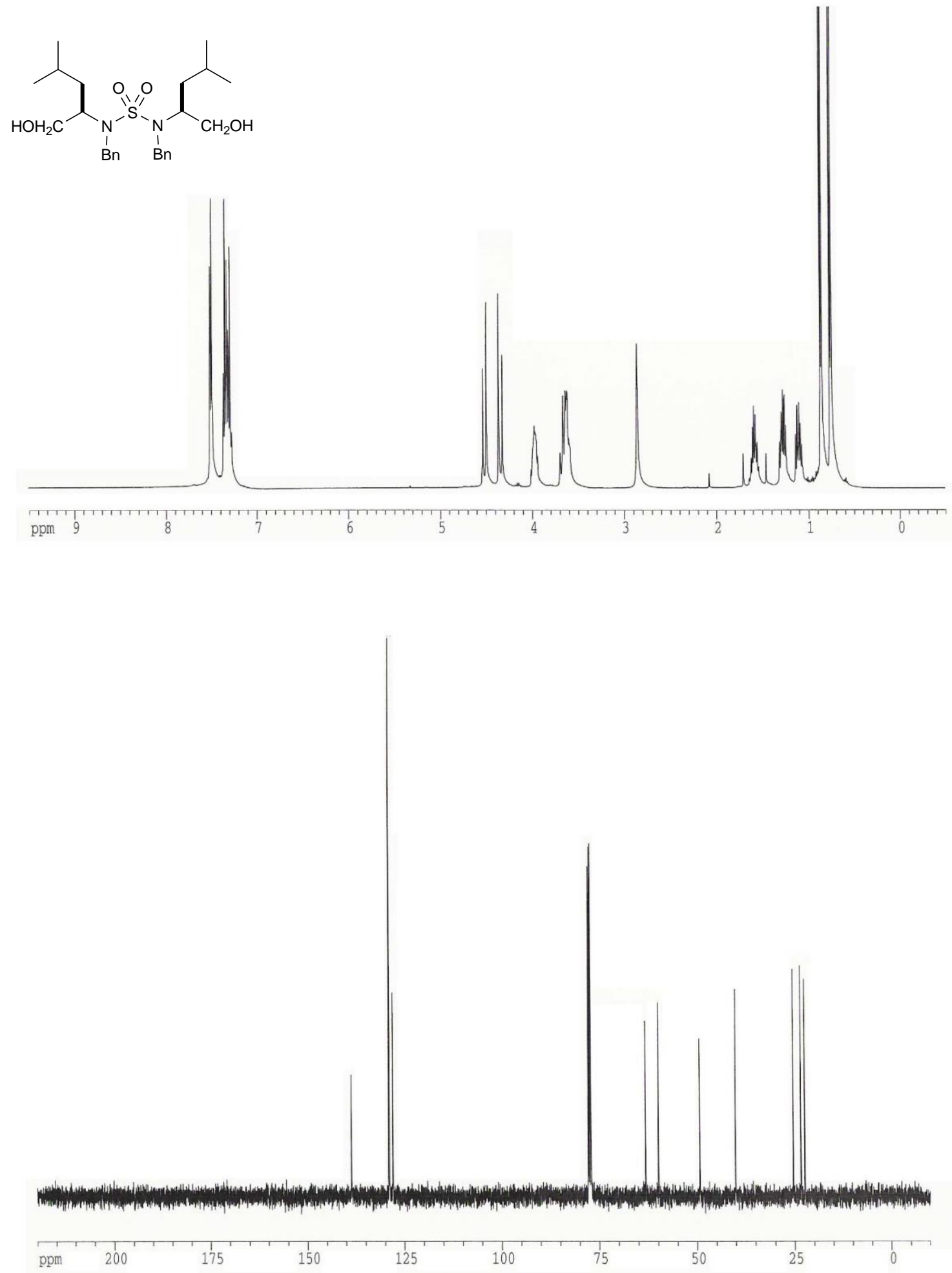
$N, N^{\prime}$-Bis-benzyl- $N$-[(1S)-1-(2-methylpropyl)-2-propenyl]- $N^{\prime}-[(1 R)-1-(2-m e t h y l p r o p y l)-2-$ propenyl]-sulfamide (32)<smiles>C=CC(CC(C)C)N(Cc1ccccc1)S(=O)(=O)N(CC(C)C)C(C=C)CC(C)C</smiles>
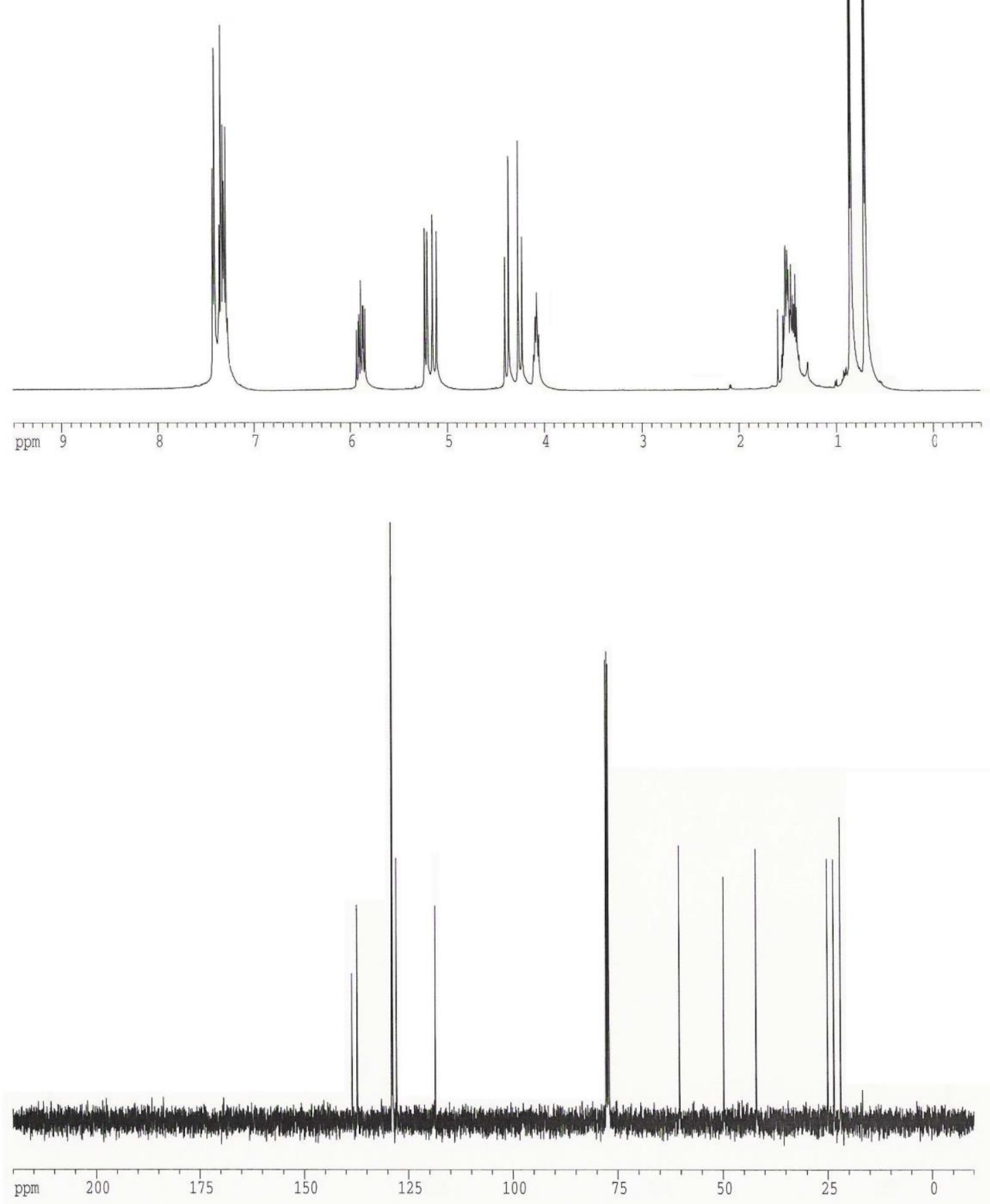

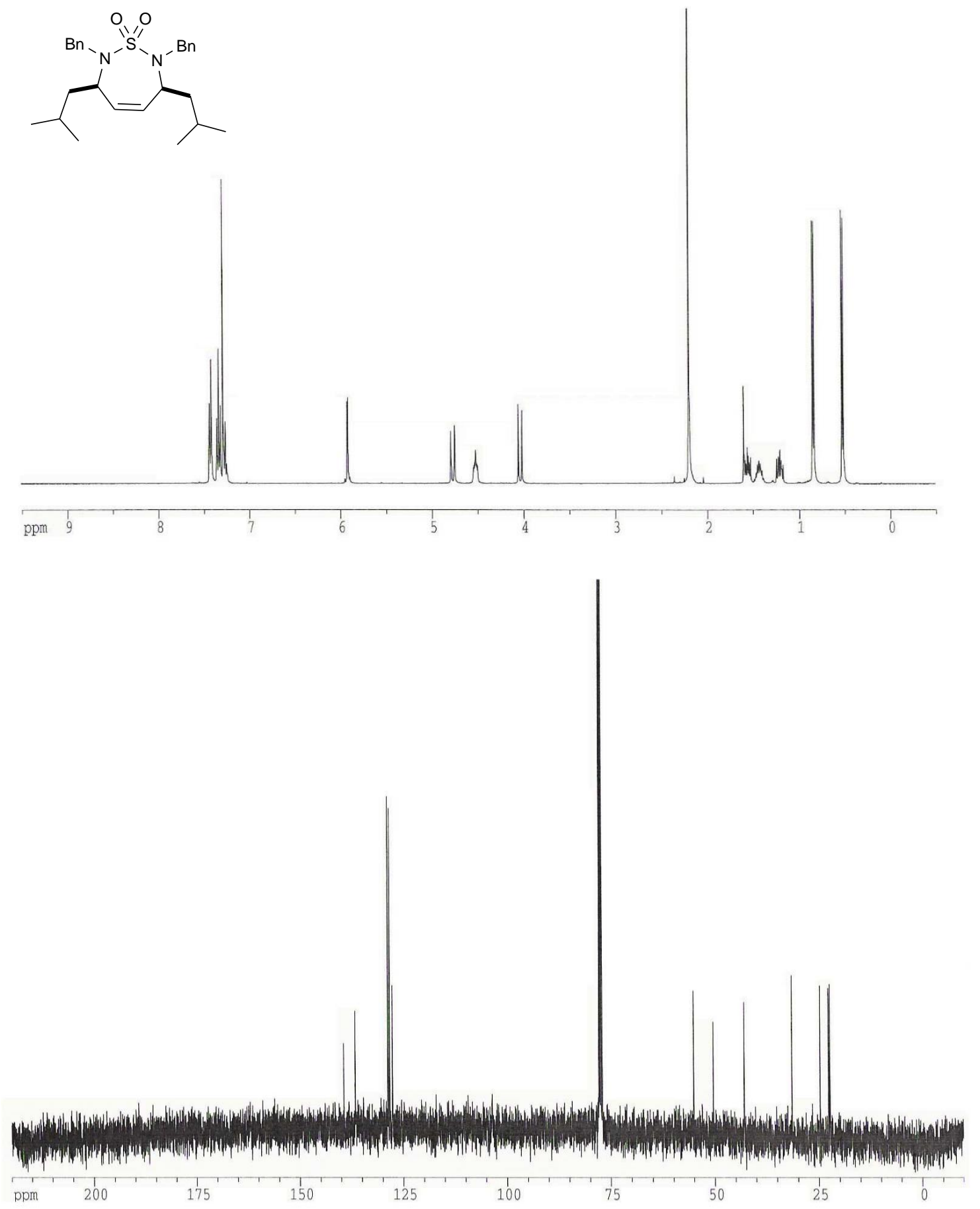

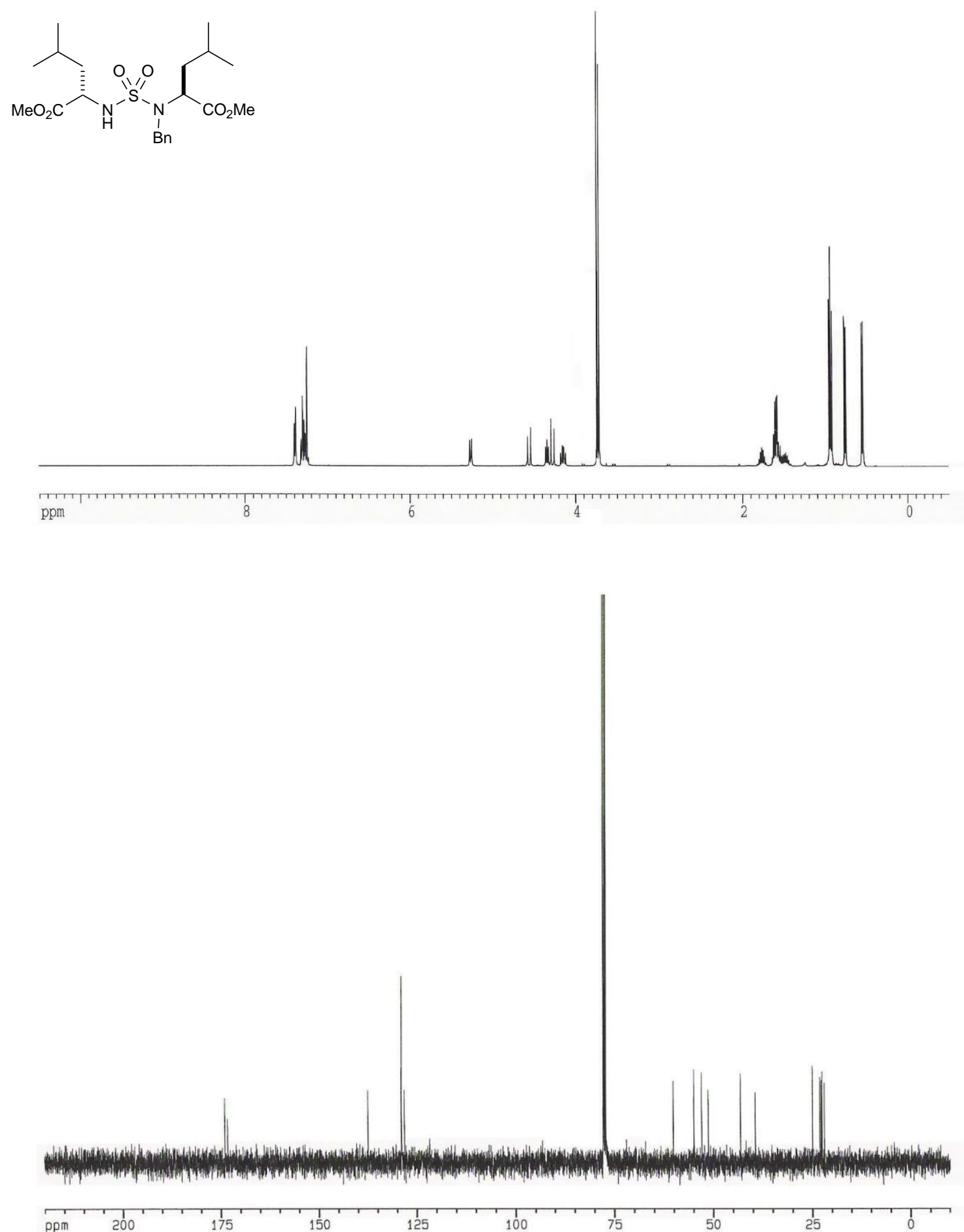
$N$-Benzyl- $N$ '-(4-methoxy)-benzyl- $N, N$ '-bis-[(1S)-1-(2-methylpropyl)-2-methoxycarbonyl]sulfamide (8)
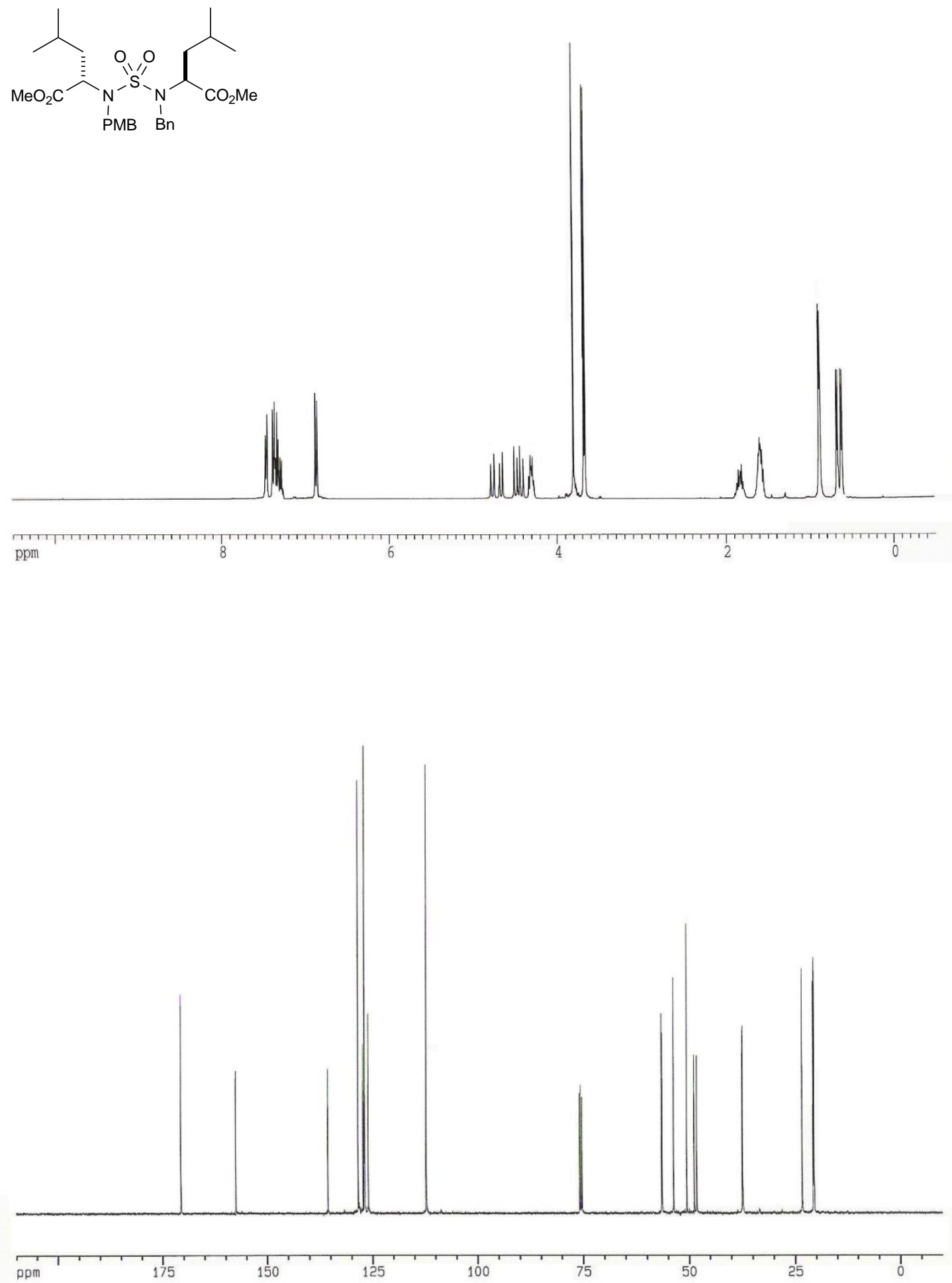
$N$-Benzyl- $N$ '-(4-methoxy)-benzyl- $N$ - $N$ '-bis-[(1S)-2-hydroxy-1-(2-methylpropyl)-ethyl]sulfamide (11)
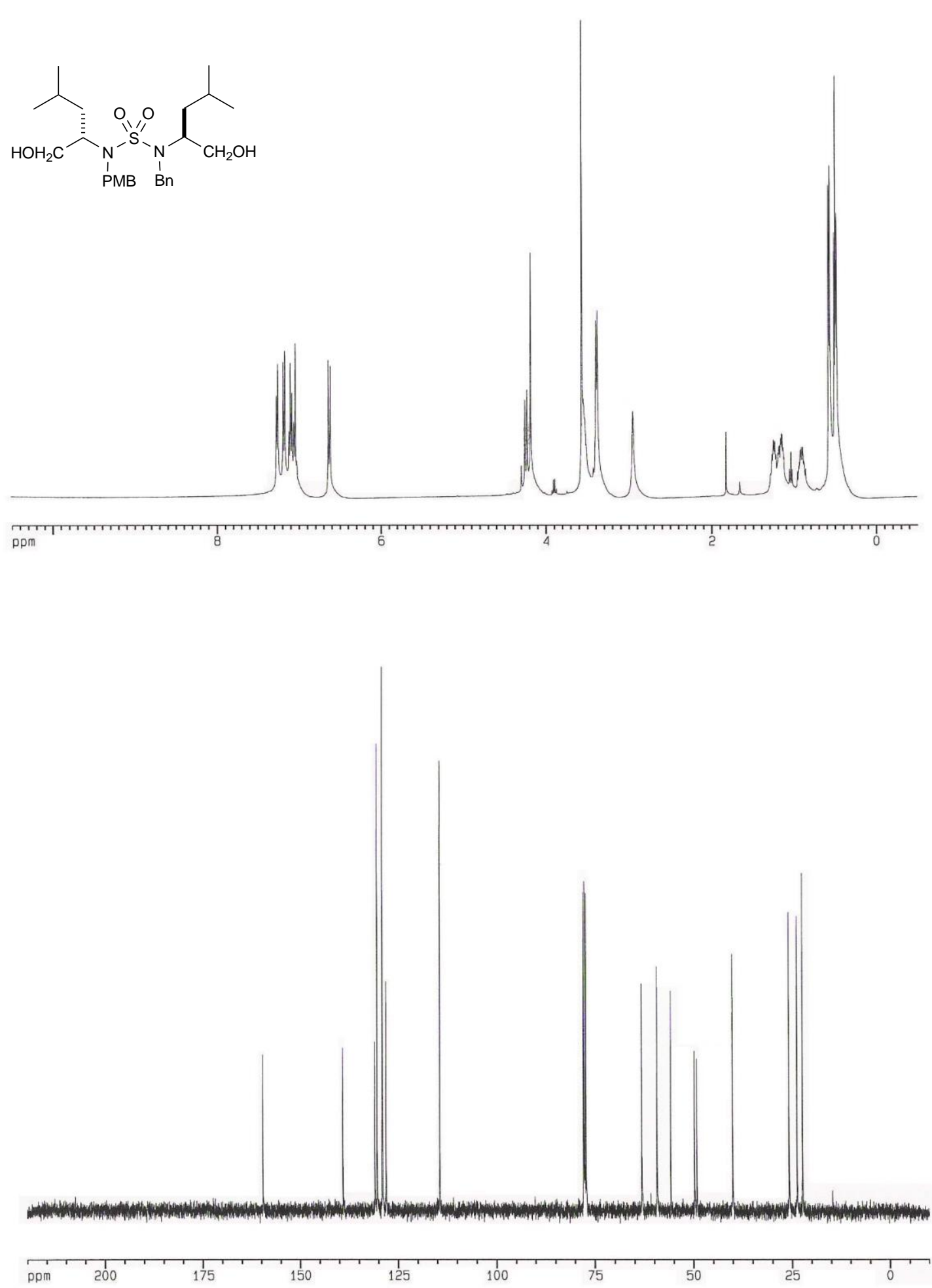
<smiles>[R5]N([C@H](C=C)CC(C)C)S(=O)(=O)N(Cc1ccccc1)[C@H](C=C)CC(C)C</smiles>
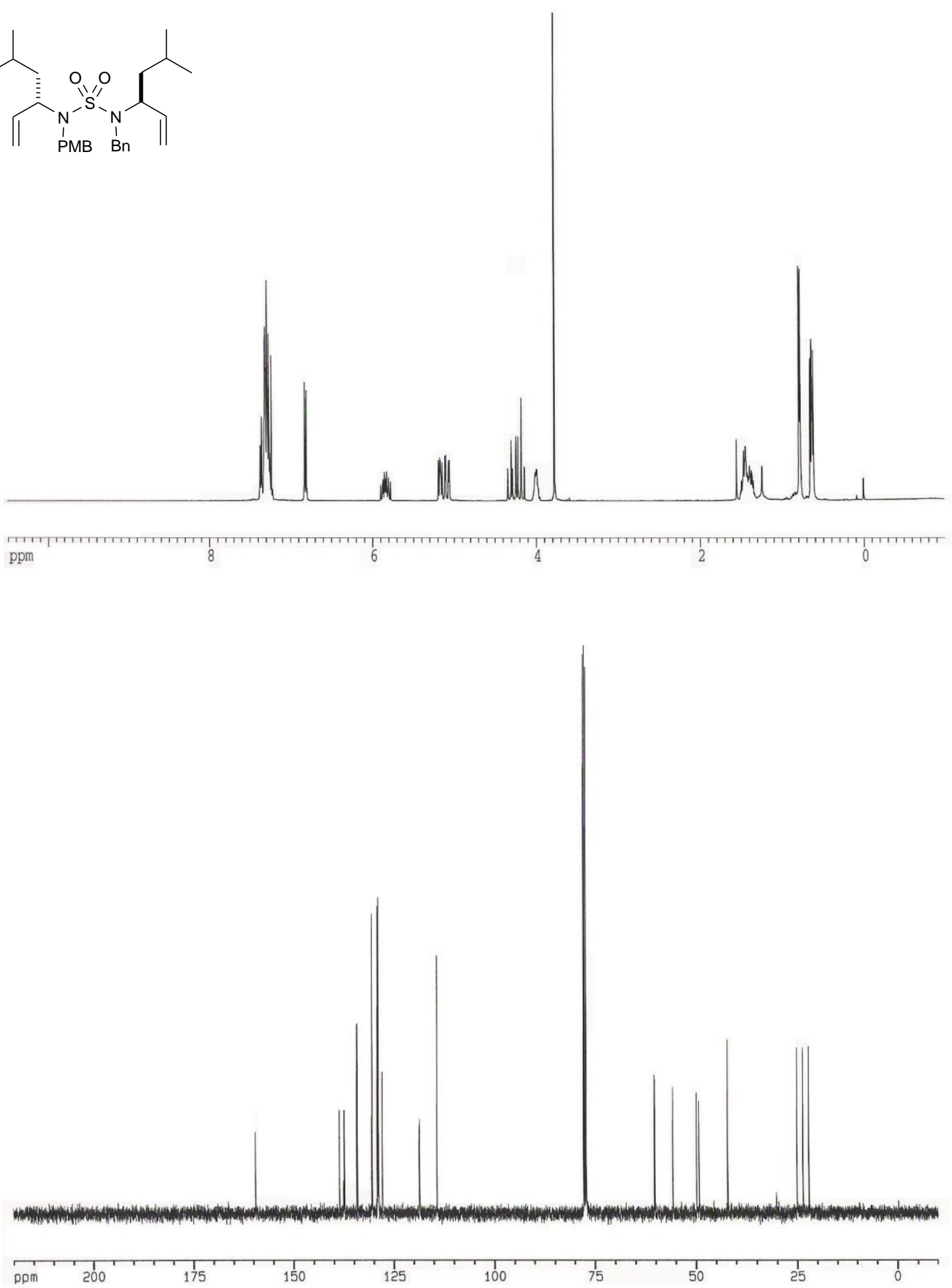
(3S,6S)-2-Benzyl-7-(4-methoxy)-benzyl-3,6-diisobutyl-2,3,6,7-tetrahydro-1,2,7-thiadiazepine1,1-dioxide (20)
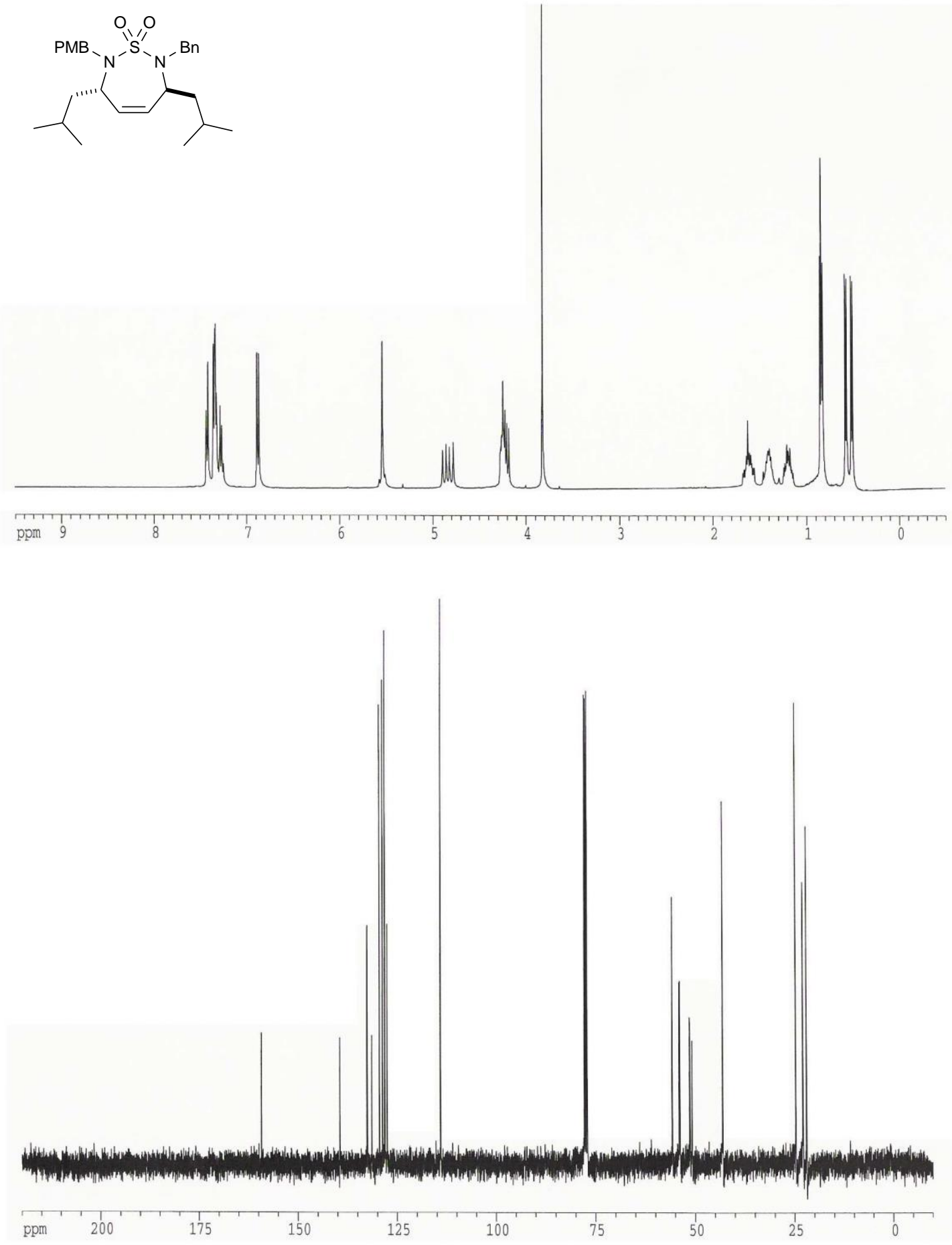


\section{References}

1. Jun, J. H.; Dougherty, J. M.; Jimenez, M. S.; Hanson, P. R. New Strategies to Symmetric and Unsymmetric Cyclic Sulfamide Analogs of DMP 323: A "Sulfur Linchpin"/RCM Approach. Tetrahedron 2003, 59, 8901-8912.

2. McReynolds, M. D.; Sprott, K. T.; Hanson, P. R., A Concise Route to Structurally Diverse DMP 323 Analogues via Highly Functionalized 1,4-Diamines, Org. Lett. 2002, 4, 4673-4676.

3. Harned, A. M.; Mukherjee, S.; Flynn, D. L.; Hanson, P. R. Ring-Opening Metathesis PhaseTrafficking (ROMpt) Synthesis: Multistep Synthesis on Soluble ROM Supports. Org. Lett. 2003, $5,15-18$.

4. Dougherty, J. M.; Probst, D. A.; Robinson, R. E.; Moore, J. D.; Klein, T. A.; Snelgrove, K. A.; Hanson, P. R., Ring-Closing Metathesis Strategies to Cyclic Sulfamide Peptidomimetics, Tetrahedron, 2000, 56, 9781-9790. 